University of Rhode Island

DigitalCommons@URI

Open Access Dissertations

1997

\title{
Development of a Muslim Religiosity Scale
}

Abdulaziz Abdurrahman Albelaikhi

University of Rhode Island

Follow this and additional works at: https://digitalcommons.uri.edu/oa_diss

\section{Recommended Citation}

Albelaikhi, Abdulaziz Abdurrahman, "Development of a Muslim Religiosity Scale" (1997). Open Access Dissertations. Paper 547.

https://digitalcommons.uri.edu/oa_diss/547

This Dissertation is brought to you for free and open access by DigitalCommons@URI. It has been accepted for inclusion in Open Access Dissertations by an authorized administrator of DigitalCommons@URI. For more information, please contact digitalcommons-group@uri.edu. 


\section{DEVELOPMENT OF A MUSLIM RELIGIOSITY SCALE}

BY

ABDULAZIZ ABDURRAHMAN ALBELAIKHI

A DISSERTATION SUBMITTED IN PARTIAL FULFILLMENT OF THE REQUIREMENTS FOR THE DEGREE OF DOCTOR OF PHILOSOPHY

IN

PSYCHOLOGY

UNIVERSITY OF RHODE ISLAND

1997 
DOCTOR OF PHILOSOPHY DISSERTATION

OF

ABDULAZIZ ABDURRAHMAN ALBELAIKHI

\section{APPROVED:}

Dissertation Committee

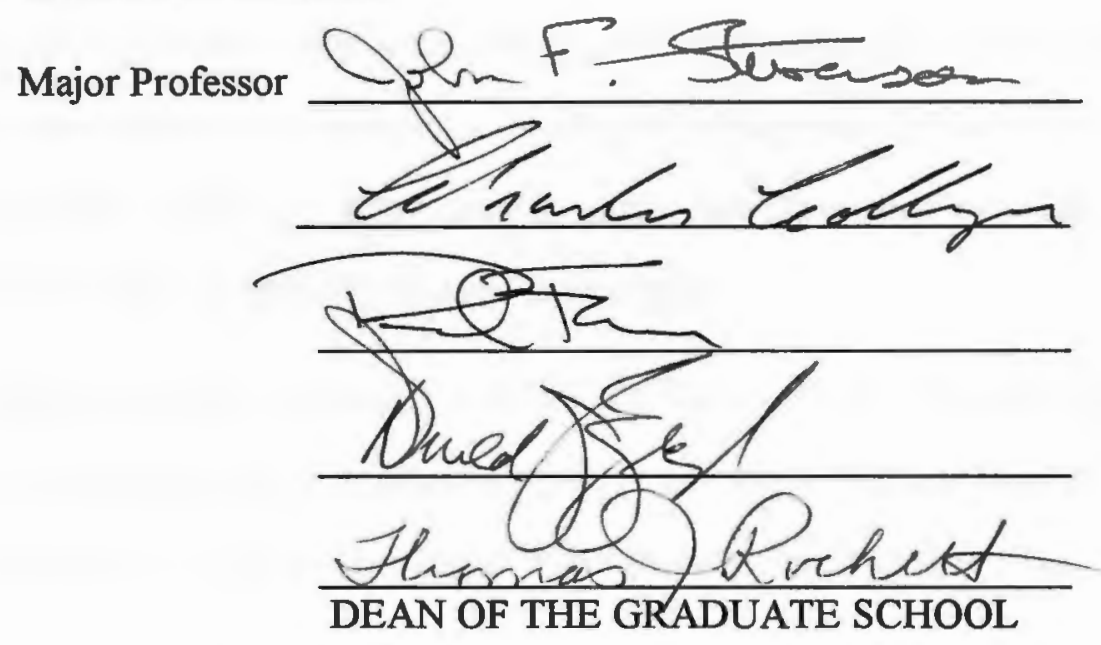

UNIVERSITY OF RHODE ISLAND 


\begin{abstract}
The main focus of the study was the construction of a new scale for measuring religiosity among Muslims. Two other existing scales were also used. Utilizing 169 (108 male, 61 female) Saudi Arabian Muslim college students, an exploratory Principal Components Analysis (PCA) was employed on a set of questionnaire items intended to measure Islamic religiosity. Six components were extracted, which represented the religious dimensions of practice, societal value of religion, belief in central tenets, personal need for religion, reliance on practical guidance, and unquestioning acceptance.
\end{abstract}

Predictions regarding multidimensionality of Muslim religiosity were generally supported. However, the PCA-based scales developed in this study will need further work to establish their psychometric robustness, particularly because some scales were difficult to label and did not conform to prior expectations.

Predictions regarding differences in levels of religiosity were also generally supported. As predicted, students of Islamic studies were more religious than students of Arts and Humanities, and females were on average more religious than males.

Special challenges in measuring the Islamic religiosity are discussed, including: measuring the belief dimension, offending participants, and gender of participants. 


\section{Acknowledgment}

I am happy to have come this far and to have made it to this point. I am very thankful, first and most of all, to my Lord, Allah Almighty, for helping me and sustaining me over all these long years it took me to get here, and giving me the physical and psychological strength and energy to go on with this project

Continuing in this process for so many agonizing years, I, besides experiencing times of frustration, despair and depression, have accumulated enormous debts to so many people.

It pleases me to have gotten to this point, not only to finally joyfully celebrate my so long over due accomplishment, but also to have the opportunity to happily express my deepest gratitude to those many whose help, support, encouragement, and belief in me have been instrumental in keeping me going all this long time. The hard part of this, however, is to find the right words and the appropriate approach in expressing my thanks to these many people. With the very long list of people to whom I am deeply indebted, I would probably need another whole volume to name and thank every one.

I will start with thanking the most important people in my life, my parents, may Allah rest their souls in peace, who set my foot in the first step on the road of education, taught me to appreciate and value education, and supported me by every means at their disposal. It saddens me, though, that they did not live long enough to celebrate this occasion with me, especially my father who--suddenly--passed away only few months ago, at a time when he was beginning to celebrate my anticipated graduation and long awaited home coming. 
My thanks also go to my major professor Dr. John F. Stevenson, for his guidance, constructive criticism, and thoughtful comments. I, particularly, thank him for his continued belief in me, his confidence in my ability to accomplish what I set myself to accomplish, his untiring encouragement, and his patience. Dr. Charles Collyer, my committee member, also deserves special thanks, for he was very helpful, and his comments and suggestions, at all stages of the process, were very valuable. My thanks also go to my other committee members, Dr. Donald Zeyl and Dr. Paul Florin, for their helpful comments and suggestions, and also to Dr. Winifred Brownell, my defense chair, and Dr. Albert Lott, the additional defense committee member.

Among the many others who deserve my thanks and sincere appreciation are the following:

Former and present officials of the Islamic University of Imam Mohammad bin Saud, in Saudi Arabia (the sponsor of my graduate study in the U. S. A.), for their understanding and continuing moral and financial support throughout these long years. My thanks also go to my colleagues at the College of Social Sciences, and other colleges, in the same university, for their support, assistance, and participation in evaluating my questionnaire.

His highness Prince Mohammad bin Faisal Al-Saud, my former supervisor at the Embassy of Saudi Arabia in Washington, D. C., not only for supporting me and granting me the time I needed out of work to pursue my study, but also for his generous, and deeply appreciated, effort in helping me get back on track.

My present supervisor at the Embassy, Dr. Majed Algheshayan for his continuous support and for allowing me to continue my pursuit of my degree, and also my office mates at the Embassy, for taking over my share of the work at the office, to allow me the time to work on my dissertation. 
Former and present administrations of the Institute of Islamic and Arabic Sciences in America (Virginia) for supporting me and allowing me to use the institute facilities during my work on my project.

My research assistants for helping in distributing and collecting the questionnaires, and the college students who participated as subjects in the study.

All those who lent me a hand, one way or the other, in my work on this project, and whose help did not go unnoticed, but whom I did not name, and all relatives, friends, and acquaintance, who offered their help, sympathy and/or prayers.

Last, but most certainly not least, my greatest gratitude and most sincere appreciation go to my closest partners in the very tiring journey: my wife and children. My thanks go to my wife, who spent a large portion of her young life with me on the run, since the second year of our wedding until now, with our oldest child at the age of 17 years. Thank you Latifah for your unlimited patience, your invaluable sacrifice, and your partnership. Sorry, kids, for the life-time you have spent away from home and the special and good times you have missed with your relatives and loved ones. I hope that you still have time to make up for some of what you have missed. I am not sure I will be able to make it up for you, but I will try. I hope this has been an educating experience for you, and wish you the best in realizing your dreams, and that you do so faster than I did.

Finally, I dedicate this very humble work to each and every one, who had a hand in my education, and helped in any way light a candle for me along the road to accomplishing my objective. 


\section{Table of Contents}

Subject

Page

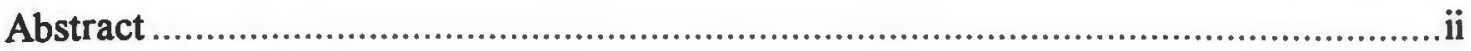

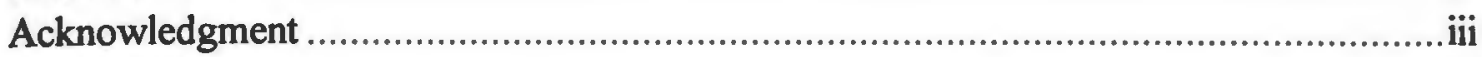

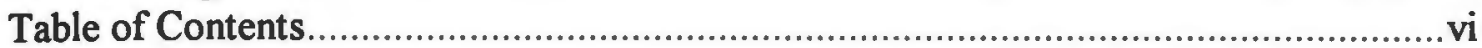

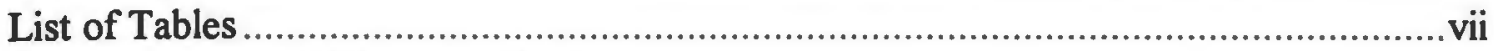

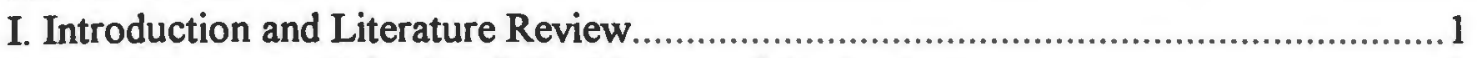

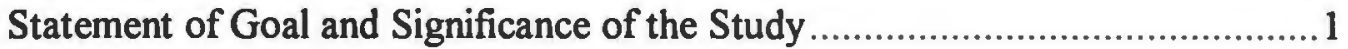

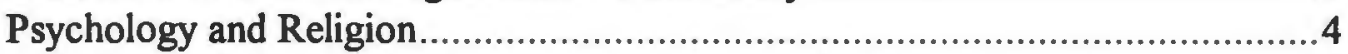

The Relationship between Psychology and Religion................................4

The Psychological Study of Religion ..................................................10

Psychological Measurement of Religion ...........................................14

Problems with Religious Measurement ...............................................15

The Psychological Study of Religion among Muslims ...........................22

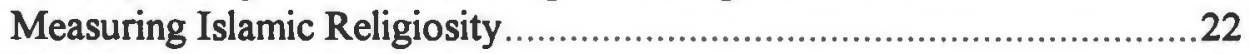

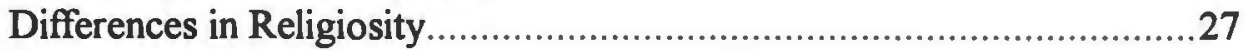

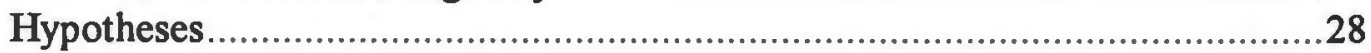

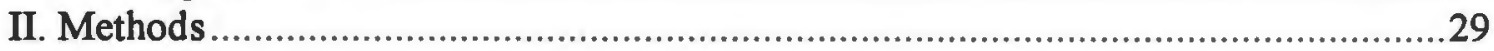

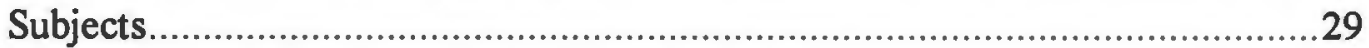

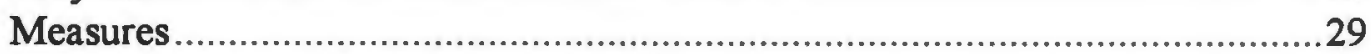

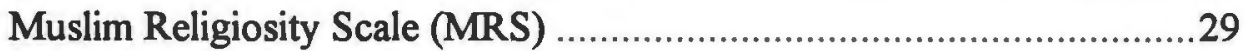

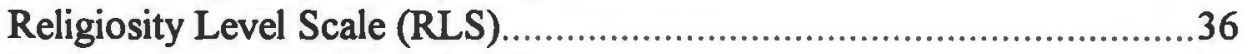

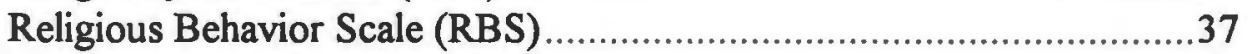

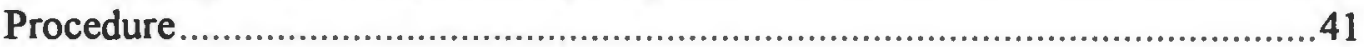

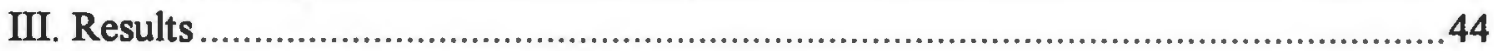

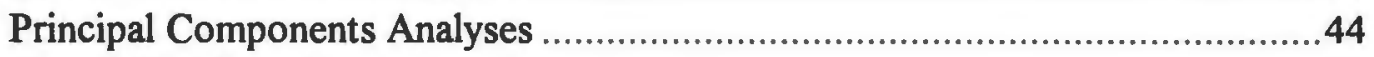

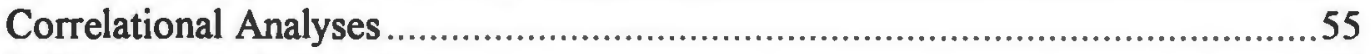

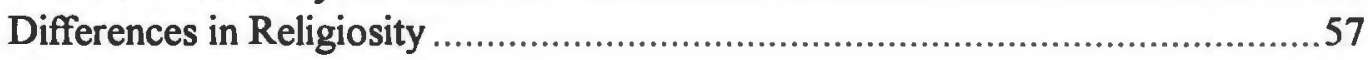

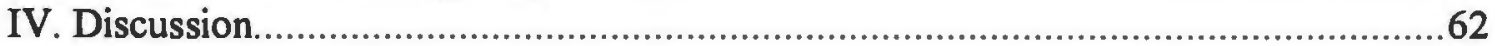

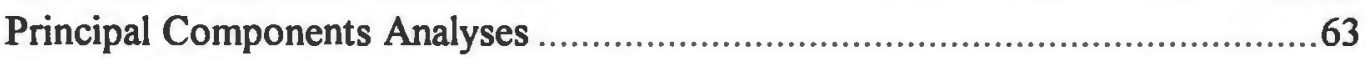

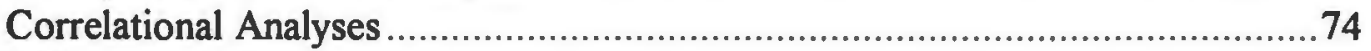

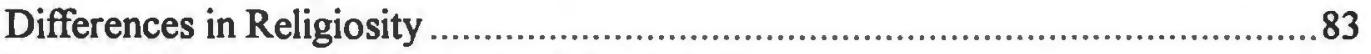

Potential Problems in Measuring Islamic Religiosity .......................................88

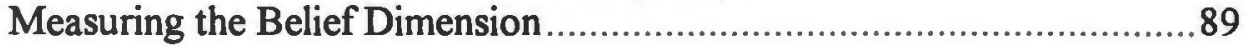

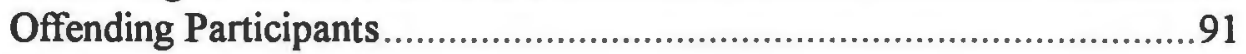

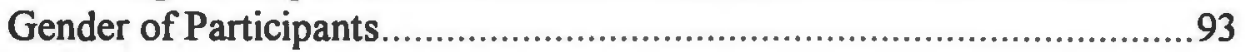

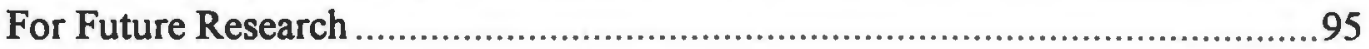

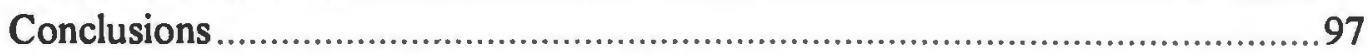

Appendix A: A Cover Letter to Respondents ...............................................123

Appendix B: A Demographic Information Sheet ...........................................125

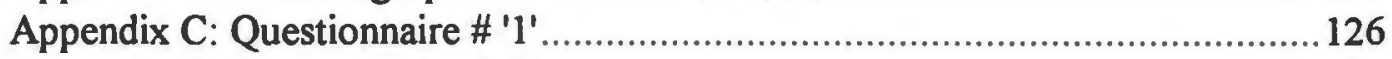

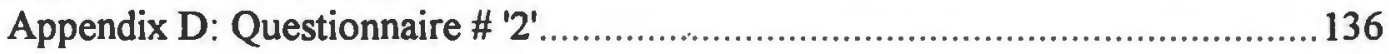


Appendix E: Questionnaire \# '3'

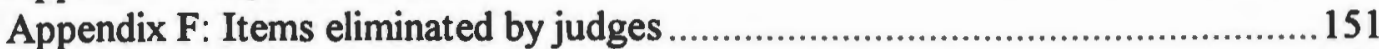

Appendix G: Gender-Neutral Scales ...........................................................153

Appendix H: Questionnaire \# ' 1 ' (Arabic Version) .........................................156

Appendix I: Questionnaire \# '2' (Arabic Version) ............................................165

Appendix J: Questionnaire \# '3' (Arabic Version) ..........................................171

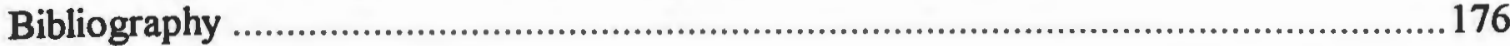




\section{List of Tables}

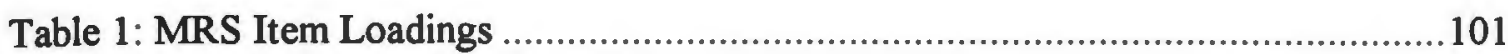

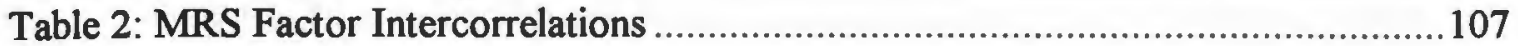

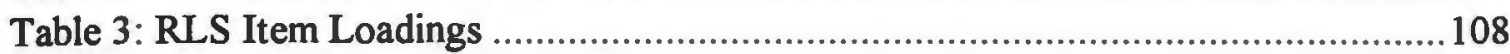

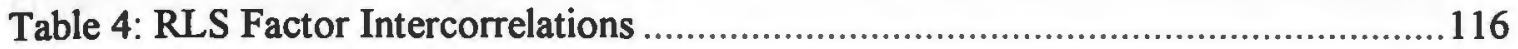

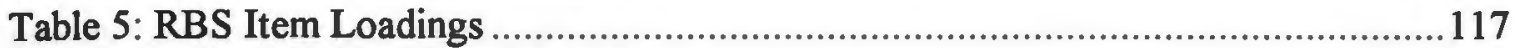

Table 6: Correlations Between Subscales ............................................................119

Table 7: MRS ANOVA Results for Group differences..............................................120

Table 8: RLS ANOVA Results for Group differences...................................................121

Table 9: RLS ANOVA Results for Gender differences ................................................121

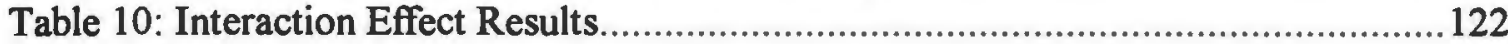




\section{Introduction and Literature Review \\ Statement of Goal and Significance of the Study}

There has been some rise and fall in the psychological study of religion. At the present time, however, religion seems to have become a major area of interest for many psychologists. The psychological study of religion has prompted the need for measuring religiosity. Serious attempts were made by psychologists to develop ways of measuring and estimating degree of religiosity among target populations. Different ways and varieties of scales were used in this process, making measurement of religiosity a major issue in the area of the study of religion. Many different religiosity scales were constructed, measuring different aspects of religion and religiosity, among different populations of different cultures and different religious backgrounds, especially Christian populations.

Consider the facts that Islam is one of the most prominent and widespread religions in the world today, that Muslims, in general, hold strong affiliation to, and express great concern for, their religion, and that Islam plays a major role in the lives of its followers. From these facts, one would be led, justifiably, to assume that a Muslim population constitutes a potentially promising and valuable target for the psychological study of religion. Such a study evidently requires careful measurement of the phenomenon of interest--the Islamic religion or the religiosity concept in the Islamic belief system.

The need for a well developed religiosity measure suitable for Muslims constitutes the main problem of this present piece of research. The central concern of the study was to develop a religiosity scale for measuring the presence and degree of general religiosity among Muslim individuals. 
Although there have been some efforts by a few Muslim researchers (e.g., Albehairi \& Demerdash, 1988; Alsanie, 1989; Hafsi, 1987; Taai, 1985) to develop psychological measures of Muslim religiosity, there still is a relative lack of sound measurement instruments for this purpose. The existing scales for Muslims have certainly paved the way to approach this problem and their authors deserve great credit for their pioneering effort. However, these scales have some shortcomings that should be noted and avoided in future attempts, as the research effort in this area progresses. This study was intended to be one attempt toward improving the psychological measurement of religiosity among Muslims.

Although some of the existing religiosity scales used with populations such as Christians may contain some concepts and items that could be useful and applicable with Muslims, such scales are, as a whole, culture-bound and unsuitable for measuring religiosity among Muslims. It has been argued that the measurement paradigm for the psychology of religion suffers from several key limitations, and one of these limitations is

that its scales are all specific to one religion, and direct cross-religion comparisons are impossible. Scales specific to Christianity are useless in studying psychological aspects of Islam, for example. . . To develop a psychology of religion with any universal application, we clearly must move beyond our excessive focus on American Christianity. (McFarland, 1984, p. 323)

However, attempts to develop universally applicable religiosity measures have not been very successful, as demonstrated by the findings of some studies that attempted using certain scales with people from different cultures and belief systems (e.g., Albelaikhi, 1988; Long \& Elghanemi, 1987; Patrick, 1979). The existence of distinct characteristics in different cultures and religious systems has hampered the 
effort of measurement developers in most areas to build satisfactory cross-cultural scales, thereby constituting, most of the time, a great necessity to have unique measures for different populations of different cultural and religious backgrounds. However, such an issue, although of justifiable concern, should not prevent attempts at early stages of religiosity measurement development to build scales that may be characterized as culture-bound to measure certain phenomena among certain populations or certain cultures, particularly with somewhat underutilized populations. Such efforts should be appreciated for their pioneering value, and we should accept them as one step in the right direction, inspired by a sufficient "faith in the cumulative nature of psychological knowledge" (Jackson, 1970, p. 62). Among such underutilized populations is the Muslim population, which is the main concern of the present study.

Originating in the Western world, empirical psychology used Western populations for its research most of the time. Therefore a psychological study, such as the present one, using a population of a different cultural and religious background should provide a useful addition to cross-cultural psychological research, "for knowledge of a different culture can be used to check on various psychological hypotheses" (Kline, 1979, p. 301). Furthermore, "A spur for a more comprehensive paradigm could develop from problems and possibilities generated by greater participation of psychologists from other cultures" (Gorsuch, 1984, p. 235).

Defining a phenomenon or measuring it is not, and should not be, considered as a final goal in itself, but rather a means to an end, because "if we are engaged only in measurement studies--if dimensionality and other such topics are the ends of research programs--then the concern with measurement will be a bane to the area" (Gorsuch, 1984, p. 235). Although the present study concentrates solely on developing a scale for measuring religiosity among Muslims, such study is still needed for the study of religion among the Muslim population, and it is hoped that its results will provide a good means 
toward the end of studying, and not merely measuring, religiosity among Muslims in subsequent research. It is a step in the "effort to make greater use of the tools of empiricism and scientific methodology ... to study a most complex phenomenon" (Cline \& Richards, 1965, p. 570) in a different culture.

\section{Psychology and Religion}

Concern with measuring religiosity by psychologists would prompt concerns about, and interests in, issues relating to the status of the study of religion in the field of psychology. Concerns and interests pertain to such issues as how the study of religion fits into the realm of psychological theories and investigations, and whether it is currently receiving attention in the field of Psychology. These are justifiable and expected concerns and the discussions in the following sections attempt to shed some light on issues related to these concerns.

\section{The Relationship Between Psychology and Religion}

The subject matter, or at least the most important subject matter, of Psychology is the human being. It has been stated that Psychologism is "the point of view that Psychology is the basic science among all those sciences that deal with man".

Psychology is "the science of human and animal behavior; the study of the organism in all its variety and complexity" (Chaplin, 1982, p. 421).

Religion, moreover, has been known to, and experienced by generations of the human race throughout the long history of humankind. According to Kung (1979), "all investigations have made one thing clear, that hitherto in the whole long history of mankind no people or tribe has ever been discovered without any trace of religion" ( $p$. 
72). From anthropological studies Ames (as cited in Arnold, 1985) concluded that "religion historically has always been the affirmation of humankind's highest social values" (p. 1061). Religion is seen as a real fact of the human experience, and believed to be an important factor in the construction of the individual's personality, and a critical part of life. In Starbuck's (as cited in Booth, 1981) words, "The fundamental assumption is that religion is a real fact of human experience" (p. 8), and "according to James, ... religion confers an enchantment on life that nothing else can ... Thus religion is said to play a vital role in human life, one that it alone can play" (Fuller, 1977, p. 4).

An immediate reasonable conclusion then, with regard to the relationship between religion and psychology, would be that religion could, and should, be an important and interesting subject matter for psychology. "There is a spiritual dimension of human experience with which the field of psychology must come to terms more assiduously. If psychologists could understand it better than they do now, they might contribute toward improving both mental and social conditions" (Bergin, 1991, p. 401). "Interaction with religious and quasi-religious themes is most frequent and obvious in those arenas in which psychological scientists extend their reach to explain the broadest domains of human behavior and take on the prescriptive function of specifying what it means to be a 'healthy' or 'normal' or 'mature' person" (Jones, 1994, p. 190). There is even the suggestion that psychology and religion complement each other. "Psychology contributes to an understanding of the nature of self and one's relationships with others, religion to an understanding of meaning and purpose in life, and the significance of these same relationships. Both may contribute to more effective living. Their purposes are parallel and supporting, not antagonistic" (Wrenn, 1958, p. 378). Allport (1950), who may quite fairly be considered an authority--among contemporary psychologists-in the psychological study of religion, argues that in many respects psychological 
science and religion have similar views regarding the origin, nature, and cure of mental distress, and that the two seem intimately tied to the future destiny of the human race. The relationship between psychology and religion has been seen to be developing and their subject matter to be overlapping. Johnson (1945) saw the dialogue between theology and psychology as accelerating in tempo and volume until it is no longer possible for theologians or psychologists to ignore each other. Domains which are traditionally those of religion have come, according to Havens (1968), within the purview of psychology. Similarities between psychology and religion and possible constructive relationships between the two have been suggested even as recently as in the 1990s (e.g., Jones, 1994, 1995).

Jones (1994) suggests the existence of similarities between the science of psychology and religion, and calls, in what he terms "perhaps the boldest model yet", for a constructive relationship between the two. Jones's argument, however, stirred some controversy about this issue as demonstrated by reactions to his suggestions from others. These reactions to Jones's (1994) article varied. Speaking of issues of objectivity and individual differences in epistemic styles, and personal-developmental and cultural influences on people's ethics of belief, Hoshmand (1995) thinks that Jones's thesis will be met with considerable skepticism, because he challenges the very foundations of faith on which most scientist-professionals base their beliefs and selfidentification.

Cox (1995), while applauding Jones for his delineation of a practical interface between religion and psychology, suggests that Jones "was generally referring only to peripheral aspects of religion in his comparison with scientific exploration" (p. 541). Cox refers to the difference between the bases of science and religion in their search for truths; the basis of science is an objective method of experimentation, while the basis of religion is subjective method of experience. Cox (1995) nonetheless, calls for 
relationship between the two, and suggests that scientists and religionists need to talk meaningfully with each other by ways of compromising and willingness of both to give up some of their cherished philosophies. Cox also suggests that genuine religion and genuine science need not fear each other, but he believes that "the integration of science and religion must ultimately go beyond Jones's (1994) 'perhaps boldest model yet"' (p. 541).

Similar to Cox (1995), Ward (1995) sees Jones's (1994) arguments as resting in large part on superficial similarities, ignoring the fundamental distinctions that separate scientific endeavors from religious beliefs. Like Cox (1995) Ward (1995) points out that in science, the ultimate criterion of what constitutes truth and knowledge is empirical observation, while, in contrast, religious belief does not rely on empirical evaluation. But, unlike Cox, who believes that the two realms may be integrated, Ward argues that despite superficial similarities, science and religion are logically distinct realms of human thought. Ward (1995) even goes as far as viewing Jones's argument as a reactionary threat to scientific objectivity. In Ward's words:

It is essential to psychology's integrity as a science to maintain a firm grasp on what constitutes valid scientific reasoning. Considerable effort was exerted in the development of psychology to distinguish it from its philosophical and pre-scientific beginnings, and the field has progressed as a result. However, psychology is not immune to unscientific ideas, and Jones's (1994) advocacy of evaluating psychological theories and paradigms 'by the individual scientist for their fit with his or her religious presuppositions' ( $p$. 194) is a reactionary threat to scientific objectivity. It would be unfortunate if such views were to become a part of the philosophy of psychology. (p. 543) 
Others also expressed some doubt, although in somewhat more moderate tone, about establishing relationships between psychology and religion. Commenting on Jones's (1994) assertion that psychology and religion cannot be considered to be categorically separated and that there should be a constructive dialectic, and dialogical relationship between them, Aguinis and Aguinis (1995) suggest that "the fundamental differences between the science of psychology and religion may not be as easily bridged as Jones indicated" (p. 541), and that the relationship between them seems to be more problematic than Jones recognized. Aguinis and Aguinis question the common ground that Jones suggested between psychology and religion, as being so general that it could apply to other cultural creations, which makes such common ground insufficient reason to claim that no hard barrier separates religious thought and science. Aguinis and Aguinis (1995) refer to some of the fundamental differences between the languages used by these two modes of inquiry, indicating, for example, that in contrast to religious assertions, "assertions generated by scientists in seeking scientific objectivity are: (a) logically neutral, (b) comprehensible impersonally, and (c) testable by observations" (p. 541). They conclude that fundamental differences between the two modes "indicate that science and religion are two distinct modes of knowing and explaining reality" (p. 542). Weiss (1995) also applauds Jones' (1994) efforts and discusses his arguments from the point of view of psychotherapy.

In response to these comments, Jones (1995) admits that science and religion are fundamentally different, and asserts that they should not be confused or overidentified. But he still rejects the claims that they are separate and mutually exclusive. Jones (1995) also states that he was not trying to establish that religion and science are equivalent, but rather that the barriers between the two are sufficiently permeable. Although admitting that the commonalties he traced (Jones 1994) between psychology and religion are so broad as to approach superficiality, Jones (1995) 
contests the claim that science and religion are utterly separate. He states that the distinctives between the two are a matter of degree rather than of absolute difference. Jones (1995) also challenges what he calls the kind of naive empiricism that some (Ward, 1995) embrace by arguing that theories are "an important but not necessary part of science". Jones (1995) concludes that "there is a strong difference of degree between science and religion, not a categorical distinction of mutual exclusion, and thus there is room for dialogue" (p. 545).

Although indicating contesting views regarding relationships between the science of psychology and religion, this most recent controversy, or may we call it discussion, is a testimony to the livelihood of the issue, and indicates a considerable degree of importance that psychologists currently are giving to the problem of psychological study of religion.

It is worth noting that writers on this issue differ in their estimations of the livelihood of the field of psychology of religion and the relationship between the two. For example, while Bergin (1991) and Jones (1994) enthusiastically and wholeheartedly celebrate what they see as renewed positive interest of psychologists and psychotherapists in religion, and the present livelihood of the field of psychology of religion, others (e.g., Neeleman \& Persaud, 1995) think that modern psychiatry has neglected the therapeutic effects of religious beliefs. Neeleman and Persaud (1995) see the gap between psychiatry and religion as a recent phenomenon. Richardson (1995) also discusses what may be viewed as slow steps in the progress of relationship between psychiatry, psychology and what are called controversial new religions.

At any rate, from the above discussion, it seems safe to conclude that there is a strong argument for the close ties between psychology and religion. The question now concerns how psychology is dealing with this relationship. 


\section{The Psychological Study of Religion}

William James (1961), a most famous figure in this area, believes that the religious aspects of human life are as important and interesting a subject for psychological research as any other. Religion has always held and continues to hold a central place in the determination of human behavior. In James' (1961) own words, "to the psychologist the religious propensities of man must be at least as interesting as any other of the facts pertaining to his mental constitution" (p. 22). Recently, Bergin (1991) argued that the spiritual perspective that there is a spiritual reality and that spiritual experiences make a difference in behavior "can be subjected to test, just as the invisible process of biology and physics have been subjected to tests" (p. 379). The issue of the influence of religion on people's lives has been widely explored and studied by psychologists with relation to different phenomena and different aspects of life, for example, prejudice ( e.g., Allport, 1959; Allport \& Ross, 1967; Boivin, Donkin, \& Darling, 1990; Feagin, 1964; Ponton, Hickel, \& Gorsuch, 1988; Wilson, 1960), locus of control (e.g., Jackson \& Coursey, 1988; Sturgeon \& Hamley, 1979), values (Schwartz \& Huismans, 1995), anxiety (e.g., Mercer, Bunting, \& Snook, 1979; Sturgeon \& Hamley, 1979; Wilson \& Miller, 1968) fear of death, (e.g., Albelaikhi, 1988; Long \& Elghanemi, 1987; Beg \& Zilli, 1982; Florian \& Kravetz, 1983; Hoelter \& Epley, 1979; Kahoe \& Dunn, 1975; Lester, 1970; Minton \& Spilka, 1976; Patrick, 1979; Spilka, Stout, Minton, \& Sizemore, 1977), grief reactions to death (Balk, 1988) mental health (e.g., Malony, 1985; Strayhorn, Weidman, \& Larson, 1990), eating disorders (Kennedy, Barnes, \& Greenwell, 1988), and many others, especially among Christian populations.

Nevertheless, there has been, as stated above, some rise and fall in the psychological study of religion. It has been claimed that religion was an active area of 
investigation within early mainstream American psychology, establishing Americans as pioneers and leaders in the field of psychology of religion (Arnold, 1985).

Generally speaking, however, psychology seemed to have a problem with studying religion. It seems justifiable to claim that the roots of psychology's crisis with religion was planted, or at least became visible, when psychology started its attempts to become an independent experimental science, which can enter the laboratory and put its subject matter under experimentation and laboratory analysis, joining therewith in the application of scientific and objective methods just like chemistry, physics, biology, and other natural sciences. Psychology has joined, or at least attempted to join, the caravan of the scientific experimental natural sciences at the time when a war, or at least its aftermath, was still, to some extent, raging, in the West, between science and religion. The problem with religion was, probably, deeper and more difficult for psychology in particular than for science in general.

The subject matter of the natural sciences is nature and material components that can be experimentally studied and tested under easily controlled and manipulated conditions, and the results of their testing can relatively easily be confirmed or falsified and accepted or rejected. Thus, there might have been some room for possible conciliation between religion, or some aspects of religion, and some of the natural sciences. The case, however, is much more difficult for Psychology. The basic subject matter of Psychology is the human being and the study of its (the human's) deep self. The nature of the inner human self is uncontrollable and hardly predictable or manipulatable with its variety of conflicting instincts and ever changing motives; not to mention a most important and significant aspect of human's life and that is religion and religious experiences that are inseparable from humans and whose effects on them are undeniable. From this perspective, psychology's problem with religion might have been deeper and more difficult than that of other sciences. 
With this in mind, it seems safe to argue that in its attempt to emancipate itself from philosophy and become an experimental science, psychology was faced with the problem of studying religion whose major and basic theme is metaphysical. And, thus, the traditional conflict between science and religion, or a version of it, seems to have arisen between psychology and religion (e.g., Freud, 1961; see also Havens, 1968; Maslow, 1970). In fact, it has been argued (Ragan et al., as cited in Brown, 1987) that "the 'truce' between religion and natural science has not extended to the relationship between religion and social science" (p. vi). That has led to some resistance, or at least kind of indifference, among psychologists toward the study of religion. As Allport (1950) describes the mode of psychologists towards religion, modern empirical psychology initially separated itself sharply from religion. "Psychology without a soul became its badge of distinction and of pride" (p. v). It is also argued that "academic psychologists have little interest in trying to establish the truth or falsity of religions" (Brown, 1987, p. 8). Wulff (1988) states that:

There apparently was widespread enthusiasm for the psychology of religion in professional religious circles. It was a subject that reportedly 'became so captivating during the first quarter of the twentieth century that it almost eclipsed theology as an academic discipline in some divinity schools' (Smith, Handy, and Laetscher, 1963, p. 429). . . Thus while there was unmistakable excitement among some philosophers, theologians, and religious educators over the first fruits of this field and the prospects for more, there is no evidence that enthusiasm spread to academic psychology. (p. 6)

Furthermore, some psychologists developed a strong negative attitude toward religion to the extent that, as Vitz (as cited in Brown, 1987) explains, "the hostility of most psychologists to Christianity is real" (p. vi). It has been shown in a study by Ragan, et al., (as cited in Brown, 1987) that "the overall level of religiosity among 
psychologists was much lower than that of the general population and academics in general, which confirmed previous finding" (p. vi). It has also been suggested (see, e.g., Havens, 1968) that some psychologists, if religious, hide their religion. Page (as cited in Cline \& Richards, 1965) notes that:

the psychological investigation of religion in America beginning about 1900 with Starbuck's studies of conversion and James' famous classic, ran a fairly lively course of productive activity during the first quarter century. But since then interest and output have steadily declined until today it would not perhaps be untrue to say that the subject is regarded by many psychologists with almost complete indifference and by some with positive suspicion and even disfavor. (p. 569)

Others (see Wulff, 1988) see the rise of psychology of religion as occurring, sudden and dramatic, in the late 1800 s, and its fall as occurring in the late 1920 s. On the empirical level, not surprisingly, Cline and Richards (1965) argue that "the evidence would suggest that significant empirical studies of the psychology of religion are a real rarity and that this has certainly not been a popular area of study for psychologists" (p. 569). Cline and Richards also cite others' arguments regarding the marked poverty of scientific knowledge in the psychology of religion.

At the present time, however, religion seems to have become a major area of concern for psychology, and an area of interest for many psychologists. It has been stated, very recently, that "trends have changed and there is now more professional support for addressing values issues in treatment. There is also more openness to the healthy potentialities of religious involvement, and therapists themselves manifest a new level of personal interest in such matters" (Bergin, 1991, p. 394). Bergin also expresses his satisfaction with the renewed positive interest of psychologists in religion by saying, "I am heartened by the existence of a growing clinical literature that provides 
descriptive evidence of the usefulness of spiritual dimensions in enhancing change ... including a renewed positive interest in religion among psychologists" (pp. 401-402). Within the general field of Psychology, interest in religion and religiosity seems to be greater and earlier among professional therapists (see for example, Allport; 1950; Arbuckle, 1975; Bergin, 1991; Havens, 1968; Link, 1936; Wrenn, 1958) than among psychologists in the more basic research arena of the field. But recently the study of, and interest in, religion seems to be gaining a momentum as a basic research area in the field of psychology.

Jones (1994), also, speaks of the present livelihood of the psychology of religion by stating that:

The psychology of religion has a long and distinguished history, being one of the major areas of study in the field from 1880s until the 1930s. Psychology of religion is alive and well today, as demonstrated by the resurgence in publication of psychology of religion textbooks, .... by the inclusion of a review of the area in the Annual Review of Psychology, .... by the recent establishment of the successful International Journal for the Psychology of Religion, and by the establishment and growth of division 36 (formerly Psychologists Interested in Religious Issues, now Psychology of Religion) within the American Psychological Association. (p. 184)

\section{Psychological Measurement of Religion}

In psychology, as it has moved toward becoming an experimental science, any phenomenon that is to be studied has to be specified and well defined, not only theoretically but, most importantly, operationally, and the phenomenon of religion is no exception. There has been the criticism that "many who hypothesize about the nature of 
religiousness do so without a sound empirical basis for determining whether their hypotheses mirror reality" (Basinger, 1990, p. 3023). But despite the difficulty stemming from some philosophical concerns (see, e.g., Basinger, 1990), psychologists, in their endeavor to study the phenomenon of religion and its influence on people, have attempted to measure religiosity by developing different measurement scales and using different ways for measuring or estimating degree of religiosity among people being studied. And thus, measurement of religiosity has become a major issue in the relevant literature, to the extent that, as Gorsuch (1984) puts it, "even a brief scanning of the psychology of religion literature suggests that there are many articles in which at least one emphasis is on constructing, validating, or critiquing a measurement device..." (p. 229). Gorsuch even goes so far as to argue that the interest in religious measurement is distracting from the study of religion itself. As he puts it, "it is possible that psychologists studying religion will study the measurement of religion rather than religion itself" (p. 235). In recent years there have been many different religiosity scales measuring different aspects of religion and religiosity, among different populations of different cultures and different religious backgrounds, especially Christian populations (see e.g., Brown \& Lowe, 1951; Butman, 1990; Cline \& Richards, 1965; Degelman \& Lynn, 1995; Lewis \& Gladding, 1983; King \& Hunt, 1975, Robinson \& Shaver, 1973; Strommen, Brekke, Uderwager, \& Johnson, 1972; Van \& John, 1990).

\section{Problems with Religious Measurement}

As alluded to above, a fundamental issue in psychological study is the issue of definition of the phenomenon to be studied. In the psychological study of religion this problem is particularly complex. Yinger (as cited in Brown, 1987), who suggested that "any definition of religion is likely to be satisfactory only to its author" (p. 19), stated later (as cited in Brown, 1987) that "many studies of religion stumble over the first 
hurdle; the problem of definition" (p. 19). The term "religion" may be so popular and so familiar to almost every one. But perhaps it is its popularity and familiarity that make it a most difficult task to try to define it in empirical research. So what is it that we are looking for, or looking at, when we try to study religion or religiosity? What is religion? "What is this 'religion', beyond the wide ranging beliefs and prescriptions of Christianity and other world religions that we recognize?" (Brown, 1987, p. 17). It has been argued that "scientists traditionally contended that religious faith cannot be measured, but are beginning to realize that its impact on a person's life is measurable" (Sleek, 1994, p. 8).

Another related problem is the dimensionality of the concept of religion. A major question, of great concern, in the psychological study of religion is: "is 'religion' multidimensional and, if so, what dimensions are of use in the scientific study of religion?" (King \& Hunt, 1975, p. 13). Theoretically speaking, we may consider as an early statement as William James's (1961) suggestion that "the very fact that they [the definitions of religion] are so many and so different from one another is enough to prove that the word 'religion' cannot stand for any single principle or essence, but is rather a collective name" (p. 39). "The truth must at last be confronted that we are dealing with a field of experience where there is not a single conception that can be sharply drawn" (p. 48). James (1961) proposes to ignore what he calls 'the institutional branch' of religion entirely and confine himself to personal religion regardless of what name it might be given, and describes religion as he takes it to mean "the feelings, acts, and experiences of individual men in their solitude, so far as they apprehend themselves to stand in relation to whatever they may consider the divine" (p. 42). Thouless (as cited in Brown, 1987) defines religion as "a particular kind of attitude (which includes characteristic ways of behaving, feeling and believing) towards the world as a whole" 
(p. 18). Clark (as cited in Brown, 1987) states that "religion has many meanings and facets" (p. 18).

Empirically, a finding that has emerged very often from psychological research concerning the dimensionality of religiosity is that religiosity has proven to be a complex multidimensional construct that cannot be easily defined in one unidimensional term or contained in one simple unidimensional measurement instrument. There are different components of religiosity that need to be considered. Many studies (e.g., Cline \& Richards, 1965) using different instruments for measuring religiosity found it not to be, simply, "a single dimension, but is factorially extremely complex" (Cline \& Richards, 1965, p. 577). A popular example of the discussion of religiosity dimensions is that concerning Allport's intrinsic-extrinsic concept of religious orientation (Allport \& Ross, 1967; for more on intrinsic-extrinsic dimensionality of religion see, e.g., Donahue, 1985; Feagin, 1964; Hood, 1971; Hunt \& King, 1971; Spilka et al., 1977). When Allport constructed his popular and widely used "Religious Orientation Scale" (ROS), the scale was originally developed to, supposedly, measure both intrinsic (I) and extrinsic (E) religious orientations as two ends of a theoretically unidimensional bipolar continuum. But empirical research has indicated, from the beginning, that it was not a unidimensional bipolar continuum, but that (I) and (E) poles were nearly independent and measured two different things. A general conclusion of the research was that the ROS is not a single-dimensional measure, and the recommendation was that the two subscales I and $\mathrm{E}$ should not be used in combination as a single unidimensional scale, but as two separate scales (see Allport \& Ross, 1967; Donahue, 1985; Feagin, 1964; Hood, 1971; Hunt \& King, 1971). Bergin (1991) states that "one finding that most scholars in this area agree on is that religious phenomena are multidimensional" (p. 399). Bergin also refers to some studies in which it became clear that religious influences are therapeutic for many individuals and a part of self-defeating 
pattern for others, arguing that "these studies thus confirm the work of others in showing that religion is a multidimensional phenomenon with divergent qualities and consequences" (p. 401). Bergin also makes the argument that the attempts made to identify religious factors "provide a good starting point toward specificity as opposed to global and misleading evaluation of a complex phenomenon" (p. 399). A more perplexing argument is one like Strommen's in his introduction to an article by Dittes (1971), in which he (Strommen) states that "Dittes establishes the fact that there is empirical evidence for regarding religion as both unidimensional and multidimensional" (p. 79). Dittes (1971) also refers to Glock's argument for multidimensionality in which he proposes five independent dimensions, arguing for the discreteness of these dimensions, but, at the same time, Glock seems, according to Dittes, to propose, in general way, some relation among them. Fullerton and Hunsberger (1982) propose a unidimensional perspective of religion, arguing that while there is some controversy over the dimensionality of religion, "there is at least some evidence to support a unidimensional view of religiousness ..., and even when a multidimensional conceptualization of religiousness is adopted, there is evidence that an ideological, or orthodoxy dimension is the best predictor of other dimensions of religious commitment" (p. 317). Fullerton and Hunsberger constructed what they call "Christian Orthodoxy Scale" (C.O.), which, according to the authors, proves to be reliable and valid, and consists of a single factor accounting for a large portion of the total test variance. Fullerton and Hunsberger's argument for unidimensionality does not necessarily suggest a denial of the multidimensionality of religion. In fact, they clearly state that their (C.O.) scale may be useful where an indication of the orthodoxy of a sample is desired. "This is not to deny that other dimensions of religiosity exist. Rather, it is suggested that when interest focuses on a dimension of Christian Orthodoxy, the C. O. Scale can be a useful tool" (p. 325). However, the result of a latter study by Lindsey, Sirotnik and Heeren (1986) showed two (or at least two) separate dimensions 
within the (C.O.) scale. Lindsey et al. discuss some possible explanations for the differences between their results and those of Fullerton and Hunsberger's. But Lindsey et al.'s findings were disputed, and their procedures were criticized by Hunsberger (1987), who argues further that the findings of the two studies (Fullerton \& Hunsberger's, 1982, and Lindsey et al.'s, 1986) are not different, but rather "very, very similar" (p. 258), and that the analyses leading to Lindsey et al.'s conclusion that a second factor is present in the C.O. scale are "difficult to justify. To add a factor which explains just $7.3 \%$ of the variance when one has already accounted for $58 \%$ of the variance with a much larger and more important factor, would seem to be a moot point" (p. 258). The problem of uni- or multi-dimensionality of religious phenomena is considered a major and unsolved problem in the paradigm of religiousness measurement (Gorsuch, 1984, p. 228). As Gorsuch puts it, "an unresolved problem is the dimensionality of religion. ... Some investigators implicitly suggest it is unidimensional by using a single measure. Others use multidimensional measures" ( $p$. 232). Gorsuch, then, goes on, raising questions and suggesting a resolution, "is religion unidimensional? If not, what are its dimensions? The resolution could be both/and rather than either/or. There may be a general religious dimension - as a unidimensionalist might assume - that can be subdivided into dimensions - as a multidimensionalist might assume" (p. 232). This compromising suggestion does not help solve the problem once and for all. Nevertheless, Gorsuch argues that "if the paradigm of religious measurement is to continue to provide the direction that is needed from a paradigm, then it is apparent that we need to resolve the issue of uni/multidimensionality as well as beginning to establish some common agreement on the nature of the dimensions" (p. 233). Whatever conclusion might be reached and whatever resolution might be discovered for this problem, at this stage of the religiosity measurement research the evidence of the multidimensionality of religion is overwhelming, and the issue now is what, and how many, dimensions there are and 
how to identify them. It seems that the best a researcher can do in this regard is to be specific as to what component, or components, he or she is concerned with, by choosing a particular theoretical construct, or constructs (components), and trying to operationalize and measure them. This view (which is the present researcher's) seems to find some support in Gorsuch's (1984) suggestion that

we are ready, in terms of empirical data, for a new subparadigm that transcends the question of unidimensionality versus multidimensionality of religious phenomena. It is a paradigm that recognizes a higher order integration and provides us with both multidimensional and uni-dimensional perspectives, which can then each be related to theory and data as needed. The new paradigm consists of a general Christianity factor that can be subdivided into factors such as those [found by different researchers]. (pp. 233-234)

Gorsuch, nonetheless, seems still to favor working on the multidimensional perspective, arguing that composite scales may be useful in many cases where we are interested in broad prediction, but for "the exacting work of science" (p. 234) it may be necessary to have scales that measure separate components, in order to produce greater accuracy for a particular question.

Another major issue in the measurement of religiosity is the applicability of religiosity scales not only to different belief systems, but also to different sects or denominations within the same general belief system, for example different denominations within Christianity, or sects within Islam. According to Gorsuch (1984), one question that is seldom used for measurement by psychologists active in psychology of religion is "religious membership ... the assumption within the current paradigm seems to be that people who are members of the same religious group vary 
widely in their beliefs and approaches to religion" (p. 230). One kind of problem in this regard is with norms. For example, Gorsuch continues to say that

Pugh (personal communication, 1982) has found that different congregations vary widely in both mean and standard deviation for such scales [median splits]. The differences are large enough for a group of 'low extrinsics' based on median split in Congregation A to have essentially the same mean and standard deviation as a group of 'high extrinsics' from a median split in Congregation $\mathrm{B}$. This may cause a considerable confusion, for the same extrinsic score called high extrinsic in a study using Congregation A would be called low extrinsic in a study using Congregation B. (Gorsuch, 1984, p. 232)

Another kind of problem is with scale content. Long and Elghanemi (1987), reporting their findings with Saudi Arabian students, state that "not surprisingly, upon empirical examination, Putney and Middleton's religious orthodoxy scale appeared inappropriate for use with Saudi Arabians. Interitem correlations were generally weak" (p. 93). In addition, Patrick's (1979) data, using Christian and Buddhist subjects, failed to support a hypothesized universality of the Intrinsic-Extrinsic religiosity concept, leading Patrick to conclude the inapplicability of the concept for the Buddhist group in his study. Another finding (Albelaikhi, 1988) also showed a low Alpha Coefficient value (.41) for Muslim participants on the Intrinsic subscale of Allport and Ross's (1967) Religious Orientation Scale, compared to a value of .75 for Christians.

The inapplicability of measures with different populations stems from the distinct characteristics of different cultures and religious systems. This problem has hampered the effort of measurement developers in most areas to build satisfactory cross-cultural scales, constituting, most of the time, a great necessity to have unique measures for different populations of different cultural and religious backgrounds. 
Among such populations is the Muslim population, which is the main concern of the present study.

\section{The Psychological Study of Religion among Muslims}

In spite of the growing interest among psychologists in studying religion and religiosity among populations like Christians, there is relatively little research on the phenomenon of religion among Muslims (e.g., Albelaikhi, 1988; Ali, 1988; Alsanie, 1989; Beg \& Zilli, 1982; Hafsi, 1987; Kershaw, 1973; Long \& Elghanemi, 1987). The Muslim population has recently become, to a limited degree, a target for psychological research in the area of religion, but little research on this topic has been reported in the literature. Most of this research looked at the relationship between religiosity and some other variables, for example, fear of death (Albelaikhi, 1988; Long \& Elghanemi, 1987), work ethics (Ali, 1988), work centrality (Hafsi, 1987), criminal behavior (Alsanie, 1989), and other variables, such as productivity, psychological well-being, and ambition (cited in Alsanie, 1989).

\section{Measuring Islamic Religiosity}

Attempts to study religion among Muslims were, as might well be expected, accompanied by attempts to measure religiosity and religious aspects of people's lives. Some researchers attempted to measure religiosity as a general one-dimensional concept (e.g., Alsanie, 1989), others measured it as manifested in religious beliefs and practices (e.g., Taai, 1985), and still others measured religiosity in terms of the intrinsic- extrinsic concept (Albehairi \& Demerdash, 1988). Examples of religiosity scales for Muslims include Hafsi's (1987), which consisted of three statements on which subjects were asked to rank the deepness of their knowledge of Quraan, their knowledge of Hadeeth (i.e., Prophet Mohammad's teachings), and the extent to which 
they follow the Islamic teachings in their daily life. This is a very simplified conception of religion, and, in addition, no psychometric scale-construction procedure was employed, or at least reported, except for the issue of translation from Arabic to English and Japanese, which was very briefly mentioned. Another earlier scale was developed by Kershaw (1973), which actually attempted to measure the attitudes of Saudi Arabian students in the United States, not only towards Islam, but also towards Christianity and religion in general in the United States. Three more recently developed scales for the Muslim population are "Religious Orientation Scale" (Albehairi \& Demerdash, 1988), "Religious Behavior Scale" (Taai, 1985) and "Religiosity Level Scale" (Alsanie, 1989). All three are in the Arabic language (the last two are to be elaborated on later, and are employed in the present study). There are, however, some points of concern that should be noted concerning these scales.

Albehairi and Demerdash's (1988) scale was developed to measure intrinsic and extrinsic [I and E] religious orientations among Muslims (in addition to another version for Arab Christians), using Allport's I-E concept. The authors claimed to have constructed the scale items through recruiting religious scholars to write items, in addition to some items that were written by the authors, and also consulting psychology experts and religious scholars on the final form of the scale items. However, almost all of Allport's and Ross's (1967) 20 items are among the 34 items comprising the Muslim version of the scale, with very slight rewording in some items, which might be due to translation. Virtually a replication of Allport's and Ross's (1967) Intrinsic-Extrinsic Religious Orientation Scale, this scale was intended to specifically measure the two dimensions ( $\mathrm{I}$ and $\mathrm{E}$ ) of religious orientation.

The "Religious Behavior Scale" (Taai, 1985) can be classified as a theoretical scale in that Taai started with a theory derived from the Islamic teaching sources. From the point of view of the theoretical framework, Taai's scale components were based 
firmly on what he called elements of belief as they were defined in the Islamic teachings sources and literature. Judging from the information provided in the test manual, the claimed effort to consult the sources is very clear, and Taai's effort to build his hypothesis is admirable, but there was what may be considered a serious flaw in classifying these elements under the proposed scale components, especially in the scales of practice. For example, on a subscale called "Worships" Taai put practices like prayer performance, fasting of Ramadhan, and giving obligatory charity, which are obligatory duties and a Muslim has no choice but to do them, with practices like seeking knowledge and devoting some time to stay in Mosque for voluntary prayer and worship (called Eatikaf), which are recommended, but not obligatory. On another subscale called "Mortals" he put things like food gluttony, talk gluttony, and wealth loving, which are discouraged in Islam, but not necessarily even sinful, with things like adultery, whose punishment, in Islam, could amount to capital punishment (death penalty by stoning), and killing oneself. Both (adultery and killing oneself) are among the so-called "mortal sins" in the Islamic faith. Similarly, the naming of some subscales seems questionable. For example, a subscale named "Redeemers" consists of 15 items representing elements of belief which, according to Taai's definition, when practiced, bring a person closer to God, for example, patience, fearing God, relying on God, truthfulness, humility, honesty, and the like. It seems reasonable to argue that categorizing things that bring a person closer to God as things that save (i.e., redeemers) is unwarranted. In the Islamic faith voluntary deeds or practices bring a person closer to God, but for a person to be granted salvation or redemption, he or she has to perform the obligatory duties. Had Taai attempted a factor analytic procedure, it is very unlikely that his categorization of items under subscales would have been confirmed. Furthermore, the interpretation of the test results is based simply on the ttest scores and percentile scores (as described in the Measures section). Another major 
disadvantage of Taai's scale is its two-choice response format, a format that has its limitations (as discussed in more details in Discussion section).

Alsanie's (1989) scale also has some weaknesses. Most important of these is one that concerns the definition and dimensionality. Alsanie in his theoretical definition of the Islamic religion describes it as a somewhat two-dimensional phenomenon, with the two dimensions being "belief" and "practice". He draws on the basic Islamic view which combines faith with deeds (or belief with action) and asserts that mere belief is not accepted if not manifested in action. However, he treats the concept in his scale as unidimensional, with the one dimension being general religiosity, or what he terms "general meaning of belief", which includes saying and action, the general meaning that accommodates the internalized belief and the physically demonstrated action, which he considers the scale to be measuring. Alsanie's treatment of religion as a general concept, considering his theoretical definition, may not be warranted. Remember Gorsuch's (1984) argument, quoted above, that composite scales may be useful in many cases where we are interested in broad prediction, but for "the exacting work of science" (p. 234) it may be necessary to have scales that measure separate components, in order to produce greater accuracy for a particular question. There might be more than one factor not only within the concept of religion Alsanie is adopting, but also in the items he is using. There may be at least two factors representing belief and behavior. Combining the two components in one concept does not seem justifiable. Although belief and behavior, in the Islamic faith, are supposed to be concomitant in people's every day lives, they are not necessarily inseparable. In other words, a person could have good faith and strong belief in the religion but not act upon that belief or practice it. On the other hand, a person could be faithfully practicing what he believes in, but his belief might not be in accordance with the teachings of the religion. Neither exclusive form of religiosity is acceptable in the Islamic religion. So belief and practice, 
which is considered a result of belief, are viewed jointly in the Islamic religious system as an indication of good religiosity. But the two are not the same and, thus, cannot be measured as one component, as Alsanie did. Alsanie, nonetheless, criticizes other scales for having overlap of items between subscales. A person cannot be considered religious or irreligious, or to have a higher, or lower, level of religiosity without considering his or her scores on both components. Furthermore, Alsanie disregards some earlier scales as not being suitable for the purpose of his study, which was concerned with the level of religiosity, and not with certain dimensions such as "religious values" and "religious attitudes". He describes his scale as consisting of items, or statements, that measure different aspects of religiosity, without mentioning or specifying these aspects. So it is difficult to interpret exactly what he means by the level of religiosity, or what aspects of religiosity his scale is intended to measure. There are indications, however, that what he considers as a criterion for religiosity is behavior. He states that the items were constructed with the postulate that only God knows the truthfulness of a person's belief, and what we can know about that is through the consequences or results of such belief, which are manifested in the person's sayings and actions. Alsanie, further, says that the basis of belief is assumed to be present in every Muslim, and thus, the items did not deal with belief but rather with the level of a person's commitment to performing duties and avoiding sins. However, the first item in Alsanie's scale measures the degree of belief in God: ("My belief in Allah (God) is: (a) similar to the belief of the most religious people, (b) similar to the belief of moderately religious people., (c) similar to the belief of the least religious people"). Alsanie's argument becomes even more confusing when we consider his dismissal of Taai's (1985) scale as being a measure of religious behavior and not level of religiosity. Another potential shortcoming of Alsanie's scale is the response format. Although Alsanie criticizes other scales, including Taai's, for the limitation of response choices, his response format was a 3point scale (this issue is discussed more fully later, in the Discussion section). 
For the purpose of this present study, the definition chosen to begin with is a working definition of Islamic religiosity in terms of the extent of agreement with all of the important beliefs, practices, and attitudes of Islam, as presented in its major teachings. However, since this is an exploratory study, this definition does not exclude other possible components of religiosity that might come out as a result of the Principal Components Analyses (further discussion of this is in a later section on constructing the Muslim Religiosity Scale).

\section{Differences in Religiosity}

Gender. Most of the research in this area has suggested that females, in general, are more religious than males (see, e.g., Donahue, 1985), in different religious systems and different cultures, for example, among Christians in the United States of America, (Alston, 1975; Cline \& Richards, 1965), English (Francis, Pearson, Carter, \& Kay, 1981), Muslims (Albehairi \& Demerdash, 1988; Taai, 1985), Hindus (Karna \& Panjiar, 1987), and Indians (Pareek, 1987).

Educational Background. With regard to differences in level of religiosity, it seems reasonable to argue that people will differ in their levels of religiosity on the basis of their attachment to their religion and familiarity with its teachings and instructions through family life, education and so forth. A study of Protestants (Wrobel \& Stogner, 1988) found a Bible-study group to score significantly higher than a college sample of undergraduate psychology students on a scale of theistic beliefs and a scale of religious participation.

\section{Hypotheses}


On the basis of the above arguments, and the findings of previous research, the following hypotheses were developed:

Hypothesis 1. There are several distinct components of religiosity in the Islamic religious system.

Prediction: At least three components of religiosity will emerge from the items, presenting such aspects as belief, attitudes, and practice.

Hypothesis 2. Alternative measures of religiosity will be related to the extent that the conception of religion on which they are based is similar.

Prediction. The belief, and practice subscales of the newly developed scale (Muslim Religiosity Scale) will have high correlations with conceptually related components of Alsanie's "Religiosity Level Scale" and Taai's "Religious Behavior Scale".

Hypothesis 3. People with different religious education backgrounds are different in their level of religiosity.

Prediction: Students of colleges of Islamic studies will be more religious than students of colleges of Arts and Humanities.

Hypothesis 4. Males and females are different in their level of religiosity.

Prediction: Female students will be more religious than male students. 


\section{Methods}

\section{Subjects}

Subjects were 169 (108 males and 61 females) Saudi Muslim college students. All were in Saudi Arabian colleges, between the ages of 17 and 31 years $(M=23.42)$, and of the Sunni sect. Participation was completely voluntary.

This total sample consisted of two groups of roughly equal numbers of subjects with, hypothetically, different religious education depending on their majors. One group (group 1) consisted of 82 (54 males and 28 females) students from colleges of Islamic studies, and the other group (group 2) consisted of 87 (54 males and 33 females) students from colleges of Arts and Humanities. Subjects were recruited from three universities and two colleges for girls in two different regions of the country.

\section{$\underline{\text { Measures }}$}

The measures used in this study included three scales.

\section{Muslim Religiosity Scale (Appendix C, and Appendix H for the Arabic}

version). This scale was constructed for this study. Actually, development of this scale is the main focus of the study. The steps employed in this process are the following:

Approach to Scale Development. The approach to developing a Muslim religiosity scale taken in this study was exploratory and thus, employed exploratory, and not confirmatory, factor analytical procedures; specifically, Principal Components Analysis (PCA) procedures. In the area of scale development strategies, scale developers often start in one of two ways. On one hand, a researcher may start scale development process, including such steps as item writing and factor analyzing and the 
like, with no specific or prior anticipation of what or how many underlying dimensions (or factors) make up the construct he or she is attempting to measure. On the other hand, a researcher may start with specific hypotheses regarding the dimensions to be looked for, and anticipate what and/or how many of these should there be, and even decide a priori what variables (i.e., items) should go under which dimension (or factor). There are certain statistical procedures such as factor analytic procedures that are used in scale development to help determine the dimensions that make up the construct being measured and that are represented by the items used in the scale. In the first instance, where a researcher starts with no prior knowledge of what might come up, the factor analytic procedures used are called exploratory factor designs. In the second instance, the researcher looks for confirmation for his or her hypothesized factor structure, and thus the procedures used are called confirmatory factor analysis (see, e.g., Kim and Mueller, 1978a).

The present study combines features of both approaches but is more of the exploratory type. Although some expected dimensions have been named a priori (i.e., belief, attitudes, and practice) to aid in item generation, there was no attempt to limit the expected dimensions to those three. In addition, no attempt was made to decide exactly which items belong to which dimensions. In fact, judges who examined the items were asked to judge the appropriateness of the items as indicators of religiosity in general (considering different aspects of religiosity), but were not asked to sort items under dimensions. In any case, it has been argued by experts in the field of scale development that the two approaches (the exploratory and confirmatory) are not always mutually exclusive, for "the division between the two uses is not always clearcut. For instance, it is possible that the researcher may specify that there will be, say, two factors but may not anticipate exactly what variables will represent each" (Kim and Mueller, 1978a, p. 10). Put another way by another expert, "confirmatory procedures 
can certainly be useful. Note, however, that a scale developer can have in mind which items should group together without explicitly programming this information into the analysis (i.e., without using formally confirmatory methods)" (Devellis, 1991, p. 108).

It is also argued that "exploratory factor-analytic procedures . . can be very helpful in the process of developing good scales, whether they be simple, homogeneous scales at the lowest level in the construct hierarchy or whether they be broad, complex scales measuring higher order constructs" (Comrey, 1988, p. 758).

The overall approach to scale development in this study, however, was guided, to some extent, by what Jackson (1970) called the "Sequential Strategy in Scale Construction".

Theoretical Framework. This scale was intended to measure religiosity in the Islamic religious belief system. Four important components of religiosity were explicitly used to generate items: belief, attitudes, practice, and knowledge. The belief component was intended to be measured as manifested in a person's belief regarding the major concepts in the Islamic religion, for example, belief in God and his existence, in Angels, Heavenly Books, Prophets, the Hereafter, and in Fate and Divine decree. The attitudes component was concerned with the person's interest in, and attitude (positive or negative, favorable or unfavorable) toward religion, in general, and his/her attitudes towards religious authorities and figures such as Allah, the Prophet, the Quraan, religious people, and various religious issues. The practice component dealt with the extent to which a person actually practices the teachings of Islam and its commands. These practices include both obligatory duties, for the performance of which a person is granted God's reward for doing, and is subjected to God's punishment for failing to perform (for example the five daily prayers), and some other recommended voluntary practices, which a person is rewarded for doing, but not punished for not doing (for example, voluntary prayer, voluntary charity, and the like). 
Belief and practice may be considered the two most important components in the religion of Islam. They go hand in hand. No deeds are good or accepted if they are not based on good faith in God and firm belief in his message. And belief is fruitless without good deeds. When Quraan praises the believers and mentions their reward, it always describes them as those who combine belief and good deeds, and so do the sayings of the prophet. Quraan, on the other hand, describes as losers those who believe but do not practice and those who do good deeds without good belief. In terms of attitudes, Islam requires a Muslim to have a positive and favorable attitude towards God (Allah), his messengers, and his religion in general. Also, Quraan and Muhammad praise those who love God and his prophet. People are expected to be led by their attitudes and act upon them, and that is how attitudes can be a good indicator of religiosity.

The fourth component (knowledge) was considered and items were written to measure the level of general knowledge a person has regarding some Islamic religious issues (see Appendix F). However, this component was eliminated later based on the results of judges' evaluation. Among the items or statements that were intended to measure knowledge only one item met the criterion for retaining items.

The results of the judges' evaluation, regarding the knowledge items, were indeed very interesting. It was argued by the author of this study, before the items were submitted to judges, that knowledge may not be a good indicator of a person's religiosity. The argument was that there might, of course, be many components that can be involved in the definition of religion. However, not all components can be useful in identifying religious people. One example of this is the religious knowledge component. A religious person might be expected to be more knowledgeable, with regard to religion, than a nonreligious or less religious person, but knowledge per se may not be a good indicator of personal religiosity. A person, for instance, could be 
most knowledgeable about a certain religion, but least religious. In fact, there might be some people who are very knowledgeable about religions with which they do not even have any affiliation. Furthermore, in a study by King and Hunt (1975), it was found that "persons with more years of schooling were 'less religious' on all scales [used in their study] except that they scored higher in religious knowledge" (p. 14). In an earlier study (Cline \& Richards, 1965) it was found that secondary loadings on a factor named by the authors "Loss of Faith", indicated that high scorers on that factor, who have changed their religious beliefs toward a less religious position, have more knowledge about religion. If the knowledge component was used in the present study, it would be expected that students of colleges of Islamic studies will score higher, on this particular component, than the Arts and Humanities students. But that might be a misleading indicator of a person's being religious or nonreligious, if taken by itself. Although Muslims are recommended to acquire knowledge about their faith in order for them to perform their duties correctly and in accordance with the teachings of Islam, mere knowledge is not enough to make a person religious or a good Muslim. In fact, Quraan condemns those who know but do not apply their knowledge and follow what they know. Nevertheless, such components may be useful for measuring general religiosity in combination with other components, or could be useful by themselves for specific purposes, for example, a subscale representing religious knowledge will be most useful if the purpose is to measure religious knowledge per se and not religiosity.

Other additional, unspecified components were expected to emerge from the items. The item pool was believed to contain many items representing unspecified components of religiosity (based on Islamic teachings) that could be named on the basis of the nature of items loadings on them following the component analysis, in addition to the ones already mentioned and named in advance. But since the intended scale is meant to specifically measure religiosity among Muslims, belief, attitudes, and practice 
components were expected to be the best indicators of religiosity, from the Islamic perspective.

Item Construction and Evaluation. The original item pool consisted of items from a variety of sources. Some were initially written by the author, and others were taken, or their ideas were adopted, from some already existing Muslim and non-Muslim religiosity scales, and discussions of religious measurement. Scales and sources that have been utilized in this regard included: "Religiosity Level Scale" (Alsanie, 1989), "Religious Behavior Scale" (Taai, 1985), these two scales were developed with and for Muslims, and a questionnaire constructed to measure "Attitudes Toward Religion of Saudi Arabian Students in the United States" (Kershaw, 1973). Other scales that were used generally with Christian populations included: "Religious Orientation Scale" (Allport \& Ross, 1967, Feagin, 1964), "Inventory of Religious Belief" (Brown \& Lowe, 1951), "Church-Sect Scale" (Dynes, 1955), "National Sample Questions on Religion" (Carroll \& Roozen, 1973), and "Religious Scales" (King \& Hunt, 1975). Other scales and discussions were also of some benefit for inspiring ideas for item writing for the MRS (see, e.g., Robinson \& Shaver, 1973).

The final version of the item pool was first subjected to further editing and modification to reduce redundancy and maximize clarity and applicability. Then it was arranged and written in Arabic in the form of a questionnaire consisting of 116 randomly listed items.

This questionnaire was then given to judges to evaluate the suitability of the items. The judges were to judge items in terms of their clarity and their relevance and appropriateness for use with Muslim individuals of both sexes. They were to do this by using a 5-point appropriateness response format ranging from $1=$ Very inappropriate to $5=$ Very appropriate. The judges' task was to read each item carefully and decide 
about its appropriateness and clarity and indicate their decision by circling one of the five rating choices.

Judges were sought for the task of evaluating the items on the basis of their Islamic knowledge and their knowledge of psychological studies and measurement, judged by their specialty of study and their level of education (a Ph.D. degree, or at least three years on the current teaching job, regardless of degree obtained).

An undetermined number of copies of the questionnaire (over 30 ) was distributed, and collected back, within a 1-month period of time to college professors of Islamic studies (different areas of Islamic Studies) and Social Sciences (Psychology, Sociology and Education) at one of the Saudi Universities. These judges were identified and recruited through personal contact by the researcher with the assistance of one of his colleagues, who helped hand out the questionnaires and collect them.

23 questionnaires were returned. Only 11 of those were used in scale construction. The main reason for discarding the remaining 12 questionnaires was the fact that some respondents (judges) left some items unmarked. Other reasons included leaving all items unmarked (two forms), giving all items the same rating (two respondents gave all items a rating of 5), and failing to provide the required demographic information. Two questionnaires (in addition to the 23) were returned too late to be used.

After collecting the item lists from judges, items that were judged to be appropriate were included in the revised version of the questionnaire. A check, in the form of examining means, was performed. Items that got a mean score of 4 points or higher were included, and those which got a mean score of less than 4 points were eliminated. A total of 84 items scored 4 points or higher. Only one item from those expected originally to be measuring knowledge was among the ones that passed the cut-off score limit, and it was eliminated, leaving only 83 items in the scale. Further 
editing and modification were performed on the chosen 83 items, based on the suggestions offered by some judges.

Five additional items, that were suggested by one of the judges, and judged by the researcher to be suitable, were included in the final version of the questionnaire (items 82 through 86, see Appendix $\mathrm{C}$, and Appendix $\mathrm{H}$ for the Arabic version), making the total number of items 88 .

The chosen set of items have two 5-point response formats, depending on the nature of item content. One is an agreement or disagreement response format, ranging from $1=$ Strongly disagree, to $5=$ Strongly agree. The other is a frequency response format ranging from $1=$ very infrequent to $5=$ very frequent (see Appendix $\mathrm{C}$ ). Some responses were reversed in the actual administration, and then recoded at the analysis stage.

\section{Religiosity Level Scale (Alsanie, 1989) (Appendix D, and Appendix I for}

the Arabic version). This scale is a 61 -item scale concerned with the general meaning of belief in the Islamic religious system, which is that "belief is saying and action", (Alsanie, 1989, p. 223) and is supposed to measure different, unspecified, aspects of religiosity.

The response format is a 3-point rank scale $(1=$ low level of religiosity, $2=$ moderate level, 3 = high level) arranged in ascending order (1-2-3) for some items (items \# 11-20, 31-40, and 51-60), and in descending order (3-2-1) for others (items \# $1-10,21-30,41-50$, and 61$)$, in order to reduce possible effect of random response factor. These numbers are used in the coding of scores but are not shown in the actual administration, only little empty squares are provided for respondents to check. In the present study letters of the alphabet $(a, b$, and $c)$ were used. The highest response (i.e., number 3 ) receives a score of 3 , the middle response (number 2 ) receives a score of 2 , and the lowest response (number 1 ) receives a score of 1 . If an item is eliminated, i.e., 
if it is not responded to, by the subject, it receives a score of zero. If more than one response is given to the same item, then only the lowest is taken. The scores are then added to produce the total scale score. This is the way this scale was to work.

However, in the present study only questionnaires that were completed properly were used. Questionnaires of respondents who left some items unmarked or marked more than one choice for the same item, and the like, were eliminated.

To test the scale reliability a test-retest correlation was calculated, in the initial scale construction procedure (Alsanie, 1989), on the scores of 70 Muslim male inmates of a correctional institution in Saudi Arabia, with a time interval of two weeks. The test-retest reliability coefficient obtained was .89 . A split-half reliability coefficient of .94 was also obtained by correlating the odd and even items of the scale. The corrected coefficient, using the Spearman-Brown Formula, was .97.

The scale's author judged its validity, in part, by its face validity as suggested by the item content, by the judges' approval of the items, by the fact that the judges' comments and suggestions were taken into consideration in the final preparation of the scale, and by the scale's internal consistency. The internal consistency reported is the item-scale correlations, which reached significance at the .01 level for 55 items, and higher than .01 for five items.

Subsequently, the scale was administered to two groups in Saudi Arabia. One group consisted of 160 male prisoners, who were jailed for committing crimes. The other group consisted of 140 male electric company workers. The scale seemed to demonstrate its discriminating ability. As hypothesized, the worker group obtained a higher score $(M=153.13)$ than the prisoner group $(M=104.86), t=18.61, p<.01$.

\section{Religious Behavior Scale (Taai, 1985) (Appendix E, and Appendix J for}

the Arabic version). This is a true-false scale designed to measure the general domain of religious behavior among Muslims on the basis of the presence or absence of 
the elements of belief in an individual. It is composed of 77 items distributed among five subscales which measure two aspects of religiosity: Religious Beliefs (a two-part subscale), and Religious Practices (4 subscales)

The first subscale, called "Elements of Belief Scale", consists of 11 items describing religious beliefs of individuals. This subscale consists of two parts: One part, called "Basic Elements of Belief", measures the six principal elements of belief: belief in God, in Angels, in Heavenly Books, in Prophets, in Fate and Divine Decree, and in the Hereafter, which define whether a person is a believer or not, or without which a person cannot be considered a believer. The other part, called "Complementary Elements of Belief", measures five other basic elements of belief that complement the previous six principal elements. They are belief in Heaven and Hell, in the Day of Reckoning (Judgment Day), in Resurrection, in enjoining the love of Prophet Mohammad, and in the Creation of the Universe. The other four subscales consist of the remaining 66 items, designed to measure religious practices of individuals. These four practice subscales include the "Worships" scale, consisting of 17 items representing the branches and elements of belief which define the relationship between the individual and his or her God, for example, seeking knowledge, performing prayer, reading Quraan, and so on. The next subscale is the "Habits" scale, consisting of 20 items representing the branches and elements of belief which describe relationships between the individual and others, for example, marriage, contacts with relatives, raising children, visiting the sick, greeting, and so on. The third practice subscale is the "Redeemers" scale, consisting of 15 items representing elements and branches of belief which, when practiced, bring a person closer to God, for example, patience, fearing God, relying on God, truthfulness, humility, honesty, and the like. The fourth and last practice subscale is the "Mortals" scale, consisting of 14 items representing elements 
that, when practiced, can demolish one's belief and drive him or her away from God, for example, eating gluttony, pride, adultery, hypocrisy, etc.

Responses to the items are scored true-false in such a way that a direct item (e.g., my conviction of God's existence is complete) receives a score of 1 if the response is "true" and a zero if the response is "false", and a reversed item (e.g., eating a lot lengthens life) receives a score of 1 if the response is "false", and a zero if the response is "true". So a false response to direct items indicates a lower level of religiosity (a score of zero), while the same (false) response to reversed items indicates a higher level of religiosity (a score of 1 ). The scales are scored by summing item scores. The possible scale scores range from 0 to 11 for the elements of belief subscale to 0 to 20 for the Habits subscale, and from 0 to 77 for the total scale.

The scale was standardized on a sample of 600 Muslim college students ( 300 males and 300 females) at the Kuwait University (K. U.) from different areas of studies, ranging in age from 17 to $33(\mathrm{~m}=23.08)$ for males, and from 17 to $32(\mathrm{~m}=21.37)$ for females, belonging mostly to the middle socioeconomic class, and representing different habitation regions.

The first step of interpretation of scores depends on the score obtained on the first part of the scale of "Elements of Belief" (which measures the 6 principal elements of belief). A respondent is considered a believer if he or she obtains a score of 6 , and a nonbeliever if he or she obtains a score of less than 6.

For interpretation of the total score of the belief scale (the total 11 items), and for interpretation of the score obtained on the religious practice scale (the total score of the four subscales collectively), T-scores and cut-offs were used to define low, moderate, and high levels of belief and practice. 
The total score of the (11-item) belief scale is interpreted in terms of Percentiles and T scores . A high score (percentile score higher than 75 and a T-score higher than 60) indicates a high level of religious belief, whereas a low score (percentile score lower than 25 and a T-score lower than 40 ) indicates a low level of religious belief. Scores, on the belief scale, falling between 50-75 percentiles and 50-60 T-scores indicate a moderate level of belief.

The second step of interpretation depends on the score obtained on the religious practice scale (the total score of the four subscales: Worships, Habits, Redeemers, and Mortals, collectively). When the score is high (percentile score higher than 75 and a T-score higher than 60), it indicates a high level of religious practices. On the contrary, when the score is low (percentile score lower than 25 and a T-score lower than 40), it indicates a low level of religious practices. The level of religious practices is considered moderate if the score falls between 50-70 percentiles and 50-60 T-scores. This way of interpreting scores applies also to the individual practice subscales and to the total scale score too. Practice subscale scores can be interpreted individually, depending on the purpose of interpretation.

Scale Reliability. Test-retest reliability coefficients (Product Moment Correlations) ranging from .67 to .88 for the individual subscales, and .90 for the total scale were obtained, using the scores of 40 psychology students (16 males and 24 females) from $\mathrm{K}$. U., with a time interval of 15 days. The scale reliability was also tested by measuring its internal consistency on the 40 students' scores in the second administration, using the K-R formula. Coefficients of .83 for the total scale, .70 for the scale of elements of belief, and .78 for the other four practice scales collectively, were obtained.

Intercorrelations of the Scale. Correlations between subscales, and between subscales and the total scale were calculated on the scores of 80 male and female 
college students of K. U. Results showed nonsignificant correlations between scale of elements of belief and three of the four scales of practices. The one significant correlation was between the scale of elements of belief and the Worships scale $(r=$ $.219, \mathrm{p}<.05$ ). For the four practice subscales, except for the correlation between Worships and Habits subscales, which was nonsignificant, all correlations coefficients were significant ranging from $r=.385(p<.05)$ between Habits and Mortals subscales to $r=.227(p<.05)$ between Habits and Redeemers subscales. The correlations between the subscales and the total score were all significant at the .01 level, ranging from $r=.718(p<.01)$ between total scale and Mortals, to $r=.332(p<.01)$ between total scale and elements of belief.

The scale's author argues that the high correlations between the subscale scores and the total scale score are evidence of the internal consistency of the scale as a whole, and also indicate the level of homogeneity between the subscales and the total scale, which has some relation to the construct validity.

\section{Procedure}

The final questionnaire package in the present study (a total of 23 pages) included:

1. A cover letter to respondents (Appendix A), describing, briefly, the general nature of the study, its significance, and some general instructions for completing the questionnaires, and reminding participants that all information gathered for this study will be confidential and used for research purposes only. Participants were also provided with the researcher's mailing address and asked to write him should they have any comments or suggestions that they can offer. One participant wrote to the researcher. 
2. A demographic information sheet (Appendix B).

3. Muslim Religiosity Scale (Appendix C, and Appendix H "Arabic version").

4. Religiosity Level Scale (Appendix D, and Appendix I "Arabic version").

5. Religious Behavior Scale (Appendix E, and Appendix J "Arabic version").

These measures were submitted to subjects in this order, and labeled "Questionnaire \# 1", "Questionnaire \# 2", and "Questionnaire \# 3"; respectively. It was estimated that it would take a respondent about 45 to 60 minutes to complete the questionnaires.

Data were collected from participants during the summer sessions of 1995.

An introduction letter was obtained from the dean of the college with which the researcher is affiliated (College of Social Sciences at the Imam Mohammad bin Saud Islamic University). The letter, which was addressed to officials of the target schools, introduced the researcher as an affiliate of the college working on his dissertation and requested cooperation with him and/or his assistants.

A number of the researcher's male and female friends and acquaintance assisted in distributing and collecting the questionnaire. Some of these assistants were themselves college students and some were college graduates holding different jobs. No specific training was given to, or required for, assistants, except some simple and general oral instructions from the researcher. In addition, they were given a typed note explaining the needed sample and providing general instructions for distributing and collecting questionnaires. The questionnaire packages were given to participants during class sessions, in most cases by the assistants, and in some cases by the class teachers. In cases where teachers helped give the questionnaires they were provided copies of the instruction note. Assistants and teachers informed students of their rights to decline from participation, reminding them that although their participation is completely 
voluntary, it is very much appreciated. Students who agreed to participate took the questionnaires home and returned them at different times later. On one occasion some questionnaires were given to dormitory male residents by a researcher's assistant through the residence's manager.

Of the 255 copies that were distributed 202 questionnaires were returned, achieving a relatively high return rate of $(79 \%)$. 


\section{Results}

The first step in testing the hypotheses was to perform psychometric analyses on the three major scales, "Muslim Religiosity Scale" (MRS), "Religiosity Level Scale" (RLS), and "Religious Behavior Scale" (RBS). Additional gender-neutral scale versions were generated, but were then excluded (see Appendix $G$ for a discussion of these).

\section{Principal Components Analyses}

Exploratory Principal Components Analysis (PCA) procedures were employed to test the first hypothesis (Hypothesis 1) regarding the existence of several distinct components of religiosity in the Islamic religious system.

Each of the three scales, namely MRS, RLS, and RBS, was subjected to a separate principal-component analysis (PCA). An interitem correlation matrix for each scale was created using the SPSS computer package. Of the original 88 items in the MRS 85 were used in this PCA procedure, after eliminating three items (\# 4, 21, and 45, see Appendix C) that had zero variance. For the RBS, the procedure was performed on 68 of the original 77 items, after eliminating nine items $(\# 7,15,34,42$, $46,48,58,60$ and 66 , see Appendix E) that were found to have zero variance. All the original 61 items of RLS were involved in the procedure. The matrix for each scale was then submitted to the CAX computer program (Velicer, Fava, Zwick \& Harrop, 1988) to determine the number of components to retain for rotation.

There are different criteria, or procedures, employed in aiding the decision as to how many components to retain in a PCA (see, e.g., Cureton \& D'Agostino, 1983 Gorsuch, 1974; Kim and Mueller, 1978b; Tabachnick \& Fidell, 1989; Velicer \& Jackson, 1990). Among these methods are the "Minimum Average Partial" correlations (MAP) (Velicer, 1976) and "Parallel Analysis" (PA) (Horn, 1965) rules. More recent 
studies comparing some of these methods, including "MAP" (Zwick \& Velicer, 1982) and "MAP" and "PA" (Zwick \& Velicer, 1986), have shown the performance of these two methods (MAP and PA) to be generally the best across all situations examined. These two procedures were used to help determine the number of components to retain in the present study. A cut-off value of .35 or higher for the size of loadings of items on components was decided on as the criterion for meaningful and acceptable loadings. The cut-off value usually chosen in research for this criterion is .30 or larger (Comrey, 1973; Tabachnick \& Fidell, 1989).

Results of PCA on MRS. According to Lautenschlager's (1989) table for estimating number of factors to retain using the "PA" method, the PA would suggest, approximately, 8-factor solution for the Muslim Religiosity Scale (MRS). The "MAP", as employed by using the CAX computer program (Velicer, Fava, Zwick \& Harrop, 1988), suggested a 6-factor solution, that is six components to retain. In addition to MAP results, several PCA procedures were performed, each time specifying a different number of components (Tabachnick \& Fidell, 1989). A range of different solutions, 3factor to 8-factor solutions, were requested of the CAX program and their varimax orthogonally rotated pattern matrices were examined. After examination and comparison of the six PCA solutions' results, the 6-factor solution, suggested by MAP, was judged to be the best to retain and interpret, and was, therefore, adopted for further analysis and discussion.

Examination of the Varimax rotated pattern matrix (i.e., the matrix of the rotated correlations between items and factors) of the 6-factor solution revealed that of the 85 items included in the analysis, 17 were unique variables, not loading on any of the six components (i.e., not reaching the criterion cut-off value). Among the remaining 68 items that were represented by the resulting components, 13 indicated complexity by loading at the .35 level or higher on more than one component. Table 1 shows the six 
factors with the items they represent and the values of their loadings. Unique and complex items were all, of course, eliminated from all analyses, and are not shown in the tables.

Table 1 about here

The first component (Factor 1) consisted of 14 items that predominantly described behavior or practice of individuals, and was, therefore, interpreted as a practice factor, and was labeled "Practice". One item (\#57) refers, as suggested by its content, to feelings and thoughts rather than a form of practice. In order to maximize the scale coherence, this item was dropped, leaving the scale with 13 items. In addition to lack of direct reference to practice, this item is second to the lowest loading item on this component; a feature that encouraged the decision to eliminate it. This deleted item is still shown under this factor (Table 1), for comparison only. (It should be noted here that all tables that present the factors and their loadings, for all scales, include items that loaded purely on the factors but were deleted in further applications. Such items are mentioned in the text, and also marked on the tables).

The second component (Factor 2) consisted of 11 items generally referring to values of religion, especially for society at large. These items represent a relatively wide range of values, including values that concern the Islamic religion in general, religious leaders, and religious people. The component was retained and given the label "Societal Value of Religion".

The third component (Factor 3 ) was easily interpreted as a belief dimension. In the 6-factor solution it consisted of eight items all very clearly expressing belief in some of the central tenets of the Islamic faith. All eight items appeared repeatedly as pure 
variables on the same component in four of the six solutions examined; on the other two solutions some of these items appeared on this component but loaded also (as complex variables) on other components. This component was, therefore, labeled "Belief in Central Tenets".

Eight items loaded on the fourth component (Factor 4). Seven of these items can be tied together, in a general sense, as expressions of the importance of, or the need for, religion. Although these items may be viewed, in some sense, as expressions of value of religion statements, this factor was labeled "Personal Need for Religion". This label "need for religion" was chosen over another potentially appropriate one, "importance of religion", in an attempt to identify this component in such a way as to distinguish it from the other dimensions since they could all be thought of as expressions of importance of religion. The emphasis on "Personal Need" is suggested because the majority of items on this component express rather individual, or personal, need for religion, distinguishing it from Factor 2, "Societal Value". The eighth item (\# 11) seems more like a practice item: "I fast the whole month of Ramadhan every year", but it loaded on this component (with a relatively low loading value: .435 ). To fit it into the label that is given to this component, this item may be interpreted as an expression of the importance of, or need for, fasting of Ramadhan as a religious duty. This, however, seems a very remote explanation. It was, therefore, judged that it is in the best interest of obtaining as a coherent scale as possible to drop this item from the scale and eliminate it from further analyses.

Nine items loaded on Factor 5. However, it was difficult to find a consistent theme across these items. As a result, this component was very difficult to label. The component included some items which expressed practice, some which expressed attitudes, others which expressed importance of religion, value of religion, need for religion, and others that expressed feelings. Despite lack of a clear and conceptually 
meaningful linkage between the items, the component was retained on the merit of its relatively high reliability coefficient (.70), and the relatively good loading values of two third of the items. It was tentatively given a very general label "Reliance on Practical Guidance".

The sixth component (Factor 6) was also difficult to interpret. Five items loaded on this factor. These same five items loaded purely on this factor in all five solutions that involved this factor. However, they represented a mixture of different contents, making this component hard to interpret and label. Considering the consistent appearance of these items and their high loadings on the same factor, it was thought that this factor was worth retaining. As the general content of the items seemed to suggest, this factor was tentatively labeled "Unquestioning Acceptance".

Percent of the total variance accounted for by the six components was 39.60 . Percent of the total variance accounted for by individual components was as follows: The first component accounted for $9.82 \%$, second component for $7.56 \%$, third component for $6.55 \%$, fourth component for $5.90 \%$, fifth component for $5.55 \%$, and the sixth component accounted for $4.22 \%$.

The intercorrelations among the six factors, as obtained by the CAX program, before deletion of items, indicated different degrees of independence among them. Although there were some positive significant correlations among the factors, these were relatively small, and some factors showed no significant correlations (see Table 2).

Table 2 about here 
In their final forms, i.e., after deleting some items, these six subscales showed relatively good reliability as measured by their internal consistency. Coefficient Alphas were .85 for Factor 1, .75 for Factor 2, .73 for Factor 3, .61 for Factor 4, .70 for Factor 5, and .57 for Factor 6 .

Results of PCA on RLS. For RLS, MAP (Velicer, Fava, Zwick \& Harrop, 1988) suggested retaining five components, and PA (Lautenschlager, 1989) suggested approximately six components. Beside the 5-factor solution, three more were requested: 6-factor, 4-factor, and 3-factor solutions.

By carefully examining and comparing the four solutions, the 5-factor solution was retained for analysis and further discussion.

Examination of the Varimax rotated pattern matrix of the 5-factor solution revealed that of the 61 items included in the analysis, 13 were unique variables, not loading on any of the five components. Among the remaining 48 items that were represented by the resulting components, six indicated complexity by loading, at the .35 level or higher, on more than one component. The resulting five components, the items that loaded on them, and the loading values are presented in Table 3.

Table 3 about here

The first component, Factor 1 represented 17 pure items. This component seems to represent a practice dimension, although a somewhat wide range of practices. Some items, including the second and third highest loading, though do not seem to refer directly to practice. Four items (\# 1, 2, 5, and 7) seem to tap the belief rather than 
the practice dimension. They have to do with some of the core elements of belief in the Islamic faith (Allah, Angels, Day of Resurrection, and Prophet Mohammad). Another item (\# 61) also does not describe practice but rather expresses opinion about one's own level of religiosity. There did not seem to be a reasonably meaningful link between these five items and the rest. The seemingly most meaningful interpretation of this component is to identify it as a practice dimension. Some of the items that did not seem to directly tap the practice dimension may be explained away in practical terms. Note that items (\# 2 and 5) which refer to Angels and Day of Resurrection, respectively, do not question one's belief in these two elements of belief in central tenets. They, instead, concern the effect of these two elements (Angels and Day of Resurrection) on one's daily practice. One can also speculate about the presence of the other item (\# 61) that has to do with opinion about one's own level of religiosity, by arguing that subjects may have been led somehow to think of their own level of religiosity in terms of their religious practices as a criterion for judging one's level of religiosity. The other two items (\# 1 and 7), which refer to belief in Allah and love for Muhammad, respectively, were deleted from the scale and eliminated from further analyses. They seemed hard to conceptually fit in the scale. Note, in addition, that they did not have impressive loading values on the component. The second one (\# 7) hardly made it on the component (.358). An appropriate and meaningful label for this scale is practice. In order to distinguish it from other identified practice dimensions, this scale, consisting of 15 items, was labeled "Positive Practices".

Nine pure items loaded on the second component, Factor 2, but the component was difficult to interpret. The nine did not collectively form a coherent dimension, or describe related content. Some items on the component (including the highest loading ones) could be interpreted as another set of practice descriptions, and this component could be another measure of practice, and it was actually considered as such. Some 
other items, however, did not seem to have a meaningfully clear link to the others, as practice manifests. For example, item (\# 3), which concerns the heavenly revealed books, clearly tap the belief dimension (belief in heavenly books). Another item (\# 21), which refers to marriage seems to express opinion rather than describe practice. Although the later can be explained in a practical term by considering the effect of marriage on one's practice, the former (\# 3) appears to be hard to conceptually fit in this component, and, therefore, was eliminated from the scale and from further analyses. This component, consisting eventually of eight items, was considered another dimension of practice and thus represents another scale of practice. As suggested by the content of the majority of items, this scale was labeled "Forbidden Practices". This label should distinguish this scale from the previously identified practice dimension "Positive Practices".

Like the second component, the third, Factor 3, also had nine items. All of these nine could be interpreted, again, as relating clearly to practice. However, unlike Factor 2 items, these items seem to share a certain feature, and that is expressing integrity or honesty. Hence, this component was interpreted as an integrity component, and, subsequently, labeled "Integrity".

The fourth component, Factor 4, was also uneasy to interpret. Four items loaded on this component, but each one described a somewhat different aspect. For example, although two dealt with the concept of imitation, they could only be remotely connected. One (\# 32) is about Muslims' imitation of non-Muslims, and the other (\# 33) is about men's imitation of women. A possible common thread that can be thought of to link these four items is that they tap one's views of, or one's consideration of or for, others. This component, subsequently, was interpreted as having to do with "Consideration for Others", and was given that label. A noticeable feature of this scale 
is that unlike the other RLS subscales (see reliability coefficients below), this one was weak in internal consistency; coefficient alpha was .34.

Only three pure items loaded on the fifth component, Factor 5 . All three have relatively considerable loading values on this component. Because there were only two items on the component that can be linked together (as having to do with place of prayer), this component would be judged to be of very limited value for the purposes of retaining good scales of reasonable length and, therefore, should be eliminated in further applications in this study. This is in addition to the difficulty faced in trying to label this component. However, a very important feature of this component is the fact that its items were all appropriate for males only. For this important attribute of this component it was retained and considered a male-only component, and labeled "Appropriate Male Conduct".

Percent of the total variance accounted for by the five components was 32.98 . Percent of the total variance accounted for by individual components was as follows: The first component accounted for $8.98 \%$, second component for $7.71 \%$, third component for $6.47 \%$, fourth component for 5.25 , and the fifth component accounted for $4.57 \%$.

The intercorrelations between the five factors (of RLS), before deletion of items, are shown in Table 4.

Table 4 about here

Coefficient Alphas for the RLS's five subscales, in their final forms without the deleted items, were .81 for Factor 1, .75 for Factor 2, .69 for Factor 3, .34 for Factor 4 , and .80 for Factor 5 . 
Results of PCA on RBS The same procedures and criteria used before were employed here with the "Religious Behavior Scale" (RBS). For this scale, the two rules, the MAP (Velicer, Fava, Zwick \& Harrop, 1988) and the PA approximation (Lautenschlager, 1989) agreed in suggesting the retention of only one component. The one component, as produced by the CAX program, consisted of 12 pure items out of the 68 that were included in the matrix. All of the 12 items loaded, at the .35 level or higher, negatively on this component. The percent of the total variance accounted for by this one component was 6.15 .

For the purpose of exploration, and hope for maximizing the utility of the scale, two additional solutions were requested: 3-factor, and 2-factor solutions, and the three were examined and compared. In each of the two requested solutions, the first component consisted of the same number of items (12) as the 1-factor solution component. Across the three solutions this first component had 10 recurring items, indicating high similarity of the component in all three cases. Most of the items on this component seemed, as suggested by their contents, to express ways of interacting with others. The second component had seven items in the 2-factor solution, and nine in the 3-factor solution. There were five common items. This component was interpreted as having to do with perception of control, and it was easier to interpret as such in the 2factor solution. Among the 7 items in the 2-factor solution, six can be thought of as expressions of perception of control. In the 3-factor solution, only five of the nine can be thought of as such. The third component in the 3-factor solution had six items, but they represented different aspects.

This examination and comparison of the three solutions led to selection of the 2-factor solution for analysis and further discussion. 
In terms of the first component (Factor 1), which consisted of 12 items, judging from the contents of the majority of items on this component, it seemed, as alluded to above, appropriate to interpret it as an interaction dimension. However, considering the contents of the two highest loading items, which also clearly relate to each other, such interpretation may not justify labeling the scale "Interaction" . It was, therefore, labeled "Secular Orientation" as the content of the two highest loading items suggest. Although the rest of the items do not clearly and directly refer to secular conduct, most of them can be accommodated under the label. The second component (Factor 2), which consisted of seven items, was interpreted, as mentioned above, and labeled as "Perception of Control". Although most of the items seem to deal more with external direction or control, the general label "Perception of Control" was chosen to refer to both external and internal forms of control. Note that the highest loading item on the component refers to internal control, or self-control.

The two factors, their items, and their loadings are presented in Table 5.

Table 5 about here

Percent of the total variance accounted for by the two components was 10.76. Percent of the total variance accounted for by individual components was $5.73 \%$ accounted for by the first component, and $5.02 \%$ by the second component.

There was a very low positive correlation $(r=.07)$ between the two factors of RBS.

For the RBS's two subscales in their final forms Coefficient Alphas were .69 for Factor 1, and .46 for Factor 2. 


\section{Correlational Analyses}

On the basis of the PCA results scales were constructed to represent interpretable constructs. The items included here were only the empirically pure, and conceptually appropriate, items. In other words, the subscales were derived from the selected PCA solutions in their final forms, after deletion of complex items that were loading on more than one component, and also after eliminating few other items that, although empirically loaded on their respective components, were conceptually judged to be inappropriate for the subscales. These eliminated items are still shown and marked in the tables presenting the factor items and their loadings.

Correlational analysis procedures were performed and examined to test Hypothesis 2 which predicted the emergence of separate subscales on the major scales used and also predicted correlations among the similar subscales, specifically those of belief and practice. A correlation procedure was performed on all of the resulting 13 subscales that were retained out of the three original scales. Table 6 presents the matrix of Pearson Product Moment correlations of these scales.

Table 6 about here

In general, the results of the correlational analyses showed some lack of consistency in the patterns of the correlations. Correlations were consistently positive, not conforming precisely to predictions. Some came out significant in the predicted directions, and some came out contrary to predictions.

It should be noted that in this matrix of intercorrelations (Table 6) within scale intercorrelations, i.e., correlations between subscales of the same major scale, showed 
some changes in their values here compared to their values in the smaller factor intercorrelation matrices (of the within scales intercorrelations). This can be seen through comparisons of some correlations in Table 6 with their corresponding ones in Table 2, or Table 4. Such comparisons will show that these changes are not consistent. That is, some are changing from significant to nonsignificant, and others are going the other way, changing from nonsignificant to significant. Some of these changes were very considerable changes, for example, from near-zero to highly significant correlations at the $\mathrm{P}<.01$ level (as an example, see and compare the correlations between Factors 1 and 2 of MRS in Table 2 and Table 6). Another feature of this matrix to be noted is that there was only one negative correlation in this whole matrix, and that was between Appropriate Male Conduct (Factor 5 of RLS) and the Perception of Control (Factor 2 of RBS). As can be seen in Table 6, this correlation was almost zero $(r=-.01)$, but it was noted because it was the only one in the negative direction. From this point on, all references to correlations in this matrix will, unless indicated otherwise, mean positive correlations, without necessarily stating so. Of the 78 correlations generated, 55 were statistically significant, all in the positive direction (see Table 6).

As shown in Table 6, the Practice subscale of MRS correlated significantly with three other MRS subscales: Societal Value of Religion (Factor 2), Personal Need for Religion (Factor 4), and the Reliance on Practical Guidance (Factor 5). It also correlated with five of the seven subscales of RLS and RBS: Positive Practices subscale (RLS Factor 1), Forbidden Practices subscale (RLS Factor 2), Integrity (RLS Factor 3), Consideration for Others (RLS Factor 4), and Secular Orientation (RBS Factor 1).

The Societal Value of Religion subscale (Factor 2) of MRS correlated significantly with 11 of the other 12 subscales, all at the $\underline{P}<.01$ level. The only one with which it did not correlate was the Positive Practices (RLS Factor 1) $(r=.09)$. 
The Belief in Central Tenets subscale (Factor 2) correlated significantly with only six of the other 12 subscales: Societal Value of Religion (MRS Factor 2), Personal Need for Religion (MRS Factor 4), Reliance on Practical Guidance (MRS Factor 5), Forbidden Practices (RLS Factor 2), Integrity (RLS Factor 3), and Perception of Control (RBS Factor 2)

Personal Need for Religion subscale (Factor 4 ) of the MRS correlated significantly with every one of the other 12 subscales (all at the $\underline{\mathbf{P}}<.01$ level). This is almost the same way it correlated before (Table 2) with all of MRS subscales. The exception was its insignificant correlation, within MRS (Table 2), with Belief in Central Tenets; $\mathrm{r}=.15$ (which is, nonetheless, approaching significance).

The Reliance on Practical Guidance (Factor 5) correlated significantly with nine of the other 12 subscales: All the other five MRS subscales, Positive Practices subscale (RLS Factor 1), Forbidden Practices subscale (RLS Factor 2), Integrity (RLS Factor 3), and Secular Orientation (RBS Factor 1).

The Unquestioning Acceptance (Factor 6) correlated significantly with five of the other 12 subscales: Societal Value of Religion (MRS Factor 2), Personal Need for Religion (MRS Factor 4), Reliance on Practical Guidance (MRS Factor 5), Integrity (RLS Factor 3), and Secular Orientation (RBS Factor 1).

Table 6 also shows correlations between subscales within each of the two major scales, RLS and RBS, and correlations between subscales of the tow scales.

\section{Differences in Religiosity}

The third hypothesis (Hypothesis 3 ) predicted that students of colleges of Islamic studies will be more religious than students of colleges of Arts and Humanities. The fourth hypothesis (Hypothesis 4) predicted that female students will be more 
religious than male students. To test the predictions of these two hypotheses, multivariate analysis of variance (MANOVA) procedures were conducted on the resulting 13 subscales. These procedures were performed with each set of the subscales separately. That is a MANOVA procedure was performed, first on the subscales of the Muslim Religiosity Scale (MRS), then on the subscales of the Religiosity Level Scale (RLS), and, finally, on the subscales of the Religious Behavior Scale (RBS).

MRS's Subscales. A MANOVA procedure was performed on the MRS's subscales, namely; Practice (Factor 1), Societal Value of Religion (Factor 2), Belief in Central Tenets (Factor 3), Personal Need for Religion (Factor 4), Reliance on Practical Guidance (Factor 5), and Unquestioning Acceptance (Factor 6), as dependent variables, with educational major (Islamic / Arts and Humanities) and sex (male / female) as the independent variables. The result of this procedure showed significant main effects for both the group and gender variables, but no significant interaction effect. There was a significant overall difference in religiosity between the two groups of majors, Wilk's Lambda $(\lambda)=.73, \underline{\mathrm{F}}(6,160)=10.02, \underline{\mathrm{p}}<.001$. There was also a significant overall difference in religiosity between the two sexes, Wilk's Lambda $(\lambda)=$ $.82, \mathrm{~F}(6,160)=5.98, \underline{p}<.001$.

The results of follow-up analysis of variance (ANOVA) tests on the individual subscales with the main effect of the group variable showed significant differences in level of religiosity between the two groups on four of the six subscales. The subscales that revealed differences were Practice (Factor 1), Societal Value of Religion (Factor 2), Personal Need for Religion (Factor 4), and Unquestioning Acceptance (Factor 6). Differences revealed by these four subscales were all in the predicted direction. That is, as predicted, group 1 subjects (students of Islamic Studies) were more religious on all 
four subscales than group 2 subjects (students of Arts and Humanities), (see Table 7 for means, standard deviations, and $\mathrm{F}$ values).

Table 7 about here

With respect to main effect of the gender variable, the follow-up ANOVA test showed a significant difference in level of religiosity between the two sexes on only one of the six subscales, Practice (Factor 1). Here, again, results supported the prediction made in this regard, showing females $(\underline{\mathrm{M}}=55.41, \underline{\mathrm{SD}}=5.62)$ to have a higher level of religiosity, as indicated by practice, than males $(\underline{M}=49.97, \underline{S D}=7.89), \underline{F}(1,165)=$ $31.24, \underline{p}<.001$.

RLS's Subscales. The same MANOVA routine was repeated involving the RLS's subscales, namely; Positive Practices (Factor 1), Forbidden Practices (Factor 2), Integrity (Factor 3), Consideration for Others (Factor 4) and Appropriate Male Conduct (Factor 5), as dependent variables, with educational major (Islamic / Arts and Humanities) and sex (male / female) as the independent variables. The result of this procedure showed significant main effects for both the group and gender variables, as well as a significant interaction effect. That is there was a significant overall difference in religiosity between the two groups, Wilk's Lambda $(\lambda)=.65, \underline{F}(5,161)=16.91, \underline{p}<$ .001 , there was a significant overall difference in religiosity between the two sexes, Wilk's Lambda $(\lambda)=.62, \underline{F}(5,161)=19.93, \underline{p}<.001$ and there was a significant difference in level of religiosity due to gender by group interaction, Wilk's Lambda $(\lambda)$ $=.90, \underline{\mathrm{F}}(5,161)=3.40 ., \underline{p}<.01$. 
ANOVA follow-up tests on individual subscales with the main effect of the group variable showed significant differences in level of religiosity between the two groups on all five subscales, the Positive Practices (Factor 1), Forbidden Practices (Factor 2), Integrity (Factor 3), Consideration for Others (Factor 4), and Appropriate Male Conduct (Factor 5). As was the case with four of MRS's subscales, differences revealed by these five RLS's subscales were all in the predicted direction. That is group 1 subjects were more religious on all these subscales than group 2 subjects (see Table 8 for means, standard deviations, and $\mathrm{F}$ values).

Table 8 about here

For the main effect of the gender variable, the follow-up ANOVA test showed significant differences in level of religiosity between the two sexes on three of the five subscales, Forbidden Practices (Factor 2), Consideration for Others (Factor 4), and Appropriate Male Conduct (Factor 5). Again, as predicted, females were shown to have a higher level of religiosity than males on two of the three. On the Appropriate Male Conduct subscale, however, males, not surprisingly, were more religious than females (see Table 9 for means, standard deviations, and $F$ values).

Table 9 about here

The follow-up ANOVA test for the interaction effect showed a significant difference in level of religiosity due to gender by group interaction on two of the five subscales, Forbidden Practices (Factor 2), $\mathrm{F}(1,165)=9.44, \underline{\mathrm{p}}<.01$, and Appropriate Male Conduct (Factor 5), $\underline{\mathrm{F}}(1,165)=5.25, \mathrm{p}<.05$. On the Forbidden Practices scale 
males and females were similar in their levels of religiosity in the Islamic Studies group, whereas in the Arts and Humanities group females were more religious than males (see Table 10 for means and standard deviations). On the Appropriate Male Conduct scale males and females were similar in their levels of religiosity in the Arts and Humanities group, whereas in the Islamic Studies group males were more religious than females (see Table 10 for means and standard deviations).

Table 10 about here

RBS's Subscales. For the RBS' subscales, Secular Orientation (Factor 1) and Perception of Control (factor 2), the MANOVA procedure resulted in a significant main effect for the group variable, but no significant effect for either the gender variable or the interaction of group by gender. There was a significant overall difference in religiosity between the two groups, Wilk's Lambda $(\lambda)=.89, \underline{F}(2,164)=$ $10.32, \mathrm{p}<.001$.

The ANOVA follow-up test showed this significant difference to be on only one of the two subscales, the Secular Orientation (Factor 1), showing that group 1 subjects $(\underline{M}=10.43, \underline{S D}=1.81)$ were more religious than group 2 subjects $(\underline{M}=8.93, \underline{S D}=$ 2.23), $\underline{\mathrm{F}}(1,165)=18.47, \mathrm{p}<.001$. 


\section{Discussion}

The pattern of results has lent substantial, though not complete, support for the hypotheses stated in this study. The majority of findings were consistent with the predictions that were made, predictions which were derived mainly from the findings of previous research. It was hypothesized (Hypothesis 1) that the Islamic religion is multidimensional, and a prediction was made that at least three separate dimensions will be found. Another hypothesis (Hypothesis 2) was that conceptually similar measures of religiosity will be related, predicting the emergence of at least two dimensions of practice and belief on each of the used scales, and that each of the two dimensions in any of the three scales will relate to its counterparts in the other scales. It was also predicted that students majoring in Islamic studies will be more religious than those majoring in Arts and humanities (Hypothesis 3), and that females will be more religious than males (Hypothesis 4). All these predictions were supported, although some only partially, by the current results.

There was only one instance where higher level of religiosity was shown on the males' side than on the females', and that was revealed by the subscale that consisted of items appropriate for males only. As discussed later, the direction of the difference in this case does not really represent contradiction to the present hypothesis prediction. With respect to interaction effects, no a priori predictions were made. The results revealed only two instances where there were interaction effects of group and gender (i.e., interaction of field of study by sex of participants). In addition to the generally strong support, for Hypotheses 3 and 4, provided by the results of the main effects of the group and gender variables, the pattern of results in the two instances of significant interaction effects implies also, as discussed later, some support for the stated predictions of these two hypotheses. 
The initial hypothesis (Hypothesis 1) of multidimensionality of the religiosity concept in the Islamic belief system was generally supported. There was, however, some lack of firmness in this support with regard to defining such dimensions, and also with regard to predicted relations of religiosity measures (Hypothesis 2).

\section{Principal Components Analyses}

There was lots of noise in the results of the Principal Components Analysis (PCA), and it is, as discussed below, believed to be due to problems in the measurement tools employed, and probably in the design of the study itself.

An obvious problem was the unstability of the results as demonstrated by the apparent lack of coherence between items. There was also considerable switching of items between different components in different solutions. This led to the somewhat difficult and unpleasant task of having to compare and choose between different solutions, none of which was completely satisfactory, and deciding on what components were worth retaining and which were not. It could be said in this context that the unstability of the PCA results and the subsequent heavier reliance on the researcher's conceptual judgment than on the empirical results give merit to the statement by Jolliffe (1986) that "It is remarkable how often it seems to be possible to interpret the first few PCs, though it is probable that some interpretations owe a lot to the analyst's ingenuity and imagination" (P. 51). This tedious task, nonetheless, had to be performed.

In the literature it is constantly suggested that in factor analysis the decision regarding what solution to adopt and how many components to retain depends, in the end, on the interpretability and usefulness of the solution, based on the judgment of the researcher and his or her knowledge of, and familiarity with, the domain of interest. It 
has been stated that "the final test of the analysis [PCA and FA] is usually its interpretability" (Tabachnick \& Fidell, 1989, P. 598). Tabachnick and Fidell (1989) continue to say:

One of the problems with PCA and FA is that there is no criterion beyond interpretability against which to test the solution...

A second problem with FA or PCA is that, after extraction, there are an infinite number of solutions available ... . The final choice among alternatives depends on the researcher's assessment of its interpretability and scientific utility. In the presence of an infinite number of mathematically identical solutions, researchers are bound to differ regarding which is best. (PP. 598-599).

Kim and Mueller (1978b) state that "the final judgment has to rest on the reasonableness of the solution on the basis of current standards of scholarship in one's own field. This criterion is elusive but, fortunately or unfortunately, all of us must live with it in order to communicate our findings to our fellow scientists" (P. 45). So it is the interpretability and scientific utility of the analysis and not only the statistical results, on which to base the decision regarding which solution to adopt, and number of components to keep.

Although anticipated main dimensions in the Muslim Religiosity Scale (MRS) were found, there was not one completely satisfactory solution for any of the scales. Speaking of the MRS, the main focus of the study, six different solutions were examined and compared to see which one could provide a reasonably sound structure pattern that can aid in easing the interpretation of the results and identifying components that corresponded to the proposed and anticipated dimensions of religiosity, as well as others not a priori specified. The 6-factor solution was chosen as an appropriate and useful solution, a decision that was encouraged by the results of the 
MAP rule, a rule that was described as a procedure "which provides accurate guidance on the number of components to retain" (Velicer \& Jackson, 1990, P. 22), and which, in this case, retained six components. This decision was also guided by Kim and Mueller's (1978b) argument concerning criteria of interpretability.

The 6-factor solution was selected not as the best that can be, but as the best that was available. However, it was not good enough for the satisfaction of the predictions put forth in the study. Even though this was intended to be an exploratory study, not looking for definite patterns, some degree of stability was expected. In light of the anticipation based on the theoretical ground of this study, it can be said that within this solution some components were chaotic, representing different dimensions, in a hard to explain fashion. Choosing this solution, apparently, did not solve the problem of the appropriateness of all the resulting components. This solution, though judged to be the most appropriate of all solutions examined, did not provide a clear cut pattern. For example, the last three components posed a problem in interpretation, especially the fifth and sixth components (see Table 1, and Results section). For instance, although having some high loading items and fair internal consistency as indicated by its alpha coefficient of .70 , the fifth component (Factor 5) was nothing more than a collection of items that did not seem to conceptually belong together, and which loaded on different components in different solutions. It would have been probably in the best interest of obtaining a more coherent scale not to keep this component. However, it seemed unwise to discard of a component of such magnitude in internal consistency and relatively good loading items. So this component was retained basically on the basis of its empirical features. But on the theoretical, or the conceptual, base it was hard to interpret or come up with an appropriate and unifying label for. This led to choosing the tentative and very general label "Reliance on Practical Guidance". Also, the persistence of Factor 6 items to show up on the same, 
and the only, factor time and time again in different solutions, with generally high loadings, gives the first impression that this is a solid component that can be easily defined and interpreted. Unfortunately, however, this was not quite the case. The items seemed to represent different content domains, such as attitudes, belief, and importance of religion. The factor could not be easily explained. So, although this factor was statistically well defined, as shown in the PCA results, practically and conceptually it was hard to interpret. However, based on the consistency and high loadings of these items on this same component, it was judged that it might be a waste of valuable information to discard this factor. It was, therefore, retained, and tentatively given a general label "Unquestioning Acceptance". Again, despite the fact that it was very poorly defined, from conceptual perspective, and despite the apparent looseness in the label it is given, this component was kept on the merit of its empirical firmness, a characteristic that almost all the other components were lacking. Note, however, that despite its firmness in the PCA solutions, it was the weakest of the six components in terms of internal consistency. Its coefficient alpha was .57. These are examples of the confusing results.

A point of concern, pertaining to the fact that some factors were empirically strong but conceptually uninterpretabel, is the issue of method variance. As mentioned before, there were two 5-point response formats used in the questionnaire: an agreement or disagreement response format, and a frequency response format. This could constitute a potential source of method variance.

The items as represented by the questionnaire statements were believed to be good representatives of the domain of interest. However, their dispersion in the PCA results raised serious doubt about this belief. This dispersion should be expected since this was intended to be an exploratory study, in which some unspecified, and actually unknown, dimensions of religiosity were anticipated. This explanation, nonetheless, 
may not be as applicable to some statements that were believed to be representing specific dimensions such as belief and practice. Despite the fact that these two dimensions were identified, there were many items that were thought to belong under these two dimensions, but they went elsewhere or nowhere. Note also that a dimension of attitudes was thought to be among the best indicators of religiosity, besides belief and practice, from the Islamic perspective, and was anticipated to appear in the results. However, no clear component representing this dimension was identified.

One explanation, regarding dispersion of items, especially with regard to the belief dimension, is that such dimension is hard to measure in a Muslim society, simply because it should apply to every Muslim, since every Muslim is supposed to possess the basic beliefs, before he or she can even be considered a Muslim. So such an undiscriminating factor may be hard to use as an indicator of religiosity because it is present in everyone. It should be noted that although a belief component was found, the three items (\# 4, 21, and 45, see Appendix C) that were eliminated in the PCA procedures from MRS for lack of variance (as explained earlier in the Results section) were all belief items regarding the existence of God, the existence of Angels, and the authenticity of Mohammad's prophethood. Each of these three items had zero variance, meaning that respondents did not differ on these items, they all gave the same answer to each of these three, and that was a high endorsement, a score of 5 . Therefore, it is suspected that with little variance between subjects' responses in most of the remaining 85 items that were subjected to PCA procedures there may not have been enough prerequisites for PCA procedures to work on. Remember that the differences in religiosity between groups and between sexes were found on the resulting subscales with limited number of items, after the elimination of many (unique and complex) items, most, may be all, of which might have been lacking enough variance. Comrey (1973) emphasizes the need for variance, especially in exploratory work, as he put it, "for 
exploratory work, it is much more important to ensure that there is plenty of variance on the factor in the sample than it is to have a representative sample from the population at large" (P. 202). Another possible explanation of the dispersion of items that were thought of as measures of belief is that there might be different kinds of belief and thus not all beliefs are highly correlated with each other. If so, then the expectation of finding a single belief dimension may be naive (see the discussion of potential problems in measuring Islamic religiosity, later).

Another related problem, related in the sense that it is contributing to lack of variance, is the nature of participants in terms of religiosity. Although the resulting subscales showed the two groups to be different in level of religiosity, the lack of variance in religiosity between groups on the whole 88-item original scale may account for the chaos in the PCA results as displayed in the loss of the large number of items and the unstability of the resulting factors. Such lack of variance may have been due to the fact that these two particular sample groups may not have been as distinct on many aspects of religiosity as has been expected. Note that the Percentage of the total variance accounted for by the resulting components, in all scales, was relatively low. On the MRS, for example, which was the highest, the percent of the total variance was only $39.6 \%$ as accounted for by the six components.

In addition to the nature or characteristics of participants in terms of religiosity, another good source of suspicion is the sample size. The size of the sample, in addition to the nature of the sample, may have been an active contributor to the pattern of the PCA results. One of the major issues of concern with regard to conducting PCA is the ratio of sample size to the number of items in a scale. The general rule is that the larger the sample size is and the smaller the number of items is, the sounder will be the PCA results. Most of the experts set the ratio of five subjects for each one item as a minimum for a good PCA design (e.g., Comrey, 1973, 1988; Tabachnick \& Fidell, 
1989). In the present case, however, the ratio happened to be less than the recommended minimum. This does not necessarily imply that a study cannot be conducted with such sample size. When experts set the minimum limit of sample-toitem ratio, they never considered a sample of a lower size to be unacceptable or worthless. As a matter of fact, the research literature has many examples of studies with much lower size ratios (e.g., Jolliffe, 1986). "In any case, a description of the sample, rather than inference about the underlying population, is often what is required, and the PCs describe the major directions of variation within a sample, regardless of the sample size" (Jolliffe, 1986, P. 54). Similar to this argument by Jolliffe, is that by Comery, cited above (Comery, 1973, p. 202).

Although a major goal of PCA is parsimony through replacing many items with a much smaller number of components, it is usually expected, or at least hoped, that such reduction would not result in loss of much useful information. It is felt that in the present study very useful information has been lost through the loss of many items. Hence, it can be argued that the goal of reducing "a large number of variables to a smaller number of factors to concisely describe (and perhaps understand) the relationships among observed variables, or test theory about underlying processes" (Tabachnick \& Fidell, 1989, P. 600), was not well served by the results of the PCA in the current study. The set of the observed variables was trimmed to such an extent that could be rendered a loss of valuable variables. In addition, the resulting factors, which can be accepted as reasonable in terms of their number (in the solutions suggested and/or selected), were not all stable enough to warrant their unquestionable utility. Using the findings of this study in future replication research, with possibly some additional new items and some refinement should produce better results and confirmation of the findings, giving a clearer picture for easier and more accurate and 
meaningful interpretations, based, hopefully, on collaboration between empirical findings and theoretical bases.

Needless to say that these sources of problems in the MRS results apply also to the other two scales, RLS and RBS, in addition to the strong possibility that these two scales had their own problems, especially their relative lack of psychometric properties, as related to such shortcomings as response format, item contents and their wording and their relatedness to the domain being measured (for description and more detailed discussion and critique of the two scales, see the section on Measuring Islamic Religiosity, the section on Measures, and some discussion below).

As expressed elsewhere (see Measuring Islamic Religiosity section), it was expected that there would be at least two dimensions of religiosity, belief and practice, in Alsanie's (1989) scale. It was also argued that combining the two dimensions in one general scale, by Alsanie, was not justifiable. The results, however, shed some doubt on this argument, since no belief component was found. Note, though, that it was argued that there were indications that what Alsanie considered as a criterion of religiosity is behavior or practice, and a practice component, actually more than one practice component, was identified. So, in light of the current findings, Alsanie's scale may be considered a measure of religious behavior, or practice, as he claimed it was. Remember his postulate that only God knows the truthfulness of a person's belief, and what we can know is the manifestation of this belief in the person's sayings and actions. It should be cautioned, however, that the PCA results revealed five dimensions of religiosity on Alsanie's scale. Although these five could still be considered as dimensions of practice, they pose a problem for the original scale by reducing its internal consistency and casting some doubt about its meaning as a single measure of a univariate construct. This conclusion, or argument, has to be considered with extreme caution, considering the unstability of the current results. Certainly, further more 
extensive research is warranted to clarify this issue. It seems fair at this point to say that it is difficult to make a final judgment about the RLS in its original entirety based on the very short version which resulted in this study.

Alsanie's scale was criticized also on the basis of its response format. Alsanie used a 3-point scale response format (the response format issue is discussed more fully later in this section).

When PCA was done on Taai's RBS, it showed a complete lack of dimensionality. There was only one component suggested for retention by both the MAP and PA rules. There are different ways to speculate about RBS's lack of dimensionality.

One problem can be easily spotted by merely comparing the scale's title with the item contents. Taai called the scale "Religious Behavior Scale". There were, however, only few items that can be considered as measures of behavior. Most of the items, by the way they were stated, actually measure knowledge and opinions, not behavior. A look at the items (Appendix E) should prove this claim (actually, Taai himself admits that the items' wording is closer to expressing religious attitudes, considering behavior to be a more comprehensive concept and an umbrella for other aspects). In addition, such items, sometimes, do not seem to even have apparent relevance, whatsoever, to whether a person is religious or not, or even a believer or a complete atheist, consider, e.g., the following: "I feel uncomfortable when I visit a sick person in a hospital", "Eating a lot lengthens life", "Those who control themselves at the moment of anger are the most capable of facing hardship situations", and the like. It is true that such statements may express some Islamic religious values, but they could also be responded to by a nonbeliever the same way as by a believer.

Another potential problem concerns the way Taai's statements represented the domain of interest. He generated 77 items in such a way that each item (only one item) 
represents one of the 77 of what he called elements of faith as they were defined in the sources and literature of Islamic teachings, giving thereby the same weight and same degree of importance to all of these elements. He, then, went further and divided these items into subscales, many of which consisted of items that did not carry the same importance or significance from an Islamic point of view. In normal circumstances, i.e., assuming that other things are psychometrically acceptable, this lack of harmony or homogeneity in the scale items would result in lack of interpretable factors in a factor analytic method. Another possibility would be to end up with as many factors as items. In this case there was a severe lack of factors. Additionally, one particular reason for the anticipated lack of confirmation of Taai's division of subscales, or categorization of items under subscales, was the arbitrary way he did the division. As discussed previously, he grouped issues that do not belong together in certain subscales (see Measuring Islamic Religiosity section for more thorough discussion and examples). This may explain, at least in part, the lack of dimensionality of the scale in the PCA results.

It is very likely that a major problem that could account for this lack of dimensionality in Taai's RBS is that of response choice format. Taai used dichotomous format, and such format has been shown to cause problems, as discussed next.

As alluded to in different places of the present paper, one of the potential problems with Alsanie's (1989) Religiosity Level Scale and Taai's (1985) Religious Behavior Scale is the response format. The issue of number of choices in response format has been investigated, and the apparent advantages of the multiple-response format for scale construction were demonstrated (e.g., Velicer, DiClemente, \& Corriveau, 1984; Velicer, Govia, Cherico, \& Corriveau, 1985; Velicer \& Stevenson, 1978). It has been argued that "the methodological impact of increasing the itemresponse format is significant" (Velicer, et al., 1985, P. 80). Velicer and Stevenson 
(1978) suggest that a multi-category approach will "permit the subject to make finer distinctions and, therefore, will provide more precise and meaningful responses. This should result in (1) increased item and scale reliability, (2) more favorable subject reactions to the inventory, and (3) a clearer and more accurate indication of the test structure" (P. 293). Further explanations were offered by Velicer et al. (1985). The findings of many studies provide support for the suggested advantages of multiplechoice format over the two-choice format. Velicer and Stevenson (1978) referred to an earlier study "which found an increase in reliability as the number of categories increased from two to five and no change for further increases in the number of categories" (P. 294). Velicer and Stevenson's (1978) own findings indicated that "a more precise definition of scales and a greater explained portion of the total variance follow from use of the expanded format" (P. 302). Other benefits include more accounted for total variance, increased external validity, enhanced factorial validity (studies cited in Velicer, et al., 1984), better defined and better replicated patterns, more stable factor structure across samples, and an increase in the overall reliability of individual items (Velicer et al., 1985) Other earlier and later experts paid great attention to the disadvantages of using two-choice responses, or what is termed dichotomous responses (e.g., Comrey, 1973, 1988; DeVellis, 1991).

In light of these findings and arguments concerning the potential advantages of multi-category responses, Alsanie's 3-point response format is still a limited form. This problem is even more acute with Taai's dichotomous response scale. It is believed that the main problem with this scale is its response format, which may very likely account for the absence of components in the scale. Comrey (1973) provides a somewhat lengthy discussion regarding correlation coefficients for dichotomous data and how little is the information they provide and how poor is the prediction they give of other variables, and how disturbing their effect is on the analyses, and Comrey (1973) offers 
the advice that "the investigator should try to avoid dichotomous data variables wherever possible" (P. 209). Comrey (1988) reiterates his argument by stating that "some scale writers persist in using the two-choice format although it is unreliable and creates many serious statistical difficulties when the data are analyzed" (P. 758). Put slightly differently, "a major shortcoming of binary responses is that each item can have only minimal variability. Similarly, any pair of items can have only one of two levels of covariance: agreement or disagreement" (Devellis, 1991, P. 73).

Discussion of problems with these two scales should call attention to the need for improving existing measures of Islamic religiosity, or perhaps constructing new ones with sounder theoretical bases and finer psychometric properties. Another question such discussion might raise concerns validity, especially construct validity, not only of the two scales themselves, but also that of the newly developed ones, such as the MRS. When a new scale is examined against other scales of questionable validity, the new scale's validity will also be questionable.

\section{Correlational Analyses}

Hypothesis 2 stated that alternative measures of religiosity will be related on the basis of similarity of the conceptions these scales represent, predicting specifically that belief and practice subscales will emerge on the newly developed Muslim Religiosity Scale (MRS), and will correlate highly with some similar subscales that will emerge on the other scales used, namely; Religiosity Level Scale (RLS) and Religious Behavior Scale (RBS). As mentioned before (see Measures section), some items in the MRS were taken, or their ideas were adopted, from other scales, including the RLS and RBS. Because all three scales were intended to measure religiosity among Muslims, there was item overlap between the three. The prediction of correlations between the resulting subscales was based on the presence of such overlap. This overlap was greater 
between the three original versions of the scales (see Appendices C, D, and E), but in the resulting subscales there were much fewer items that were overlapping (see Tables 1,3 , and 5). The overlap was mostly in the supposedly underlying constructs. Few items, however, were very similar in their wordings.

As the results of the correlational analyses show (see Table 6), the present data provided only partial support for the hypothesized relationships between the resulting religiosity subscales. There were conflicts in the correlational results. A few of these correlations provided support, but many did not. This conflict, however, should not be surprising in light of the chaotic results of the PCA. The prediction that was made implied that the PCA will result in distinct components in each of the scales, that similar dimensions will be found in the three scales, and that components representing those similar dimensions will correlate with each other. Since the results of the PCA in this regard did not come out as solid as was hoped for, it is not surprising to see correlations between the resulting subscales going in the same direction.

A comparison between the correlation coefficient values of the same pairs of subscales in any of the factor intercorrelation matrices, the within scales intercorrelations, obtained through the PCA procedures (Table 2, and Table 4) and in the matrix of the overall intercorrelations of all subscales (Table 6) shows changes, some of which are considerable, in coefficient values of some correlations in the two cases (i.e., Table 6 and the other two tables: 2 and 4). There was no significant change in the RBS factor correlation, from .07 before to .10 in Table 6 .

The changes in the correlation patterns between the within scales factor intercorrelation matrices and the overall intercorrelations matrix are understandable. The within scale factor intercorrelations included all items that empirically loaded on the components in addition to the complex items that were present on more than one component, and each item was weighted by its loading. In the later case, the overall 
intercorrelations, some items were excluded that were included before (items that were complex and those which were judged to be conceptually inappropriate to include), and items were unit-weighted in calculating scale scores. This considerable change in the entries can explain the changes in the correlation patterns. However, the magnitude of some of these changes was rather surprising and somewhat difficult to understand.

With regard to within scales correlations, that is, factor intercorrelation within each general scale, the intercorrelations between the first scale (MRS) factors (see Table 2) provided initial evidence of independence among the first three identified components, suggesting that these subscales are measuring different aspects of religiosity. The RBS's two subscales were also independent of each other. This is a result to be expected after an orthogonal rotation, since such rotation is intended to separate components. Note, however, that even after the orthogonal rotation there was relatively lack of independence of factors in the RLS.

In the final analysis, however, what is of more concern for the purpose of testing the proposed relationships is the correlations in the second case, the overall intercorrelations, because those represent the scales in their final forms.

For the Practice subscales, the results provided conflicting evidence in terms of supporting the predicted emergence of this dimension and relationships between these subscales. As predicted, there emerged practice components in two of the scales; MRS and RLS. With regard to relationships between these practice subscales, on one hand, the Practice scale in the MRS correlated significantly with the Practice scales in the RLS, which can be taken as evidence of support. On the other hand, however, this scale correlated significantly also with other scales that were not identified as practice scales, such as the Societal Value of Religion, Personal Need for Religion, Integrity, Consideration for Others, and Secular Orientation scales. One may be able to explain the correlations of Practice with some of these scales, such as with Integrity, 
Consideration for Others, and with Secular Orientation scales. A possible explanation of these correlations is that although these three scales were labeled as Integrity, Consideration for Others, and Secular Orientation, they still represent some form of practice, and hence, their correlations with the practice scale. Looked at in this way, such correlations would be taken to indicate validity of the Practice scale. But there is still the conflicting correlations with the other scales whose item contents do not describe practice, such as Societal Value of Religion and Personal Need for Religion. This pattern of relation somewhat contradicts the predictions made in this regard, and the link between these scales is hard to explain. Could it be the subjects' perception of the item contents as suggesting practical sense of religiosity? Or could it be the Muslim subjects' perception and understanding of Islamic religiosity that led them to respond to all, or most, of the items in such a way that these components correlate with each other in this manner? The second question may suggest a plausible explanation. Remember that, as alluded to elsewhere in this paper, the concept of religiosity in the Islamic religious belief system consists of two concomitant and inseparable parts: belief and practice, or action, and that one's level of religiosity is considered in terms of one's belief as manifested in his or her actions. In light of this speculation about Muslim subjects' perception of item contents, this point deserves more attention and further examination.

With respect to the Belief scale, because there was only one component that was identified in all three scales as a belief scale, it is hard to make definite interpretations with regard to its significant correlations with other scales. It should be noted, however, that this scale was clearly defined by the PCA results, and, as can be seen in Table 6, had near zero correlations with two of the three defined Practice scales, and with the Consideration for Others, Appropriate Male Conduct, and Secular Orientation scales, which can be considered, as mentioned above, as describing forms 
of practice. So this scale, of Belief, had demonstrated its almost complete independence from the Practice scales (It had a significant, although weak, positive correlation with Forbidden Practices of RLS). This scale had significant positive correlations with the scales of Societal Value of Religion, Personal Need for Religion, Integrity, and Perception of Control. Although the independence of belief from these dimensions was hoped for and would have been appreciated had it been shown, these correlations can still be explained. A plausible explanation is that these concepts of belief, value, perception of control, and also integrity are seemingly difficult to separate. There is no question that one's values and perception of control, especially in the contexts concerned with here, are contingent on one's belief. It is argued, elsewhere in this paper, that a religious person will be hard pressed to offer an opinion or express an attitude towards something about which he or she is not sure what the religious view is. In other words, before a person, especially a religious person, expresses his or her value, or perception, of something, his or her reply will certainly be determined by his or her belief. Integrity can also apply to one's belief as well as practice. The same thing, with integrity, can be said about personal need for religion, which correlated with every other scale. In conclusion, the identified belief component can be considered a good measure of belief.

The pattern of the Societal Value of Religion subscale's correlations is one of the most, if not the most, perplexing and confusing patterns. Not only did this factor correlate significantly, in the positive direction, with both Belief and Practice factors (in MRS), which did not correlate with each other, but also had contradicting correlations with Practice factors that were positively correlating highly among themselves. Consider, for example, the Societal Value of Religion high positive correlations with the Practice scale (Factor 1$)$ of MRS $(r=.35, \underline{p}<.01)$, and with the Forbidden Practices scale (Factor 2$)$ of RLS $(r=.49, p<.01)$, and its very low positive 
correlation with the Positive Practices (Factor 1) of RLS $(r=.09)$, despite the fact that these three Practice scales correlated positively high with each other $(r=.66, .66$, and $.46 \mathrm{p}<.01$, see Table 6). The Positive Practices scale (Factor 1) of RLS was the only one, among all 12 subscales, with which the Societal Value of Religion scale did not correlate. The Societal Value of Religion component was also the one whose correlation coefficient value with practice (Factor 1 of MRS) exhibited a dramatic change from a very low correlation $(r=.06)$ in the within MRS factor intercorrelations (Table 2) to a high positive significant correlation $(r=.35, p<.01)$ in the overall intercorrelations (Table 6). Presently there is no plausible explanation for this factor's correlation pattern. Although the Belief scale, as mentioned above, also had a tendency to exhibit a similar pattern by having significant, although weak, positive correlation with Forbidden Practices scale (Factor 2$)$ of RLS $(r=.18, \mathrm{p}<.05)$, and very low nonsignificant correlations with the other two practice scales: Factor 1 of MRS ( $\mathrm{r}=$ $.08)$ and Factor 1 of RLS $(r=.09)$, the problem with the scale of Societal Value of Religion is much more acute.

The sixth component of MRS was, as mentioned previously, actually difficult to interpret. It did not contain items that represented a clearly identified single dimension. It was tentatively labeled Unquestioning Acceptance. Generally, this component had a very interesting feature. It has shown some uniqueness, relative to other scales. It was consistent in the PCA results, and was the second (beside Perception of Control, Factor 2, of RBS) most independent of the 13 scales, as exhibited by its significant positive correlations with the second fewest number (five) of scales. As mentioned earlier, this factor appeared with the same items, with relatively high loadings, in every PCA solution. As can be seen in Table 6, in the correlational analysis it also exhibited its independence of the belief and all practice, and conceptually practice related components. But this component also had significant positive 
correlations with Societal Value of Religion (Factor 2), Personal Need for Religion (Factor 4), Reliance on Practical Guidance (Factor 5) of MRS, and Integrity (Factor 3) of RLS. It is interesting to note that the Unquestioning Acceptance scale significantly correlated with these scales which were significantly correlating with Belief, however, it had a near-zero correlation with Belief $(r=.04)$. This is another indication of conflict in the correlational results that was difficult to explain.

The scale of Personal Need for Religion (Factor 4) of MRS had a significant positive correlation, at the $p<.01$ level, with every one of the other 12 scales. With sound findings that show firm results of PCA and correlational analyses, this pattern of correlation for a scale that expresses need for religion would not have been particularly surprising, and may even be welcomed as showing that need for religion is related to all aspects of religiosity, and thereby providing some evidence of validity for the religiosity scales with which it is positively correlated. Alas, this may not so confidently be said here with these conflicting and confusing results. The same line of argument could also be followed in talking about the Societal Value of Religion scale which had a significant positive correlation, at the $\mathrm{p}<.01$ level, with every other one, except the Positive Practices (Factor 1) of RLS.

This discussion here is intentionally focused on the MRS as the main subject matter of the study, and the one of most concern as a newly developed measure. Moreover, most of what is said about the MRS can generally be repeated in talking about the two other scales; RLS and RBS, especially RLS. For this reason, further discussions of these two, with regard to correlational analyses, are kept to a minimum. Some points that may be noted about the two are provided next.

Despite problems with the RBS, its two subscales were uncorrelated, indicating their independence of each other in both within and overall intercorrelations $(r=.07$, and .04; respectively). The second one, Perception of Control, had significant positive 
correlations with only four subscales, three of which were of the MRS, and did not correlate significantly with any of the remaining eight. Note, however, that in addition to the major problem of dichotomous response format, the 2-factor solution that was selected for this scale was requested from, or we can say forced on, the PCA procedure. Remember that the two rules for retaining components, MAP and PA, that were employed in this study, agreed in suggesting the retention of only one component. That is in addition to the relative weakness of this scale (Perception of Control) in terms of internal consistency (alpha $=.46$ ). It is, therefore, not very clear what to make of the correlational results of these two scales.

In the RLS, the subscale that was labeled Appropriate Male Conduct (Factor 5) had a unique pattern of correlation among the RLS's subscales, as it did in terms of consistency of PCA results by having the same highly loading items in every solution. It also had a relatively good internal consistency, its alpha coefficient was .80 . In the within RLS factor intercorrelations (shown in Table 4), this subscale did not correlate with any of the others within the RLS general scale. This pattern of correlations, however, changed considerably in the overall intercorrelation matrix. As can be seen in Table 6, this scale correlated significantly in the positive direction with every one of the RLS's subscales. It also correlated significantly with the two practice scales of RLS, but not with the practice scale of MRS. So even though it exhibited firmness and consistency in the PCA results, this component was confusing in its correlational results. Remember that this component was given the very general label "Appropriate Male Conduct" because its three items did not represent a purely one coherent dimension more than its being for males only. Another point of serious concern, which deserves noting, with respect to this subscale is that although the item contents were appropriate only for males, females' scores were also involved in the analysis of this component. 
As can be seen in Table 6, All five of the RLS's subscales correlated

significantly in the positive direction with each other within the RLS. Could this pattern of correlation be an indication that all five subscales are generally describing forms of practice. This may be a plausible explanation.

A very general conclusion that can be made here is that the MRS can be considered the best of the three, with respect to dimensionality of the Islamic religion. Its identified components were uncorrelated after the orthogonal rotation. Two clearly defined scales of practice and belief were identified and they showed independence of each other, and also correlated positively with similar ones on the other scales. This does not necessarily warrant unconditioned acceptance of the scale as a reliable and valid measure of religiosity before further research can be done on it. Keep in mind the previously mentioned item overlap between the three scales. Although the amount of such overlap was limited in the resulting subscales, it is possible that the construct validity evidence derived from the correlations between these subscales is weak. Otherwise, extreme caution has to be observed in using the scale as it is now, and in interpreting its findings.

A question that remains to be answered, with respect to the MRS, is regarding whether to keep these scales as measures of the supposedly different dimensions for which these scales are labeled even though these measures are highly positively correlated, or keep some of them and discard others, and if so, which ones to keep and which to discard, or whether to combine all or some of them and use them as a one composite scale. In light of the generally unstable results, it is difficult to give more weight to any of these alternatives. It is strongly felt, by the author, that further research with a better designed study needs to be done on these scales before a definite decision can be made in this regard. In future research more items based on hypotheses 
about the constructs measured by these MRS subscales should be written and a new sample be used to test such hypotheses and see if the factor structure can be replicated.

A tentative suggestion, however, would be that scales whose contents can be thought of as different, for instance Practice and Personal Need for Religion, may be used as separate scales, and others may be combined. Results of such an application should be interpreted with extreme care and caution.

\section{Differences in Religiosity}

The results provided substantial support for the hypothesized differences in level of religiosity between students of Islamic studies and students of Arts and Humanities. Only partial support was provided for the hypothesized differences between males and females.

Differences between groups were shown on more scales than were differences between sexes. Among the 13 scales used (these are the resulting subscales of the original three scales), ten showed differences between group 1 (students of Islamic studies) and group 2 (students of Arts and Humanities), with group 1, as indicated earlier, being more religious, as predicted, than group 2 on all ten scales. With respect to gender, differences in religiosity were found on four of the 13 scales, showing females to be more religious than males on three of these four. Only two of the 13 subscales revealed differences in religiosity due to interaction of field of study and gender.

There were no differences between students of Islamic studies and students of Arts and Humanities, or between males and females on the dimension of religious belief, as measured by the only one clearly and easily identified belief subscale. This subscale is the "Belief in Central Tenets" component, or Factor 3, of the MRS (see 
Table 1). This result, concerning belief, comes as no surprise at all, in light of the argument offered earlier in this (Discussion) section, concerning the expected presence of religious belief in every Muslim.

Beside lack of differences in belief, there were no differences between males and females on four of the other subscales of the MRS. In other words, males and females differed in their level of religiosity on only one (the practice) of the six MRS subscales. The two sexes did not differ in their beliefs, in their views of the issues of value of religion for society, need for religion, reliance on practical guidance, or the issue of unquestioning acceptance. They also did not differ on the subscales of Positive Practices and Integrity of the RLS. This may be explained by the possible strong links between these issues and the issue of belief on which participants did not differ.

Groups, however, did differ with respect to societal value of religion, personal need for religion, unquestioning acceptance, integrity, and consideration for others. Students of Islamic studies showed more adherence to Islamic religious views than did students of Arts and Humanities. Group differences on these dimensions may be explained in the same ways discussed below with respect to differences in practices.

There were differences between groups with respect to religious practice, on all three subscales that were labeled "Practice" on both scales: the MRS, and RLS (see Table 1, and Table 3). Sexes, on the other hand, with respect to practice, differed on two of the three practice subscales. The RBS's Factor 1, which was labeled "Secular Orientation", and which can also be considered a form of practice, also revealed a difference between the two groups, but not between the sexes. This was the only statistically significant difference on the RBS two subscales. There were no differences between sexes, or differences due to interaction effect on these RBS's two subscales.

It may be worth noting here that although the support these results provide for the hypothesized differences in religiosity is not complete, it can be considered 
substantial enough to suggest a reasonably good degree of consistency of the results with the underlying hypotheses, which in turn suggests some value of the newly developed subscales

What makes the practice dimension a discriminating factor in level of religiosity is a point deserving attention and discussion. No particular or definite explanation can be offered, in this study, at this point. But, it could be noted that with respect to gender, consistent with the literature on differences in religiosity between males and females, it was found that where males and females differed in their religiosity, it was the females who tended to have higher level of religiosity. As mentioned earlier, there was only one instance in the current study where higher level of religiosity was shown on the males' side than on the females'. It was also noted earlier that the direction of the difference in this case does not really represent contradiction to the present hypothesis prediction. This direction of difference was revealed by the subscale that consisted of items appropriate for males only (Factor 5 of RLS), and this should come as no surprise at all. In fact, it would have been perplexing surprise if the results of this subscale came the other way around, that is, showing higher religiosity for females than for males. This results can be interpreted as showing that males and females are merely different with respect to the content of this subscale, but does not mean males are more religious. These items cannot be considered as measures of religiosity for females.

Generally, the kinds of statements which apply for some participants and not for others, unless they are meant to be that way for a particular purpose of a study, certainly pose a serious problem for interpreting results and may actually constitute a major flaw in the measuring instrument being used. This issue, as pertaining to participant gender, is discussed further in a later section. One implication of such explanation concerns whether these questionnaire items were good representatives of the domain of interest with respect to female subjects. 
Speaking of explanation of gender differences with respect to religiosity, it is not very clear and definite in the relevant literature what accounts for differences in religiosity between males and females. One, however, may be able to speculate on that, with respect to the present findings. One possibility is that all, or at least most, of the statements included in the questionnaires used in the present study may have more tendency to target males than females. The similarity of results of the so called genderneutral scale versions (see Appendix $G$ ) to the results of the original scales, which included some items that were applicable only for males, such similarity gives more merit to this speculation. Another explanation may be found in the effect of the role of sexes in the Muslim society, in general, and in the Saudi Arabian, in particular. The way the roles are defined may give more chance to females for conveniently practicing religion than males, especially at the college age range. These explanations, however, remain mere speculations that warrant further research on the issue. Speaking in terms of group membership, it may be said that in general, differences between students of Islamic studies and students of Arts and Humanities may be explained in different ways, among which is that it may be the person's religiosity, to begin with, that drove him or her to major in Islamic studies, making it logical to assume, and actually find, more religiosity in students of Islamic studies than in those of other majors. Another way to explain this difference is the effect of knowledge about Islamic rules and teachings regarding "does and don'ts" from an Islamic perspective. Such knowledge acquired on a higher level by students of Islamic studies than by others in other majors, makes them more aware of what and what not to adhere to. Put differently, the lack of religious characteristics of students of Arts and Humanities regarding certain issues and different practices may be due to ignorance of the Islamic views concerning these issues. For example, it is reasonable to expect students of Islamic studies to have more knowledge of the Islamic view regarding bank interests, fasting Mondays and Thursdays, manners of dressing, and so on and so forth. This, of course, should not be understood to imply 
that knowledge of religion per se could be a better indicator of religiosity or lack of it. This is an issue that has been discussed elsewhere in this paper (see Measures section for discussion of the theoretical framework of the MRS). What is meant here is that subjects not majoring in Islamic studies may commit some religiously unacceptable deeds not because of lack of religiosity but because they do not know such deeds are unacceptable.

Differences due to effect of interaction between group membership, field of study in this case, and gender were not predicted, and there was only two instances in which statistically significant interaction effects were shown. They were revealed, as pointed out earlier, in the "Forbidden Practices" and "Appropriate Male Conduct" subscales of RLS, amongst all 13 subscales. In both cases the pattern of this significant interaction effect was in favor of the stated predictions. On the Forbidden Practices scale the difference in level of religiosity was slight between the two sexes among students of Islamic Studies group (predicted to be more religious), whereas the difference was greater among students of Arts and Humanities, with females being more religious. Looked at from a different angle, males in the Arts and Humanities group appeared less religious than their male counterparts in the Islamic Studies group, while females were at roughly equal (high) levels of religiosity in both groups. On the Appropriate Male Conduct scale while males were more religious than females in the two groups, the difference was greater in the Islamic Studies group than in the Arts and Humanities group. Thus, being in a category that was predicted to be more religious (i.e., being in the Islamic Studies group or being a female) contributed to significantly higher level of religiosity than being in the other category, i.e., being in the Arts and Humanities group or being a male. (Note that the fact that males were more religious than females on the Appropriate Male Conduct scale poses, as explained before, no real contradiction to predictions). 
It was mentioned earlier that there were some perplexing patterns in the results of correlational analyses, where, for instance, a certain subscale (see, e.g., discussion of correlation pattern of the Societal Value of Religion subscale) had contradicting correlations with subscales that had significant positive correlations among themselves. A similar pattern can be noticed also, at least in one instance, in the results of MANOVA procedures. While sexes differed in their level of religiosity on two of the three practice scales, they did not differ on the third (Positive Practices), even though the three subscales were correlating significantly in the positive direction with each other. This hard to explain pattern may account for the previously noted incomplete support of the hypotheses, thereby, shedding some doubt about the validity of at least some of these measures. This kind of shadowy results warrants replication of the study to clarify the seemingly confusing patterns.

\section{Potential Problems in Measuring Islamic Religiosity}

As might well be expected in any scientific endeavor, there are problems that are faced in the process of conducting research. These problems become even more apparent and more felt in social sciences when trying to probe sensitive issues, whether they are sensitive from personal, social, legal, moral, or whatever perspectives. All this is in addition to the practical and scientific methodology perspectives. Religion, quite justifiably, has a history of being a most sensitive subject for scientific inquiry. Such sensitivity becomes of even more delicacy when dealing with religiously conservative cultures or societies. This problem is particularly apparent in the case of Islamic religion.

Some of the potential problems are discussed below. It should be noted that these are not necessarily the most serious or tedious problems in measuring Islamic religiosity, nor are they necessarily unique to Islam or to Islamic societies. 
Measuring the Belief Dimension. It was argued earlier that the lack of variance in participants' responses to some items may account for the loss of many potentially good items. It was also noted that the result concerning the absence of differences between subjects in religious belief, comes as no surprise at all. The argument offered was that such dimension is hard to measure in a Muslim society, simply because it should apply to every Muslim, since every Muslim is supposed to possess the basic beliefs before he or she can even be considered a Muslim. So such undiscriminating factor may be hard to use as an indicator of religiosity because it is present in everyone. It, then, becomes clear that the measurement of the construct of basic elements of belief in Islam poses a real problem for measurement and a great challenge for scale developers. First of all, it is difficult, and may be unjustifiable, to go about measuring religiosity among Muslims without first assuring the presence of belief in Islam and its tenets in those whose religiosity, as Muslims, we are attempting to look at. Additionally, it seems that it will be guaranteed that we will get zero variation in items that measure that construct. How, then, can we deal with such a dilemma?

In light of this argument, and in light of the results, which revealed complete lack of variance in some items representing basic elements of belief, the realization becomes clear that it was no coincidence that some previous researchers, who attempted to measure Muslim religiosity, seem to have a problem in dealing with this issue. Alsanie (1989), for instance, never intended to tap the construct of belief directly. $\mathrm{He}$, in fact, clearly stated that his hypothesis assumes the presence of belief in all of the people he was studying, and that his task was merely to measure the level, not the existence, of such belief along a continuum ranging from something like high to low, but not, e.g., from existent to nonexistent. An example of how Alsanie attempted to tap the construct of belief is the following statement, which is, incidentally, the first item on his scale: "My belief in Allah (God) is: (a) similar to the belief of the most religious 
people, (b) similar to the belief of moderately religious people, (c) similar to the belief of the least religious people". Notice that this statement does not question the presence or absence of belief in God (Allah) but its degree. This can be said about all the statements in Alsanie's scale (RLS) that dealt with belief, regarding, for example, belief in Angels, Heavenly Revealed Books, Prophets, and Day of Resurrection. So it can be said that Alsanie avoided the dilemma of measuring belief itself by measuring its degree and/or effect, rather than its presence or absence.

Taai (1985) also seems to have had the same dilemma, and he dealt with it in a different way. Taai arbitrarily, i.e., without utilizing statistical or psychometric procedures, divided his scale into subscales (see description of the scale in the Methods section), one of which is the scale of basic elements of belief, which consisted of six items corresponding to the six basic elements of belief in the Islamic religious system. Then his decision was that a respondent's score on this subscale is to be looked at first, and if the respondent responded to any of the six items in the opposite direction of the statement, meaning that he or she did not conform with it, then this respondent's entire scores or responses to all the subscales will all be discarded and the respondent will be completely eliminated from the study. So Taai seems to have used this subscale, of the basic elements of belief (BEB), as a criterion upon which to decide whom, and whom not, to include in the study. However, if a respondent responded positively to, or in other words, agreed to the contents of all of these six items, not only will the rest of his or her responses to the remaining scales be looked at, but also his or her scores on this subscale (the BEB) will be included for analysis. As discussed below, this strategy could create a serious problem from psychometric perspective in scale development.

Again, the question is how to deal with such a problem? Can we be justified in trying to measure Islamic religiosity or examine its presence or absence in individuals without looking at the most important aspect of such religiosity, the basic belief aspect? 
And what advantage will we have, in our attempt to assess religiosity, by including a dimension that will not distinguish between subjects, and thereby will not add any variation, of which a great amount is needed to maximize the performance of our statistical and psychometric procedures?

There is no specific suggestion the present author can offer at this point. However, until a better solution can be figured out, Taai's way, in part, seems to be one possible and reasonable solution in dealing with this problem. To make sure that we, in our attempt to measure Muslim religiosity, adhere to the conceptualization of Islam regarding the construct of religiosity, i.e., religiosity is belief and practice, we measure the basic elements of belief and use that measure, as Taai did, to decide who can be called a Muslim, in the first place, and, subsequently, can be included in a study to measure Muslim religiosity. But we, then, stop there. That is, unlike what Taai did, we do not include the scores on the basic elements of belief measure with the rest of whatever other measures we use. In other words, we, like Taai, use the (BEB) measure as a criterion to decide who can and who cannot be considered as a representative of a Muslim population. But, we should not repeat what is considered, as alluded to earlier in this section, Taai's mistake by assuming, or actually demanding, the absence of scores' variation and then including these variance lacking scores in our analysis, a mistake which could create a serious problem from psychometric perspective in scale development by minimizing, or may be even demolishing completely, the performance of our statistical and psychometric procedures. The subsequent result of that, of course, is a serious flaw in our analysis procedures and misleading or even uninterpretable results.

Offending Participants. Another potential problem faced is the possibility of offending participants or provoking their sensitivity, particularly religious respondents, by the item content, especially when respondents are asked not to leave an unanswered 
questions or statements. It may be hard for a religious person to be forced into making a decision regarding something about religion that the respondent does not have a clear idea about, especially items that have to do with attitudes, opinion, and knowledge, for example a statement like the following "In the Muslim Society, religious leaders have to have the first and last word". If a religious respondent does not know what the Islamic perspective on this issue is, he or she will find it hard to answer, because for him or her, as a religious person who is supposed to adhere to all of the teachings of the religion, it is not a matter of opinion, but of faith. Many other examples can be found in the employed instruments. So sensitivity of respondents to the contents of questionnaire items is a very important aspect to be realized and dealt with. In what appears to be related to the issue of participants' sensitivity and perception of offensiveness, it has been recommended that to improve item stem quality, a researcher is advised to consider the limits of subjects' willingness to respond. Comrey (1988) offers the following advice: "Do not exceed the willingness of the respondent to respond. Asking a subject a question that he or she does not wish to answer can result in several possible outcomes, most of them bad" (P. 757). In fact, a considerable number of questionnaires in the current study was discarded because of many unanswered items.

It is strongly felt by the present author that the sensitivity of the respondents and the reaction of people's to the whole idea of questioning them about their religiosity might have to do with the unstable results. For example, items that were thought of as good items were eliminated from the item pool by the judges for the sole reason of the way they were worded (for examples of these items see Appendix F). Items that were stated in a negative mode, especially those which had to do with faith and basic beliefs, were judged inappropriate to be asked of Muslims or about Islamic issues. There was a clear tendency among judges not to endorse items that were negatively phrased. Some judges expressed (orally and/or in writing) their discomfort 
about some of the negatively phrased items saying that these items were so strong and might be offensive to Muslim respondents. In fact, except for items that were intended for tapping religious knowledge dimension, all items that were eliminated by the judges were the ones phrased in a negative mode (see these items in Appendix F).

Another example of the role of sensitivity is the hesitation of some officials to allow the questionnaires to be given to their students, and also the hesitation and reservation expressed by some teachers about their own involvement in giving the questionnaires to their classes, and their concern about some students' reaction and perception.

It can be argued, further, that in addition to the difficulty of tapping the religious belief dimension, the issue of sensitivity might have played a major role in previous researcher's (e.g., Alsanie, 1989, Taai, 1985) decisions to avoid directly questioning people's beliefs.

In conclusion, the sensitivity of society in general to questioning people's views towards religion, and/or the sensitivity of individuals to one's evaluation of one's own religiosity should be taken into consideration.

Gender of Participants. It seems to be difficult to have one single reliable scale that measures religiosity in both sexes. There are, for example, many issues that are good measures of religiosity, but apply only to men, for example, praying in mosque, wearing gold and silk, way of dressing, Jihad, and the like. The reverse is also true, meaning that what is appropriate to ask women may not be so for men.

In the present study there was concern about this issue since there were many statements applicable for males but not for females, especially in Alsanie's (1989) Religiosity Level Scale (RLS), and at least two statements in the new Muslim Religiosity Scale (MRS). An attempt was made to encounter this problem by creating 
new versions of the scales in which the statements of concern were eliminated, and using both old and new versions to see if there would be a difference (see Appendix G for a further discussion about the new versions). As previously indicated, there were no significant differences between the results of these versions and the original scales. This lack of differences should be viewed in the context of the general results of the study, which exhibited some lack of firmness.

One solution to this problem may be to construct two separate scales, one for each sex. This is not particularly a good solution. In addition to the issue of efficiency and cost of developing two separate scales, this may not be practically advantageous for research work that studies both sexes and compare them, as is most often the case. Separate scales will be useful in studying one sex and comparing variables of interest within the same sex. Additional efforts will be needed to make the two versions parallel so that their results can be compared. Another possible solution to the gender problem is to make pairs of alternative items on the same version of a scale, for example, "shortening clothes above ankle" for men, and "Putting on scarf or veil" for women, and asking respondents to respond to the appropriate item only, depending on their sex. An extra care will, of course, be needed to assure that the two alternative statements are as parallel, in every aspect, as possible, and carry the same weight. Such paired items may be needed for purposes of targeting specific aspects of certain areas, for example, shortening clothes, specifically, or putting on veil, in the area of dressing. Otherwise, general single statements can be used for both sexes. With respect to the area of dressing, for instance, a general statement like: "I make sure to preserve the Islamic manner regarding how to dress" will suffice in targeting both sexes without creating a problem in comparison. Such practice, of making general statements, may be the best way to deal with the problem, again, unless there is a specific purpose to be served by using specific statements. 
In cases where general statements and parallel alternatives may be hard to come up with, a possible solution may be to include items that are specific to one sex or the other and include somehow qualifying instructions concerning them, for example, by asking participants to reply to statements that do not apply to them by giving their opinion regarding what a person of the opposite sex, for which the statements apply, should do. An instruction statement like the following could be included: "With items that are specific to participants of the opposite sex of yours, please choose the response that expresses your opinion as to what a Muslim of the opposite sex should do in such a situation." It may also be important to consider placement of such instructions. It may be more beneficial to place these instructions by the concerned items. For example, a statement like: "I shave my beard" could be accompanied by the following: "If you, the respondent, are female, choose the response you think a Muslim male should choose", and the like, for both sexes.

These alternative solutions are certainly not the best and may not even be of great value for certain situations. However, the issue of participants' gender has to be taken seriously into consideration, and something be done about it. Perhaps further research targeting this specific problem could provide good solutions. But in the final analysis, the issue of gender remains to be a problem that has to be dealt with.

\section{For Future Research}

From previous discussions, it can be advised that future research authors consider the following:

- Participants' gender. Take into account, and do something about, gender differences in measuring Islamic religiosity. 
-Sensitivity and offensiveness. Pay attention to, and find a way around, sensitivity of items' contents for target sample, and for society of interest at large. In other words, give special consideration to social, cultural and religious contexts, when studying issues such as religion.

- Item soundness. Related to the previous point is the issue of item contents, not only in terms of sensitivity and offensiveness, but also in terms of representativeness of, and relatedness to, the construct of concern and the domain of interest, and in terms of clarity, and understandability. Remember the issue of exceeding the participant's willingness and/or ability to respond. "Scale development can proceed more smoothly and effectively if every item can be answered by every respondent" (Comrey, 1988, P. 757).

- Response format. As discussed before, the apparent advantages of multipleresponse format for scale construction have been demonstrated. Therefore, it should be emphasized again that researchers should particularly avoid the two-response format, and use at least five alternatives for response choices. "Prepare items so that every respondent can find a response alternative that is reasonably appropriate" (Comrey, 1988, P. 757).

- Sample size. Obtain as a large sample size as possible. Keep in mind the recommended minimum ratio of five subjects for each item. Consider also a sample size that is large enough to be divided further for possibly conducting further confirmatory analyses following results of exploratory analyses.

-Sample characteristics. Make an extra effort to ensure heterogeneity of, or differences between, groups of subjects to be compared, with respect to the subject of interest, in order to have useful variance. If interested in the role of beliefs, include a mix of subjects with a broad range of intensity of belief. 
- Confirmatory analysis. Assuming that the research in this area is still at the exploratory stage, it would be beneficial to follow promising exploratory studies with further confirmatory ones, adding, perhaps, new items in line with hypothesized scale meaning.

-Validity examination items. There are many factors that can influence people's responses to a questionnaire. In the social science research, involving personal and social issues, these are mostly self-serving kinds of factors, such as social desirability, concern about possible consequences, and the like. It will be helpful if something can be done to minimize the negative effects of such factors. One way is to include items that can detect these kinds of influences. An example of that is social desirability items. According to Comrey (1988), various procedures have been developed to evaluate the truthfulness of respondents, procedures that can be adopted to different situations.

\section{Conclusions}

Substantial support was provided for some of the predictions that were made. For some others there was only partial support. Predictions concerning differences in religiosity were supported the most, especially with regard to differences between people from different areas of studies. Although the hypothesized dimensionality of religion was supported, there was some lack of firmness in this support concerning the definitions and interpretations of the resulting dimensions.

One clear conclusion of this study is that there is still lack of sound measurement to assess religiosity among Muslims. In terms of the goal for which the study was carried out, and that is to construct a useful instrument to measure Muslim religiosity, the results, although promising in some aspects, are generally not very satisfactory. Although two of the three proposed main dimensions have been identified, 
the findings did not provide clear cut confirmation of the proposed or anticipated structure that had been sought, or, at least, expected. The resulting structure lacks firmness and stability, as shown by the pattern of items dispersion as they easily switched between components in different solutions, and also in the difficulty in interpreting and labeling some components. In addition, there were many items, that were believed to be good items for tapping those identified dimensions, but they did not come out as expected.

With this kind of shaky findings, it cannot be claimed that the resulting scale (MRS), with its weaknesses and drawbacks, pointed out earlier, can be considered at this stage a suitable instrument for measuring Islamic religiosity before further research, with a larger sample and clearly diverse groups, is conducted on it. Such conclusion does not necessarily void the study of its significance. The study was concerned with constructing a new scale, and the predictions dealt with aspects of the scale validity. Some of the resulting subscales were interpretable, most of them have reasonable Alphas (pertaining to their internal consistency), and some correlated with others in ways that usually make sense, and discriminated groups in predicted ways. Note also that belief and practice dimensions which may be considered, as argued before (see Measures section), the two most important components in the religion of Islam, were identified in the present findings. In addition, despite the noisiness of its findings, the current study is still of some more significance. It has helped highlight some problems and obstacles in the road to measuring religiosity among Muslims. This study may be considered as a first step in a programmatic scale development process, or, at least, a good pilot study for a further large-scale work. It is the author's feeling that the items of this scale have at least a good face validity that indicates a relatively good content validity, and, thus, further and sounder work of replication research on these same items, after throwing out items that seem useless and generating new ones based on the 
meanings suggested by the resulting measures, is expected to yield better and more easily interpretable results, producing, hopefully, sounder measures and an advancing theory about empirical dimensions of Muslim religiosity. But for now, if the resulting scales of the MRS are to be used before further examination, extreme care and caution have to be exercised in using the scales and interpreting their results.

The general findings of the current study, combined with an examination of the relevant literature, support the suggestion that religiosity is multidimensional. Although no sound scale was developed, the general results support the assumption of dimensionality in the Islamic religion. It could also be concluded that the nature of religiosity, Islam in this case, is a profoundly complex construct to measure. In addition, the way of approaching the problem of measuring religiosity is another delicate issue.

A combination of the complexity highlighted in the construct of religiosity, the potential problems encountered in the attempt to measure religiosity, and the suspected shortcomings of the study, as discussed more fully before, may provide a reasonable account for the somewhat unsatisfactory results. But, if it is any consolation, one can argue that it is the nature of the scientific progress, that long roads have to be traveled and endless efforts have to be exerted to obtain sound results, and attain objectives that are being pursued. This study is but one step towards that end. As well put by Comrey (1973):

If it were possible to ensure that every factor analysis would turn up at least one "good" construct, progress in the social sciences would be much faster than it is in fact. . . [W] [Wll-defined factor constructs usually emerge only out of a well-designed and integrated series of investigations. Finally, useful constructs are not necessarily revealed as such upon inspection. It is necessary to establish their claim to such status by appeal to evidence outside 
the factor analytic investigations themselves. This requires a great deal of painstaking work and hence is frequently left for "other" investigations to carry out.

... Factor interpretation at its best becomes an activity to be developed over a series of related studies rather than something to be based solely on a single investigation" (P. 229).

With this in mind, we can look forward to future research to continue the process of finding better ways to measure religiosity among Muslims. 


\section{Table 1}

MRS Item Loadings on the Six Factors from the Varimax-Rotated

\section{Component Pattern}

Item No. Item Content Loadings

\section{Factor 1 (Practice):}

(80) I care a lot about preserving the Islamic manner in all my dressing

(87) I perform "Istikharah prayer" (decision making supplication) whenever I am about to make an important decision

(42) I fast Mondays and Thursdays whenever I can

(20) I try to enjoin what is right and forbid what is wrong whenever I can

(79) My first motive for visiting relatives and friends is mostly to please Allah (God)

(75) b I perform the voluntary prayers:

1. Always

2. Sometimes

3. I cannot specify

4. Seldom

5. Never

(74) b I perform voluntary nightly prayer:

1. Every night

2. More than three times a week

3. About once a week

4. At least once a month

5. Never 
Table 1 continued .....

Item No.

\section{Item Content}

Loadings

(61) b During the past year:

1. I finished reading Quraan more than once

2. I finished reading Quraan once

3. I read more than 15 chapters of Quraan

4. I read less than 15 chapters of Quraan

5. I did not read Quraan at all

(2) I like to read a lot about religion

(78) If I could perform "Omrah" (out of season form of pilgrimage) every year, I would

(5) If I could have a chance, I would read Quraan every day

(77) Since I started fasting Ramadhan, I never broke my fasting without an Islamicly legitimate excuse

(57) a b I sense, and think about, God's watching me in all my conducts:

1. Always

2. Sometimes

3. I cannot specify

4. Seldom

5. Never

(7) b I mention Allah's (God's) name:

1. Always

2. Sometimes

3. I cannot specify

4. Seldom

5. I do not do that at all 
Table 1 continued .....

Item No.

Item Content

Loadings

Factor 2 (Societal Value of Religion):

(16) The Islamic religion is capable of dealing effectively with today's problems

(17) I admire a person with a firm religious belief

(49) I think that sincerely religious people are more trustworthy than nonreligious people

(36) Humankind cannot dispense with a religious belief that directs one's life

(15) Religious leaders have to be consylted about the important affairs of the nation

(6) b Trying to involve religion in all of one's daily life's affairs is annoying to me

(23) Islam -as it is- can get along with modern technology

(52) I think that lack of religion is the most important cause of Muslims' troubles today

(54) I think that religious people -in any religion or any society-are better than nonreligious people

(34) I think a Muslim should follow the teachings of Islam even in the smallest details of his life's affairs

(33) b With all due respect and consideration for the religious leaders, there has to be a limit to their role in directing the society 
Table 1 continued .....

Item No.

Item Content

Loadings

Factor 3 (Belief in Central Tenets):

(72) I believe in the eternal life in the Hereafter

.871

(73) Heaven and Hell are true to me

(39) I believe there will be a day of judgment when everyone will be held accountable for whatever they did in this worldly life

(64) I believe that Mohammad's Message came for all people

(68) I believe in all previous revealed books (before Quraan)

(65) I believe in all previous prophets (before Mohammad)

(67) I believe that there will be a life after death

(56) I believe that everyone's fate is in the hands of God

\section{Factor 4 (Personal Need for Religion):}

(84) b I see no need for what is called "agency for enjoining the right and preventing the wrong"

(55) My love for Allah (God) exceeds my love for anyone or anything else

(19) Without religious commitment, life will be without purpose

(59) No human being can live normally without faith in God

(63) Prophet Mohammad is my greatest model

(11) a I fast the whole month of Ramadhan every year

(81) b There needs to be a reconsideration of Muslim women's position in accordance with modern life 
Table 1 continued .....

Item No. Item Content

Loadings

(51) Religion is very important to me .399

\section{Factor 5 (Reliance on Practical Guidance):}

(8) I think the distribution of inheritance between man and woman in Islam is just and fair

(31) I have no doubt that Islam is the only true religion

(44) I think the Islamic distribution of duties and rights between man and woman is an appropriate one

(26) I am showered with feelings of happiness and comfort whenever I perform a religious duty

(32) I feel that my belief in Allah (God) gives lots of meaning to my life

(27) It pleases me to spend from my money for the service of Islam and its cause

(28) Religion helps to keep life balanced and steady

(9) Believing in Mohammad's Prophethood is necessary for salvation from Hell

(76) I make sure that I give my obligatory charity whenever it is du .368

\section{Factor 6 (Unquestioning Acceptance):}

(1) I am very convinced that religion is the greatest thing in a person's life

(3) There is no doubt in my mind that Quraan is the revealed words of Allah (God) 
Table 1 continued .....

Item No.

Item Content

Loadings

(53) For Science to be of service to Humanity, it has to have religious restraints that regulate its steps

(22) I rely on Allah (God) in all my affairs

(12) b I think that women in non-Islamic societies are in a better position than in Islamic societies

Note. Item No. in this table refers to the item numbers in the original questionnaire (see Appendix C).

a These are items which emerged on the components from the PCA, but were not included in further uses of the scales.

b These are items which are reverse-keyed: $1=5,2=4,3=3,4=2,5=1$. 
Table 2

Factor Intercorrelations Between the Six Components of MRS's

PCA Results

\begin{tabular}{lcccccc}
\hline Factors & $\mathbf{1}$ & $\mathbf{2}$ & $\mathbf{3}$ & $\mathbf{4}$ & $\mathbf{5}$ & $\mathbf{6}$ \\
\hline 1. Factor 1 & 1.00 & .06 & .06 & $.26^{* *}$ & $.18^{*}$ & $.19^{*}$ \\
2. Factor 2 & & 1.00 & .15 & $.23^{* *}$ & $.22^{* *}$ & .09 \\
3. Factor 3 & & & 1.00 & .15 & .15 & .13 \\
4. Factor 4 & & & 1.00 & $.30^{* *}$ & $.21^{* *}$ \\
5. Factor 5 & & & & 1.00 & $.22^{* *}$ \\
6. Factor 6 & & & & & 1.00 \\
\hline${ }^{*} \mathrm{p}<.05 ;{ }^{* *} \mathrm{p}<.01$ & & & & &
\end{tabular}




\section{Table 3}

RLS Item Loadings on the Five Factors from the Varimax-Rotated

\section{Component Pattern}

\section{Item No. Item Content}

Loadings

\section{Factor 1 (Positive Practices):}

(13) b The recommended charity:
a. I rarely give it
b. I give it sometimes
c. I always give it

(5) The Day of Resurrection:

a. concerns me a lot

b. concerns me somewhat

c. I forget about it because of the distractions of life

(2) Angels and their worship of Allah:

a. motivate me to increase the level of my worship a lot

b. motivate me to increase the level of my worship

c. do not change the level of my worship

(56) b I repeat mentioning God's name:

a. few times because of the many distractions

b. sometimes

c. at all times

(38) b If I have an appointment with someone:
a. I skip it and give reasons of forgetting or getting busy as an excuse
b. I go to it if the person is dear to me
c. I go to it on time with no delay 
Table 3 continued .....

Item No.

Loadings

(18) b Enjoining what is right and forbidding what is wrong:

.493
a. I rarely do it
b. I do it sometimes
c. I do it all the time

(19) b Obeying parents:

a. I rarely do it, because of my many distractions

b. I do it sometimes

c. I always do it

(48) Participating in Jihad (Fighting):

a. I participate with whatever I have

b. I participate monetarily to support the fighters

c. I participate by offering advice and counseling

(54) b If I see someone having a boon [being blessed]:
a. I wish that it shifts from him to me
b. I wish to get the same
c. I wish him more

(12) b The obligatory charity:

a. I give it when demanded of me

b. I give it at the appropriate time for my finances

c. I give it on its due time

(61) The level of my religiosity, in general, is:
a. high
b. moderate
c. low 
Table 3 continued .....

Item No.

Item Content

Loadings

(20) b Keeping in touch with relatives
a. I am often lazy in doing it
b. I do it sometimes despite its inconveniences
c. I do it in all circumstances

(14) b During Ramadhan:
a. my life style remains as it is in other months
b. I increase the amount of my voluntary worship a little bit
c. I increase the amount of my voluntary worship a lot

(1) a My belief in Allah (God) is:
a. similar to the belief of the most religious people
b. similar to the belief of moderately religious people
c. similar to the belief of the least religious people

(46) If I offered a service to someone:
a. I tend to forget it
b. I tend to forget it, unless I need something from that person
c. I remind him of it so he does not forget it

(17) b The Omrah (an out of season form of pilgrimage):
a. I do not think about it now
b. I do it sometimes
c. I do it frequently

(7) a My love for Mohammad (peace be upon him) is:
a. more than my love for myself
b. like my love for myself
c. more than my love for the closest relative 
Table 3 continued .....

Item No.

\section{Factor 2 (Forbidden Practices):}

(58) b Music and songs:

a. I listen to them a lot

b. I listen to them sometimes

c. I avoid listening to them

(49) Beard hair:

a. I leave it and take nothing of it

b. I shave some of it

c. I shave all of it

(45) Drawing pictures of living beings:

a. I refrain from it

b. I refrain from it for people

c. I practice it as a hobby

(16) b The pilgrimage:
a. I do not think about it now
b. I am thinking of doing it at the first chance
c. I did it

(39) b Magic:

a. amazes me whenever I watch it

b. attracts my attention if the magician is skillful

c. I avoid it

(57) b If I see someone ridicule another who is religiously committed:

a. I do not interfere

b. I interfere without exasperating either side

c. I interfere to the best of my ability to stop the ridiculer 
Table 3 continued .....

Item No.

Item Content

Loadings

(3) a The Heavenly Revealed Books

a. agree upon the fundamentals

b. agree upon the fundamentals and the subsidiaries

c. contradict each other

(21) Marriage:

a. protects me, my wife, and the society

b. protects me from committing sins

c. puts a limit to my pleasure

(53) b Looking at a non-relative woman:

a. I look at her to see how pretty she is

b. I look at her if she is young

c. I refrain from looking at her

\section{Factor 3 (Integrity):}

(30) Unjustly accusing others:
a. is difficult for me to do
b. I do it in some circumstances
c. I do it so that I can get along with people

(29) Telling something not as it is:
a. I rarely do it
b. I do it sometimes
c. I dot it a lot

(36) b Gossiping to ruin people's relationships:
a. I do it with people who are hostile to me
b. I avoid doing it with friends
c. I avoid it 
Table 3 continued .....

Item No.

Item Content

Loadings

(23) Taking interest from banks:
a. I avoid it
b. I find some benefit in it
c. I find it appropriate for modern life

(37) b I use cursing in my speech:
a. often
b. sometimes
c. seldom

(28) Giving a false oath:
a. is easy for me to avoid
b. I do it sometimes
c. I do it a lot

(27) Taking others' properties without their knowledge:
a. I do not allow it
b. I allow it if one is in great need
c. does not matter if the property is insignificant

(47) Listening to others' talk without their knowledge:
a. I refrain from it
b. I entertain myself with it sometimes
c. I practice it to learn what is going on between people

(26) Paying money to get what one does not deserve:
a. I avoid it
b. I resort to it when I need to
c. offers lots of benefits for me 
Table 3 continued .....

Item No.

Item Content

Loadings

Factor 4 (Consideration for Others):

(33) b Man's imitation of woman is:
a. not bad
b. not bad under certain circumstances
c. has bad consequences

(34) b Violating others' right:

a. I resort to it sometimes

b. I resort to it once in a while

c. I avoid it

(59) b When someone talks about religious issues:

a. I turn away from him

b. I listen to him a little, then turn away

c. I listen to him until he finishes

(32) b Imitating non-Muslims is:

a. not bad considering the circumstances of modern time

b. not bad while in their lands

c. brings nothing but harm

Factor 5 (Appropriate Male Conduct):

(10) The place where I pray is:
a. the mosque at all times
b. the mosque most of the time
c. the mosque sometimes

(9) I pray in congregation:
a. always
b. most of the time
c. sometimes 
Table 3 continued .....

Item No.

Item Content

Loadings

(43) Wearing Gold and Silk:

a. I avoid wearing them

b. I wear them in occasions

c. I wear them to be distinguished among others

Note. Item No. in this table refers to the item numbers in the original questionnaire (see Appendix D).

a These are items which emerged on the components from the PCA, but were not included in further uses of the scales.

b These are items which are reverse-keyed. That is they are scored in ascending order: $\mathrm{A}=1, \mathrm{~B}=2, \mathrm{C}=3$. 


\section{Table 4}

Factor Intercorrelations Between the Five Components of RLS's PCA Results

\begin{tabular}{lccccc}
\hline Factors & $\mathbf{1}$ & $\mathbf{2}$ & $\mathbf{3}$ & $\mathbf{4}$ & $\mathbf{5}$ \\
\hline 1. Factor 1 & $1.00^{* *}$ & $.33^{* *}$ & $.21^{* *}$ & $.25^{* *}$ & .07 \\
2. Factor 2 & & 1.00 & $.23^{* *}$ & $.26^{* *}$ & .13 \\
3. Factor 3 & & & 1.00 & .12 & .11 \\
4. Factor 4 & & & 1.00 & -.02 \\
5. Factor 5 & & & & 1.00 \\
\hline${ }^{*} \underline{\underline{p}}<.05 ;{ }^{* *} \mathrm{p}<.01$ & & & &
\end{tabular}




\section{Table 5}

RBS Item Loadings on the Two Factors from the Varimax-Rotated

\section{Component Pattern}

Item No.

Item Content

Loadings

\section{Factor 1 (Secular Orientation):}

(37) b Life is sweet, so it has to be cared about

.589

(18) b Collecting wealth is the best assurance for the future

.508

(35) b Love is for one to love those around him as he pleases

(61) b I think it is an acceptable practice in religion to swear by God a lot

(12) b Whoever stands by in a dispute, will be safe

(9) b I think that staying away from relatives is peace of mind

(53) b Nothing prevents one from joking even when the joke is a lie

(16) b I think an ascetic is an introvert person

(50) b I do not greet a neighbor who does not greet me

(36) b It is one's right to be famous and have prestige

(49) b Good treatment to servants spoils them

(73) b I think it is wise that we satisfy others in dealing with them no matter what the motives are

\section{Factor 2 (Perception of Control):}

(38) Those who control themselves at the moment of anger are the most capable of facing hardship situations 
Table 5 continued

Item No.

Item Content

Loadings

(39) We must be careful in accepting extreme teachings such as .489 Darwin's theory

(55) Arrogance is belittling others' performance and admiring one's own

(21) Everything that happens to us is being predetermined by fate

(22) The Day of Resurrection is a fact which humankind cannot escape

(28) I think that commitment to one's group, and following its views, in what is right is obligatory

(69) I, most of the time, remove from the road what might cause harm to people

Note. Item No. in this table refers to the item numbers in the original questionnaire (see Appendix E).

b These are items which are reverse-keyed: True $=0$, False $=1$. 
Table 6

Correlations Between Subscales

\begin{tabular}{|c|c|c|c|c|c|c|c|c|c|c|c|c|c|}
\hline Scales & 1 & 2 & 3 & 4 & 5 & 6 & 7 & 8 & 9 & 10 & 11 & 12 & 13 \\
\hline 1-MRS- Practice & 1.00 & $.35^{* *}$ & .08 & $.33^{\star *}$ & $.36 * *$ & .10 & $.66 * *$ & $.66^{* *}$ & $.43^{* *}$ & $.38 * \star$ & .15 & $.42^{* *}$ & .10 \\
\hline 2-MRS- Societal Value ... & & 1.00 & $.24^{\star \star}$ & $.43^{* *}$ & $.44^{\star *}$ & $.23 * *$ & .09 & $.49^{* *}$ & $.23^{\star *}$ & $.31 * *$ & $.24^{\star \star}$ & $.35 * *$ & $.30 * *$ \\
\hline 3-MRS- Belief .... & & & 1.00 & $.27^{* *}$ & $.27^{\star *}$ & .04 & .07 & $.18^{\star}$ & $.20 * *$ & .06 & .04 & .14 & $.16^{*}$ \\
\hline 5-MRS- Reliance ... & & & & & 1.00 & $.26 * *$ & $.26 * *$ & $.32^{* *}$ & $.39 * *$ & .13 & .09 & $.41 * *$ & .14 \\
\hline 6-MRS- Acceptance & & & & & & 1.00 & .13 & .09 & $.20 * \star$ & .14 & .11 & $.16^{*}$ & .15 \\
\hline 9-RLS- Integrity & & & & & & & & & 1.00 & $.34 * *$ & $.24^{* *}$ & $.36 * *$ & .11 \\
\hline 10-RLS- Consideration ... & & & & & & & & & & 1.00 & $.18^{*}$ & $.40^{\star \star}$ & .13 \\
\hline 11-RLS-Male Conduct & & & & & & & & & & & 1.00 & $.20 * *$ & -.01 \\
\hline 12-RBS- Secular Orientation & & & & & & & & & & & & 1.00 & .10 \\
\hline 13-RBS- Perception of Contro & & & & & & & & & & & & & 1.00 \\
\hline
\end{tabular}

Note. MRS = Muslim Religiosity Scale; RLS = Religiosity Level Scale; RBS = Religious Behavior Scale.

${ }^{*} \mathrm{p}<.05 ; \quad * * \mathrm{p}<.01$ 


\section{Table 7}

MRS's Subscales' Means, Standard Deviations, and F Values for Students of Islamic Studies and Students of Arts and Humanities (Group Differences)

\begin{tabular}{lcccccc}
\hline & \multicolumn{3}{c}{ Islamic $(\mathrm{N}=82)$} & \multicolumn{3}{c}{ Arts \& Hum. $(\mathrm{N}=87)$} \\
\cline { 2 - 3 } \cline { 5 - 7 } Scales & $\underline{\mathrm{M}}$ & $\underline{\mathrm{SD}}$ & $\underline{\mathrm{M}}$ & $\underline{\mathrm{SD}}$ & $\underline{\mathrm{F}}(1,165)$ \\
\hline Practice & 55.30 & 6.85 & 48.76 & 6.90 & $41.73^{* * *}$ \\
Societal Value & 50.54 & 3.40 & 46.99 & 5.39 & $21.84^{* * *}$ \\
Personal Need & 33.60 & 1.74 & 31.75 & 3.11 & $18.27^{* * *}$ \\
Acceptance & 24.29 & 1.10 & 23.87 & 2.31 & $3.90^{*}$ \\
\hline
\end{tabular}

Note. $\underline{\mathrm{M}}=$ Means, $\underline{\mathrm{SD}}=$ Standard Deviations.

$* \mathfrak{p}<.05 ;{ }^{* * *} \mathfrak{p}<.001$ 


\section{Table 8}

RLS's Subscales' Means, Standard Deviations and F Values for

Students of Islamic Studies and Students of Arts and Humanities

(Group differences)

\begin{tabular}{lcccrrrr}
\hline & \multicolumn{3}{c}{ Islamic $(\mathrm{N}=82)$} & \multicolumn{3}{c}{ Arts \& Hum. $(\mathrm{N}=87)$} \\
\cline { 2 - 5 } \multicolumn{1}{c}{ Scales } & $\underline{\mathrm{M}}$ & $\underline{\mathrm{SD}}$ & $\underline{\mathrm{M}}$ & $\underline{\mathrm{SD}}$ & $\underline{\mathrm{F}}(1,165)$ \\
\hline Positive Practices & 36.87 & 4.17 & 34.30 & 3.98 & $18.57^{* * *}$ \\
Forbidden Practices & 21.60 & 2.33 & 17.68 & 2.97 & $80.55^{* * *}$ \\
Integrity & 26.35 & 1.52 & 25.42 & 1.67 & $13.65^{* * *}$ \\
Consideration & 11.73 & .72 & 11.21 & .99 & $14.25^{* * *}$ \\
Male Conduct & 7.49 & 1.85 & 6.26 & 1.69 & $16.73^{* * *}$ \\
\hline
\end{tabular}

$\underline{\text { Note. }} \underline{\mathrm{M}}=$ Means, $\underline{\mathrm{SD}}=$ Standard Deviations.

$* * * \underline{p}<.001$

\section{Table 9}

$\underline{\text { RLS's Subscales' Means Standard Deviations and F Values }}$ for Male and Female Subjects (Gender Differences)

\begin{tabular}{|c|c|c|c|c|c|}
\hline \multirow[b]{2}{*}{ Scales } & \multicolumn{2}{|c|}{ Males $(\mathrm{N}=108)$} & \multicolumn{2}{|c|}{ Females $(\mathrm{N}=61)$} & \multirow[b]{2}{*}{$\underline{F}(1,165)$} \\
\hline & $\underline{\mathrm{M}}$ & $\underline{\mathrm{SD}}$ & $\underline{\mathrm{M}}$ & $\underline{\mathrm{SD}}$ & \\
\hline Forbidden Practices & 19.08 & 3.60 & 20.46 & 2.54 & $13.28 * * *$ \\
\hline Consideration & 11.33 & .99 & 11.69 & .67 & $7.40^{* *}$ \\
\hline Male Conduct & 7.54 & 1.43 & 5.66 & 1.96 & $58.46^{* * *}$ \\
\hline
\end{tabular}

Note. $\underline{M}=$ Means, $\underline{\mathrm{SD}}=$ Standard Deviations.

${ }^{* *} \mathrm{p}<.01 ; * * * \mathrm{p}<.001$ 


\section{Table 10}

Means and Standard Deviations for Group by Gender Interaction Effect

$\underline{\text { Results }}$

\section{Islamic Studies}

Arts \& Humanities

\begin{tabular}{|c|c|c|c|c|c|c|c|c|}
\hline \multirow[b]{2}{*}{ Scal } & \multicolumn{2}{|c|}{ Ms. $(\mathrm{N}=54)$} & \multicolumn{2}{|c|}{ Fs. $(N=28)$} & \multicolumn{2}{|c|}{ Ms. $(N=54)$} & \multicolumn{2}{|c|}{ Fs. $(\mathrm{N}=33)$} \\
\hline & $\underline{\mathrm{M}}$ & $\underline{D}$ & $\underline{\mathrm{M}}$ & $\underline{\mathrm{SD}}$ & - & $\underline{\mathrm{SD}}$ & $\underline{\mathrm{M}}$ & $\underline{\mathrm{SD}}$ \\
\hline & 21.52 & 2.56 & 21.75 & 1.84 & 16.65 & 2.74 & 19.36 & 2. \\
\hline & 8.31 & 1.11 & 5.89 & 1.97 & 6.76 & 1.29 & 5.45 & 1.9 \\
\hline
\end{tabular}

Note. Ms. $=$ Males, Fs. $=$ Females, $\underline{M}=$ Means, $\underline{\mathrm{SD}}=$ Standard Deviations. 
Appendix A

A Cover Letter to Respondents

Greetings:

I am a Saudi student working presently on my dissertation for the Ph.D. degree. My research for the dissertation involves an attempt to measure opinions about some social and religious issues.

I request that you kindly help me in that by participating in responding to the attached questionnaires.

I thank you and greatly appreciate your willingness to participate in this study by taking the time to respond to the questionnaires. I hope that, with your assistance, this study will add something new and contribute some useful ideas to the field in which it is conducted. The significance of the study and the usefulness of its results depend heavily on your carefulness in completing the questionnaires and your honesty in providing information. I remind you that all information collected by way of this survey will remain confidential and be used for research purposes only.

In the following pages you will find, first, a sheet consisting of a request for some simple demographic information. Then you will find three different questionnaires, each having its own specific directions. Please carefully read and follow all instructions and directions and answer each statement as honestly and truthfully as you can. 
Of course, there is no right or wrong answer to any of the statements. Each individual is requested, and expected, to express his/her own opinion in reply to each item by checking the responses that fit him/her and express his/her opinion the most. It should not be surprising to find certain statements for which none of the responses seems to describe you or express your view. In such cases, please do not leave the statement unanswered, but rather choose the response that you feel is closest to your view. (Leaving any item with no response, will forfeit your participation of its significance).

Finally, if you have any comments or suggestions that you could provide me, I -thanking you in advance- ask that you kindly write to me at my address below.

Sincerely yours; Abdulaziz Albelaikhi 


\section{Appendix B}

A Demographic Information Sheet

Please, fill in the following information before starting to respond to the questionnaires:

School or University:

College \and Major:

Year $\backslash$ and term:

Nationality:

Religion:
For Muslims:
( ) Sunni
( ) Sheeai

Sex:

( ) Male

( ) Female

Age: 


\section{Appendix C}

\section{Questionnaire \# "1"}

The following statements are intended to express opinions regarding some religious issues, or describe the frequencies of some practices. Your task is to read each statement carefully and decide whether you agree with it or not, or whether or not it applies to you, expresses your opinion or describes your practice, then indicate your agreement or disagreement with each statement, or the extent to which it expresses your opinion or describes your practice, using the 5-point rating scale that succeeds the statement: $\left(\begin{array}{lllll}1 & 2 & 3 & 4 & 5\end{array}\right)$. Meanings of these numbers are as follows:

$$
\begin{aligned}
& \mathbf{1}=\text { Strongly Disagree } \quad \mathbf{2}=\text { Disagree } \\
& 3=\text { Not sure } \quad 4=\text { Agree } \\
& 5=\text { Strongly Agree }
\end{aligned}
$$

So, for example, if you strongly agree with a statement or feel that it strongly expresses your opinion, then circle number "5" (i.e., Strongly Agree), if, on the other hand, you strongly disagree with a statement or feel that it does not express your opinion at all, then circle number "1" (Strongly Disagree), if you cannot make your mind about a statement, then indicate that by circling number " 3 " (Not sure), and so on. Or indicate the frequency of your practice of the behavior mentioned in the statement by choosing the response that describes the frequency of your practice (for example, always, sometimes, seldom, and so on, as 
mentioned in the alternative responses to the statements describing frequencies of practice).

(As a reminder, the key numbers for the rating scale are repeated on the top of each page of the items list).

Please, do not leave any statement without a response 
1 = Strongly Disagree 2 = Disagree 3 = Not Sure 4 =Agree 5 =Strongly Agree

(1) I am very convinced that religion is the greatest thing in a person's life

(2) I like to read a lot about religion

12345

(3) There is no doubt in my mind that Quraan is the revealed words of Allah (God)

(4) I believe in the existence of angels

(5) If I could have a chance, I would read Quraan every day .....

(6) Trying to involve religion in all of one's daily life's affairs is annoying to me

(7) I mention Allah's (God' s) name:

1. Always

2. Sometimes

3. I cannot specify

4. Seldom

5. I do not do that at all

(8) I think the distribution of inheritance between man and woman in Islam is just and fair

(9) Believing in Mohammad's Prophethood is necessary for salvation from Hell

(10) I give (voluntary) charity to real needy people:
1. Always
2. Sometimes
3. I cannot specify
4. Seldom
5. never

(11) I fast the whole month of Ramadhan every year 
1 = Strongly Disagree $2=$ Disagree $3=$ Not Sure $4=$ Agree 5 =Strongly Agree

(12) I think that women in non-Islamic societies are in a better position than in Islamic societies

(13) Religious education has to be among the basics of the formal schooling curriculum

(14) I drink wine (or intoxicant drinks):

1. Very much

2. Much

3. I can not answer

4. Little

5. Never

(15) Religious leaders have to be consulted about the important affairs of the nation

(16) The Islamic religion is capable of dealing effectively with today's problems

(17) I admire a person with a firm religious belief

12345

(18) I prefer the company of religious people over the company of nonreligious people

(19) Without religious commitment, life will be without purpose

12345

(20) I try to enjoin what is right and forbid what is wrong whenever I can

(21) I believe in the existence of Allah (God)

12345

(22) I rely on Allah (God) in all my affairs

12345

(23) Islam -as it is- can get along with modern technology

(24) Commitment to religion offers great comfort for a person when life's sorrow and misfortune strike 
$1=$ Strongly Disagree 2 = Disagree $3=$ Not Sure $4=$ Agree $5=$ Strongly Agree

(25) I think this world would be a better place if all people believed in Islam and followed it .............................. 12345

(26) I am showered with feelings of happiness and comfort whenever I perform a religious duty

(27) It pleases me to spend from my money for the service of Islam and its cause

(28) Religion helps to keep life balanced and steady 12345

(29) I think that any country that embraces some religion has to make that religion its sole source of legislation

(30) If not prevented by unavoidable circumstances, I will certainly go to mosque for every prayer

(31) I have no doubt that Islam is the only true religion 12345

(32) I feel that my belief in Allah (God) gives lots of meaning to my life

(33) With all due respect and consideration for the religious

leaders, there has to be a limit to their role in directing the society

(34) I think a Muslim should follow the teachings of Islam even in the smallest details of his life's affairs

(35) I like gatherings where the subject of conversation is religion 12345

(36) Humankind cannot dispense with a religious belief that directs one's life

12345

(37) Most of my friends are religious people

(38) Islam has to be the sole source of legislation in all affairs in the Islamic countries 
1 = Strongly Disagree 2 = Disagree $3=$ Not Sure 4 =Agree 5 =Strongly Agree

(39) I believe there will be a day of judgment (hereafter) when everyone will be held accountable for whatever they did in this worldly life

(40) Performing the obligatory prayers is a constant part of my daily practice

(41) I believe that Islam is a true heavenly religion, but do not practice it very often

(42) I fast Mondays and Thursdays whenever I can

(43) I have already performed my pilgrimage, (or I have sincere intention to perform pilgrimage as soon as possible) .....

(44) I think the Islamic distribution of duties and rights between man and woman is an appropriate one

(45) I believe that Mohammad is a true messenger of Allah (God) 12345

(46) In the Muslim Society, religious leaders have to have the first and last word

(47) I try hard to carry my religion over into all my other dealings in life

(48) The more Science advances in its discoveries, the clearer the truth of religious teachings becomes

(49) I think that sincerely religious people are more trustworthy than nonreligious people

(50) I take drugs:
1. Very much
2. Much
3. I can not answer
4. Little
5. Never 
1 = Strongly Disagree 2 = Disagree $3=$ Not Sure 4 = Agree 5 =Strongly Agree

(51) Religion is very important to me

(52) I think that lack of religion is the most important cause of Muslims' troubles today

(53) For Science to be of service to Humanity, it has to have religious restraints that regulate its steps

(54) I think that religious people -in any religion or any societyare better than nonreligious people

(55) My love for Allah (God) exceeds my love for anyone or anything else

(56) I believe that everyone's fate is in the hands of God

(57) I sense, and think about, God's watching me in all my conducts:
1. Always
2. Sometimes
3. I cannot specify
4. Seldom
5. Never

(58) Every person's duty is to serve God

(59) No human being can live normally without faith in God

(60) Quraan is the only constitution capable of encompassing all life's affairs

(61) During the past year:

1) I finished reading Quraan more than once

2) I finished reading Quraan once

3) I read more than 15 chapters of Quraan

4) I read less than 15 chapters of Quraan

5) I did not read Quraan at all 
1 = Strongly Disagree 2 = Disagree $3=$ Not Sure 4 =Agree 5 =Strongly Agree

(62) If I needed an advice about something, I would seek it from a religious person

(63) Prophet Mohammad is my greatest model

12345

(64) I believe that Mohammad's Message came for all people

12345

(65) I believe in all previous prophets (before Mohammad)

12345

(66) I try hard not to miss praying on time

12345

(67) I believe that there will be a life after death

12345

(68) I believe in all previous revealed books (before Quraan)

12345

(69) I believe in the existence of Satan

12345

(70) I never allow myself to skip an obligatory prayer

12345

(71) I believe in Satan's capability of alluring man

12345

(72) I believe in the eternal life in the Hereafter

(73) Heaven and Hell are true to me

12345

(74) I perform voluntary nightly prayer:

1) Every night

2) More than three times a week

3) About once a week

4) At least once a month

5) Never

(75) I perform the voluntary prayers:

1. Always

2. Sometimes

3. I cannot specify

4. Seldom

5. Never 
1 = Strongly Disagree 2 = Disagree 3 = Not Sure 4 = Agree 5 =Strongly Agree

(76) I make sure that I give my obligatory charity whenever it is due

(77) Since I started fasting Ramadhan, I never broke my fasting without an Islamicly legitimate excuse

(78) If I could perform "Omrah" (out of season form of pilgrimage) every year, I would

(79) My first motive for visiting relatives and friends is mostly to please Allah (God)

12345

(80) I care a lot about preserving the Islamic manner in all my dressing

(81) There needs to be a reconsideration of Muslim women's position in accordance with modern life

(82) I do not discriminate in my relationships and friendships between religious and nonreligious people

(83) I am annoyed by the interference of religious scholars in every small and big affair of the nation

(84) I see no need for what is called "agency for enjoining the right and preventing the wrong"

(85) Men and women have to be equal in everything, even in inheritance and testimony

(86) I think it is important that women participate in all fields of life, including holding leading and political positions ....

12345

(87) I perform "Istikharah prayer" (decision making supplication) whenever I am about to make an important decision .... 
$1=$ Strongly Disagree 2 = Disagree 3 = Not Sure 4 = Agree 5 =Strongly Agree

(88) During the past month I attended morning (dawn) prayer in mosque:

1) More than 20 times

2) Between 10 and 20 times

3) Between five and 10 times

4) Less than five times

5) None (not even once) 
Appendix D

Questionnaire \# "2"

This questionnaire consists of a number of statements about different subjects. Each of the statements has three response options. Read each statement and its options carefully, then chose one of the three options and circle the number of your choice $(a, b$, or $c)$. 
1. My belief in Allah (God) is:
a. similar to the belief of the most religious people
b. similar to the belief of moderately religious people
c. similar to the belief of the least religious people

2. Angels and their worship of Allah:
a. motivate me to increase the level of my worship a lot
b. motivate me to increase the level of my worship
c. do not change the level of my worship

3. The Heavenly Revealed Books:
a. agree upon the fundamentals
b. agree upon the fundamentals and the subsidiaries
c. contradict each other

4. I know among the messengers mentioned in Quraan:
a. most of them
b. some of them
c. Mohammad (peace be upon him) only

5. The Day of Resurrection:
a. concerns me a lot
b. concerns me somewhat
c. I forget about it because of the distractions of life

6. The fate:
a. is God's fair lot to His creatures
b. one has to submit to it
c. is imposed on people whether they like it or not

7. My love for Mohammad (peace be upon him) is:
a. more than my love for myself
b. like my love for myself
c. more than my love for the closest relative

8. The obligatory prayer:
a. I always do it on time
b. I do it on time most of the time
c. I do it on time sometimes 
9. I pray in congregation:
a. always
b. most of the time
c. sometimes

10. The place where I pray is:
a. the mosque at all times
b. the mosque most of the time
c. the mosque sometimes

11. The supererogatory prayer:
a. I do obligatory prayer only
b. I do it [the supererogatory] sometimes
c. I always do it

12. The obligatory charity:
a. I give it when demanded of me
b. I give it at the appropriate time for my finances
c. I give it on its due time

13. The recommended charity:
a. I rarely give it
b. I give it sometimes
c. I always give it

14. During Ramadhan:
a. my life style remains as it is in other months
b. I increase the amount of my voluntary worship a little bit
c. I increase the amount of my voluntary worship a lot

15. The voluntary fasting:
a. I fast in Ramadhan only
b. I do it [the voluntary] sometimes
c. I do it a lot

16. The pilgrimage:
a. I do not think about it now
b. I am thinking of doing it at the first chance
c. I did it 
17. The Omrah (an out of season form of pilgrimage):

a. I do not think about it now

b. I do it sometimes

c. I do it frequently

18. Enjoining what is right and forbidding what is wrong:
a. I rarely do it
b. I do it sometimes
c. I do it all the time

19. Obeying parents:

a. I rarely do it, because of my many distractions

b. I do it sometimes

c. I always do it

20. Keeping in touch with relatives:

a. I am often lazy in doing it

b. I do it sometimes despite its inconveniences

c. I do it in all circumstances

21. Marriage:

a. protects me, my wife, and the society

b. protects me from committing sins

c. puts a limit to my pleasure

22. Mixing with a nonrelative woman:
a. I do it only when it is a matter of necessity
b. I do it in social occasions
c. I do it to go along with modern life

23. Taking interest from banks:
a. I avoid it
b. I find some benefit in it
c. I find it appropriate for modern life

24. Wine [or any intoxicant]:
a. I do not drink it
b. I drink it sometimes
c. I drink it most of the time to experience ecstasy 
25. Offering testimony:
a. I offer it in all circumstances
b. I offer it if circumstances allow me to
c. I do not offer it, to avoid getting in trouble

26. Giving money to get what one does not deserve:
a. I avoid it
b. I resort to it when I need to
c. offers lots of benefits for me

27. Taking others' properties without their knowledge:
a. I do not allow it
b. I allow it if one is in great need
c. does not matter if the property is insignificant

28. Giving a false oath:
a. is easy for me to avoid
b. I do it sometimes
c. I do it a lot

29. Telling something not as it is:
a. I rarely do it
b. I do it sometimes
c. I dot it a lot

30. Unjustly accusing others:
a. is difficult for me to do
b. I do it in some circumstances
c. I do it in order to get along with today's people

31. Profits from questionable sources:
a. I take them in order to increase my income
b. I take them if I am in need for them
c. I avoid taking them

32. Imitating non-Muslims is:
a. not bad considering the circumstances of modern time
b. not bad while in their lands
c. brings nothing but harm 
33. Man's imitation of woman is:

a. not bad

b. not bad under certain circumstances

c. has bad consequences

34. Violating others' right:

a. I resort to it sometimes

b. I resort to it from time to time

c. I avoid it

35. Pretending to prefect my work in the presence of others:

a. I do it to serve my interests

b. I do it sometimes

c. I stay away from it

36. Gossiping to ruin people's relationships:

a. I do it with people who are hostile to me

b. I avoid doing it with friends

c. I avoid it

37. I use cursing in my speech:

a. often

b. sometimes

c. seldom

38. If I have an appointment with someone:

a. I skip it and give reasons of forgetting or getting busy as an excuse

b. I go to it if the person is dear to me

c. I go to it on time with no delay

39. Magic:

a. amazes me whenever I watch it

b. attracts my attention if the magician is skillful

c. I avoid it

40. My treatment of neighbors:
a. not good
b. nice
c. good 
41. My treatment of people:

a. good in general

b. good with whom I know

c. good with those from whom I get favors

42. Shortening clothes above the ankle:

a. I preserve that in all my clothes

b. I overlook that in some occasions

c. I avoid that to appear neat

43. Wearing Gold and Silk:

a. I avoid wearing them

b. I wear them in occasions

c. I wear them to be distinguished among others

44. If I had a shop and used a scale:

a. I would balance the scale

b. I would slide the scale in my behalf if the customer was a foreigner

c. I would slide the scale in my behalf to increase my profits

45. Drawing pictures of living beings:

a. I refrain from it

b. I refrain from it for people

c. I practice it as a hobby

46. If I offered a service to someone:

a. I tend to forget it

b. I tend to forget it, unless I need something from that person

c. I remind him of it so he does not forget it

47. Listening to others' talk without their knowledge:

a. I refrain from it

b. I entertain myself with it sometimes

c. I practice it to learn what is going on between people

48. Participating in Jihad (Fighting):

a. I participate with whatever I have

b. I participate monetarily to support the fighters

c. I participate by offering advice and counseling 
49. Beard hair:

a. I leave it and take nothing of it

b. I shave some of it

c. I shave all of it

50. If I had a custody of an orphan:

a. I would work on investing his money

b. I would work on investing his money and take, from it, what I am entitled to

c. I would work on profiting from his money as much as I can

51. Food imported from non-Islamic countries:

a. I buy it if I like it

b. I buy it after consulting the seller

c. I buy it after consulting someone whom I trust

52. Patience:

a. I seldom have patience

b. I have patience sometimes

c. I always have patience

53. Looking at a non-relative woman:

a. I look at her to see how pretty she is

b. I look at her if she is young

c. I refrain from looking at her

54. If I see someone having a boon [being blessed]:

a. I wish that it shifts from him to me

b. I wish to get the same

c. I wish him more

55. I read some Quraan:

a. at wide intervals

b. every week

c. every day

56. I repeat mentioning God's name:

a. few times because of the many distractions

b. sometimes

c. at all times 
57. If I see someone ridicule another who is religiously committed:
a. I do not interfere
b. I interfere without exasperating either side
c. I interfere to the best of my ability to stop the ridiculer

58. Music and songs:
a. I listen to them a lot
b. I listen to them sometimes
c. I avoid listening to them

59. When someone talks about religious issues:
a. I turn away from him
b. I listen to him a little, then turn away
c. I listen to him until he finishes

60. When I go to school, I do that for:
a. bettering my income level
b. bettering my social status
c. bettering myself and others

61. The level of my religiosity, in general, is:
a. high
b. moderate
c. low 
Appendix E

\section{Questionnaire \# "3"}

This scale aims at knowing the behavior of individuals towards some social issues that are related to the daily life.

In this scale there is a number of statements some of which are agreeable to you, or that you feel they are true and accept them, and others are not agreeable to you, or that you feel they are false and reject them

Your are asked to carefully read each statement, and distinguish between the true and false statements and put the mark (X) in the box under the appropriate response.

Example:

$\underline{\text { Statement }}$ $\underline{\text { Response }}$ True False

1. Belief in God offers peace

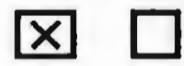

2. Birth control is a social necessity for a working woman $\square \quad x$

Please respond to all statements without leaving any one, and in case of inability to give a certain answer, guess the response from the two choices (true) or (false).

Try not to spend more time than needed in answering any statement, instead record your first impression about it. 
(1) My conviction of God's existence is complete

(2) I think a believer is one who believes in some of the prophets and not others

(3) The claim of the existence of invisible world (Angeles and Jinnis, etc.) lacks scientific proof

(4) I think a faithful scholar is better than a worshiper

(5) Handshaking with a nonrelative from the opposite sex is mandatory

(6) A prayer without submission is like a tree with little fruits

(7) Fasting is a believer's abstaining from food and drink only .....

(8) Marriage is an agreement between a man and a woman with no need for further proceedings

(9) I think that staying away from relatives is peace of mind

(10) The wise is one who avoids leading others (even) when he finds himself capable of leading

(11) I think it is necessary not to support parents who are capable of supporting themselves

(12) Whoever stands by in a dispute, will be safe

(13) "Whoever takes patience, will gain" is a true statement

(14) A true believer is one who believes that God's mercy is bigger than one's sins

(15) Graces increase with increasing thanks to God

(16) I think an ascetic is an introvert person

(17) Eating a lot lengthens life

(18) Collecting wealth is the best assurance for the future 
(19) A good personality follows the wisdom that "the best talk is the short and meaningful"

(20) The Heavenly books, other than the Quraan, have been distorted from their origins

(21) Everything that happens to us is being predetermined by fate

(22) The Day of Resurrection is a fact which humankind cannot escape

(23) To succeed in one's work, one should not tell others about it

(24) Breeding (or raising) dogs does not contradict belief

(25) The obligatory charity (alms) is not necessary at all times, even with the availability of wealth

(26) Pilgrimage is an emigration to Allah (God) that has to be done

(27) Obeying authorities in issues that are religiously acceptable is indisputable

(28) I think that commitment to one's group, and following its views, in what is right is obligatory

(29) The basis of cooperation between people depends on good deeds

(30) It is everyone's duty to enjoin the right and forbid the wrong

(31) Disclosing people's mistakes in front of others is necessary so they can clean their acts

(32) Hope is the lamp of worship

(33) "Fear of things pushes you away from them, but fear of God pulls you closer to Him

(34) Relying on God in every deed is necessary

(35) Love is for one to love those around him as he pleases 
(36) It is one's right to be famous and have prestige

(37) Life is sweet, so it has to be cared about

(38) Those who control themselves at the moment of anger are the most capable of facing hardship situations

(39) We must be careful in accepting extreme teachings such as Darwin's theory

(40) I think that the worldly life comes to eternal mortality with no resurrection after it

(41) I believe that the ultimate purpose of the creation of Humankind is the Day of Judgment

(42) Persistent remembrance of Allah makes a person comfortable

(43) It is better to pray for the dead without following their funeral to cemetery and participating in their burial

(44) The condition for "E'atikaf "(worship in seclusion) is to be in a mosque

(45) I think Jihad (war) is part of faith

(46) It is part of goodness that we be kind to our youngsters and respect our elders

(47) I Feel showering happiness when I see children

(48) Whoever accompanies the believers will acquire their behavior

(49) Good treatment to servants spoils them

(50) I do not greet a neighbor who does not greet me

(51) One cannot live longer than what has been predetermined for him 
True False

(52) "Tell that who does not work sincerely, do not tire yourself" is a true statement

(53) Nothing prevents one from joking even when the joke is a lie

(54) Shyness is a socially undesirable behavior

(55) Arrogance is belittling others' performance and admiring one's own

(56) Adultery leads to decrease in belief .

(57) Envy is harmful to you mundanely and religiously

(58) Heaven and Hell are only symbolic concepts

(59) I consider the Holy Prophet (Mohammad) -peace be upon him- my greatest model

(60) Reading Quraan assiduously encourages one's thinking about the Universe

(61) I think it is an acceptable practice in religion to swear by God a lot

(62) I do not think that offering penance is necessary

(63) This life is a farming ground for the Hereafter, therefore it is necessary to be committed to God's sake

(64) It is better to offer sacrifices once every two years

(65) I feel uncomfortable when I visit a sick person in a hospital ....

(66) When a guest visits me, I offer a generous hospitality

(67) It is imperative that we reply to every greeting

(68) Sneezing is a bad habit

(69) I, most of the time, remove from the road what might cause harm to people 
True False

(70) Someone who is in need can use money that he is entrusted with

$\square \square$

(71) He who keeps his commitments in this time, is not fit to deal with people

(72) Humbleness draws one closer to people's hearts

$\square \square$

$\square \square$

(73) I think it is wise that we satisfy others in dealing with hem no matter what the motives are

$\square \square$

(74) I think it is necessary that people stand in respect for me when I enter a place

(75) One factor of hatred is anger

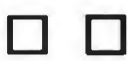

(76) It is one's right to punish one's self with death

$\square \square$

(77) It is better that a person shows the opposite of what he conceals 


\section{Appendix F}

\section{Items that were eliminated by judges from the original item pool}

1. I think a person can be happy and enjoy life without believing in God.

2. It does not matter whether a person is religious or not as long as he leads a straight life.

3. Some of the Islamic teachings are impractical in today's world.

4. It is necessary to modify some of the Islamic rules, so that Islam can be in harmony with the spirit of the time.

5. I think among the reasons for Muslims' backwardness today from the caravan of civilization is their adherence to the teachings of Islam and the directions of the Quraan.

6. Religion, as has been said, is "Opium of the people".

7. I refuse to let religious considerations influence my everyday affairs.

8. I do not think that religion is the most important thing in life.

9. Sometimes I find it necessary to compromise some of my religious convictions in order to adapt to the reality of life.

10. The role of the mosque should not exceed being a place for congregational worship.

11. At the present time, religion (or religiosity) should be the last thing one thinks about.

12. Some of the Islamic teachings can be considered among myths and superstitions.

13. I do not think that a religious person is happier in his life than a nonreligious person.

14. I often do things and make decisions without thinking about Islam's stand regarding them. 
15. I believe that this universe is controlled by a supreme power, but I am not sure if it is God.

16. The best answer to the question regarding God's existence is: "I do not know".

17. The idea of "God" or "a god" is unnecessary at the present civilized age.

18. Sometimes I have some doubt about the truth of God's existence.

19. The term "God" is an abstract concept like the term "nature" and similar terms.

20. I do not think that Quraan is completely devoid of some mistakes and contradictions.

21. I think the Human history is not devoid of persons who are better than Prophet Mohammad.

22. I think that Heaven and Hell are only symbolic concepts.

23. I think Islam has oppressed woman's rights.

24. I consider myself a religious person.

25. My general Islamic knowledge is good.

26. I think that my knowledge of "Shareah's" (Islamic law) teachings is above average.

27. The number of chapters in Quraan is 123.

28. All the chapters in Quraan start with (the statement) "In the Name of Allah, the Beneficent, the Merciful", except two.

29. The names of all prophets and messengers are mentioned in Quraan.

30. There is no difference -in the Sunnah's sect- between saying that Quraan is revealed or that it is created.

31. Pillars of Faith are the Pillars of Islam (five pillars).

32. For the comfort of a traveling Muslim, he is permitted to pray all five daily prayers (collectively) at one time of the day. 
Appendix G

\section{Gender-Neutral Scale Versions}

Islam provides many prescriptions for practice that are genderspecific. For example, the practice of attending prayer in a mosque is an obligatory requirement for a Muslim male, and should, therefore, be an indicator of a Muslim male's level of religiosity. But that does not apply to Muslim females because they are not required, or encouraged, to attend prayer in a mosque. Hence, although a low score on this kind of item indicates a low level of religiosity with respect to men, such a score does not mean the same for women.

Two of the scales used in the present study, "Religiosity Level Scale" (RLS) and "Muslim Religiosity Scale" (MRS), included items that were applicable for males only. Because both males and females respondents participated in the study, it was thought that such male-only items may not be good measures to use with both sexes. Therefore, it was deemed appropriate to generate gender-neutral versions of these two scales.

From RLS a new version named RLSV2 (V2 stands for version 2) was created by eliminating from RLS items that were appropriate only for male respondents but not for females. Eight items (\# 9, 10, 22, 42, 43, 48, 49 , and 53, see Appendix D), which asked about group prayers, prayer in a mosque, mixing with a nonrelative woman, shortening clothes above the ankle, wearing Gold and Silk, participating in Jihad, shaving one's beard, and looking at a nonrelative woman; respectively, were dropped from RLS to create the new version (RLSV2). The concepts that were represented by 
these items are, in the Islamic religious system, applicable, or appropriate, only for males. All eight items were dropped on this ground.

Many of the statistical and psychometric analysis procedures that were performed on the three major scales "Muslim Religiosity Scale" (MRS), "Religiosity Level Scale" (RLS), and "Religious Behavior Scale" (RBS), were also performed on the additional version that was created out of the RLS. The results of the analyses done on this version were very similar to those of the original scale. For example, comparisons of PCA solutions for RLSV2 with the corresponding ones for RLS revealed that results of the two scales' PCAs were, generally, similar in their overall patterns. A noticeable difference, however, was that RLS's PCA had a unique factor which emerged on three of the RLS's solutions. This factor, or component, consisted, repeatedly, of the same four items, which were among the eight items that were eliminated from RLSV2.

Specifically, examination of the solutions suggested by the MAP rule (5-factor solution for RLS, and 3-factor solution for RLSV2), showed that six of the eight items eliminated from RLSV2 appeared on the resulting subscales of RLS. Three of these six formed a separate component, Factor 5 of RLS (see Table 3), two (\# 49 and 53) loaded on Factor 2, and one (\# 48) loaded on Factor 1.

Other results of the RLSV2 are very similar to, and generally in the same directions as, those of the RLS, making the new version of little significance. Based on that, and also to avoid possible confusing results in correlations and MANOVA procedures, that might appear due to the confounding effects of including similar versions, it was judged that the 
new version should not be kept for further application or discussion in the study.

In the Muslim Religiosity Scale (MRS) there were two items (\# 30 and 88, see Appendix C) which were appropriate for males only, asking about attending prayer in a mosque. These two items were eliminated from the MRS and a new version was created. However, there were no significant differences between this version and the original one in all analyses performed on the two. The new version (of the MRS) was, subsequently, discarded early in the analyses. These two items did not load on any factor in the MRS's PCA selected solution. 


\section{Appendix $\mathrm{H}$}

\section{Questionnaire \# "1" (Arabic Version)}

\section{الإستباتة رقم "1"}

العبار ات التالية معدة للتعبير عن الرائي تجاه بعض القضايـا الدينية أو وصف مدىى

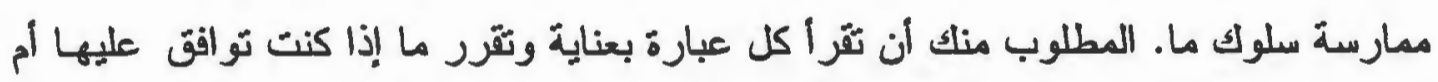

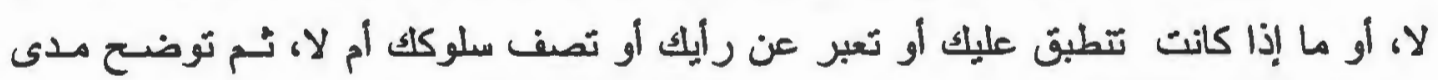

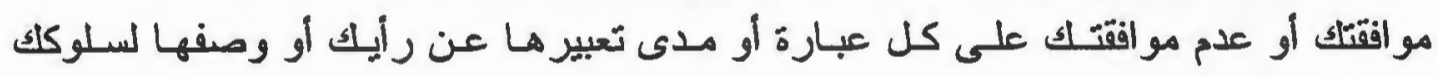

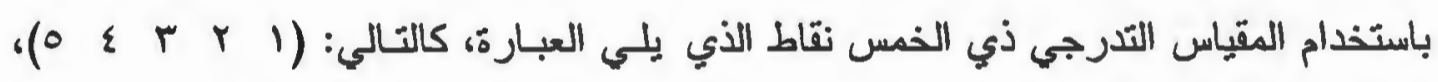

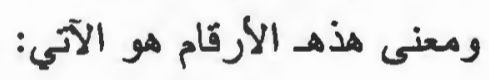

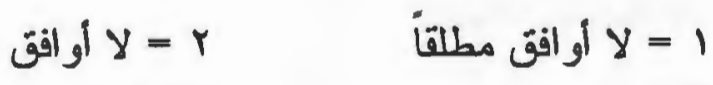

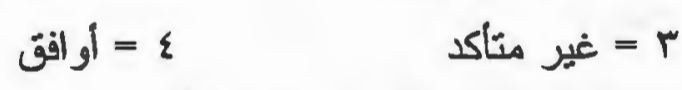

$$
\begin{aligned}
& \text { o = أوافق تماماً }
\end{aligned}
$$

فئلاً إذا كنت توافق على العبارة أو ترى أنها معبرة تمامـاً عن رأيك، ضـع دائرة

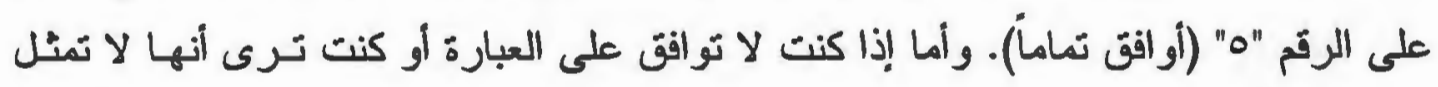

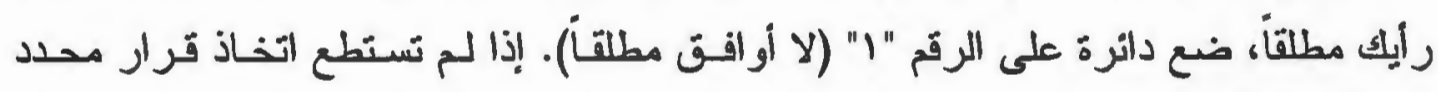

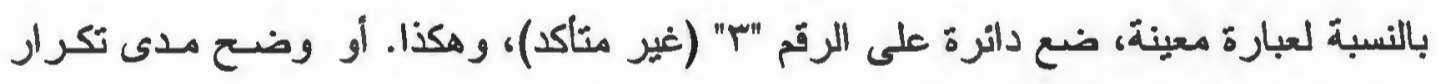

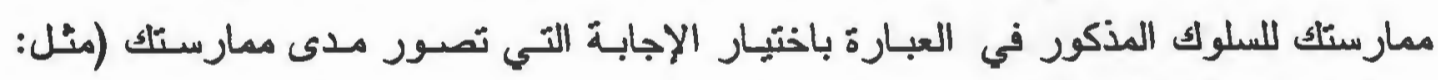

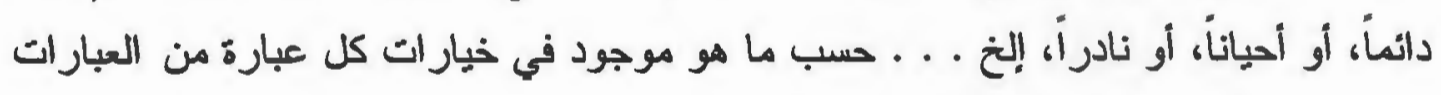
التي تصف الممارسة).

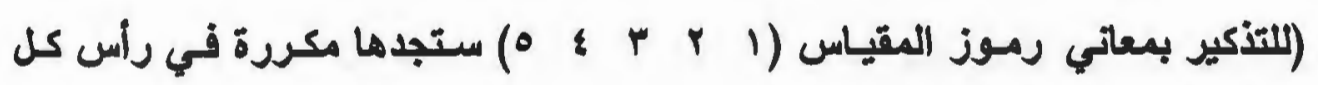
صفحة من قائمة العبارات). الرجاء عدم ترك أبي عبارة دون إجابة.

الاستباتة رقم "ا" .... صفعة (1) 


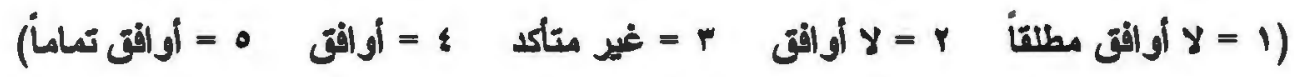

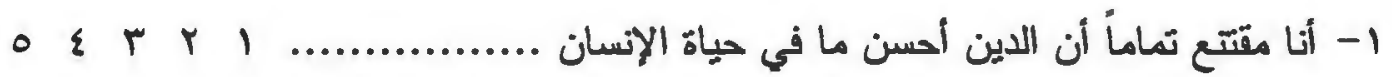

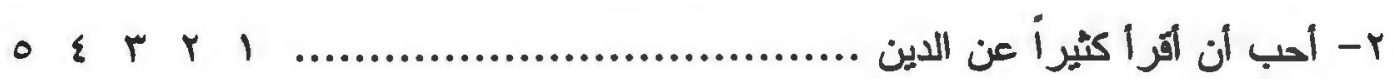

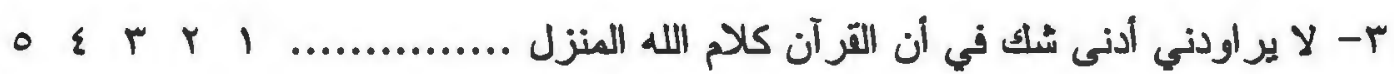

ع- أؤمن بوجود الملانكة ..............................................

ه- لو سنحت لي الفرصة لقرأت القرآن كل يوم ........................

T- تز عجني محاولة ربط الدين بكل شؤون الحياة اليومية للفرد ...........

- V - إنتي أحرص على ترديد ذكر الله:

1- 1 دائماً

r- أحياناً

r- با أستطيع التحديد

أن

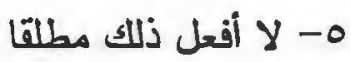

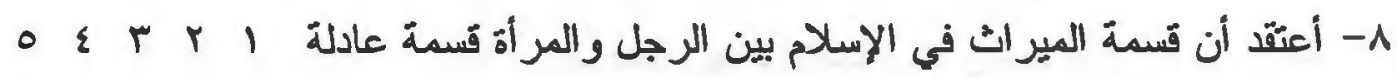
9- الإيمان برسالة محمد ضروري للنجاة من عذاب النار ................ • 1 - أتصدق على الفقر اء المحتاجين حقاً: أو دائمان

r

r- r أسنطبع التحديد

i

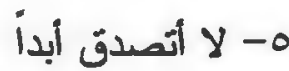

1

الاستبتة رقم " ا" .... صفحة (Y) 


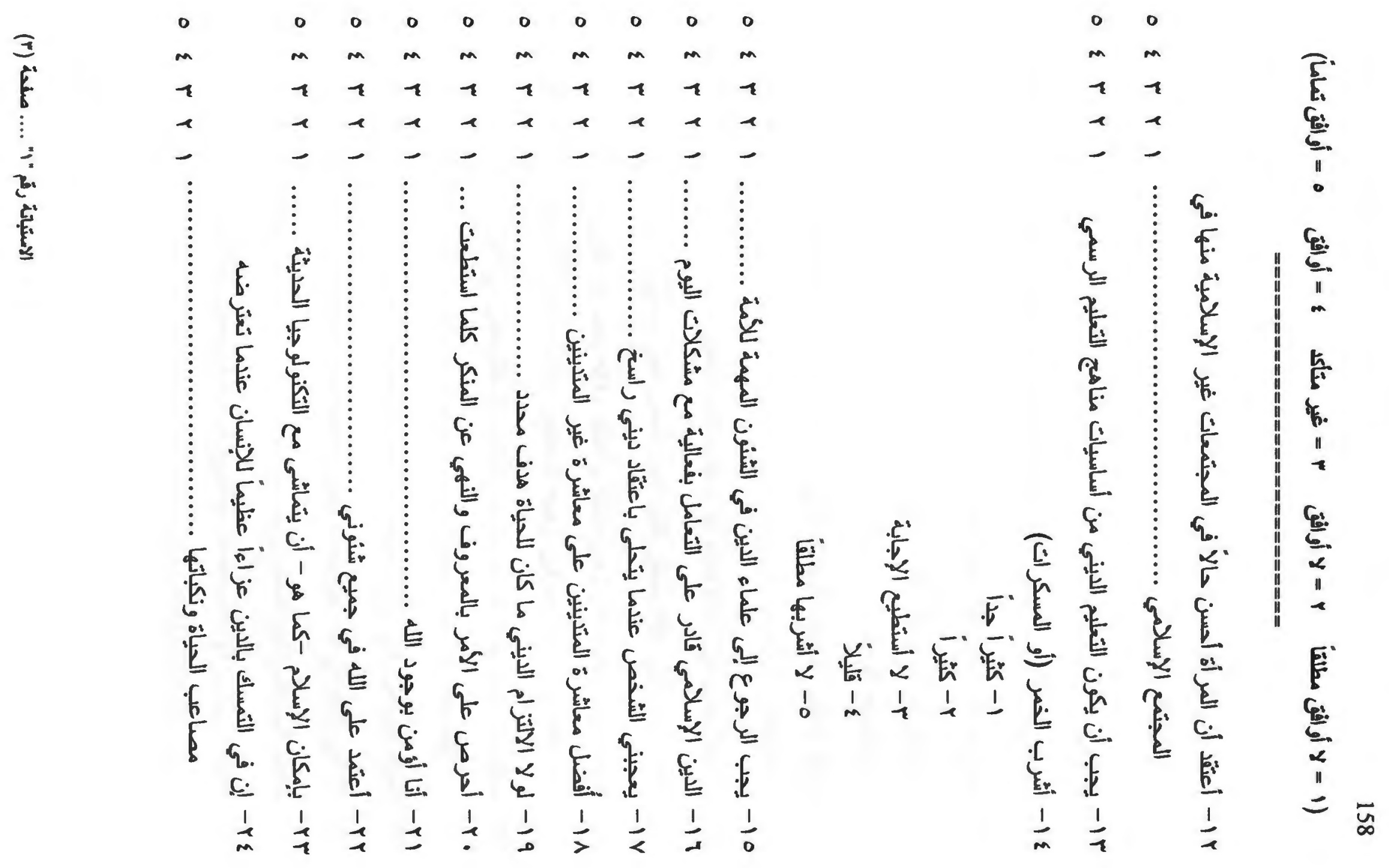




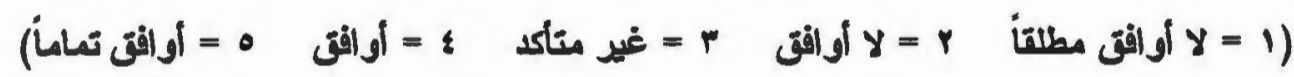

هب- أعنقد أن هذا العالم سيكون أحسن حالاًّلو أن كل الناس آمنوا

- \& r $\quad$ I

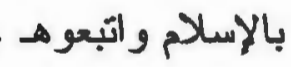

Tr- يغمرني إحساس بالسعادة والراحة كلما أديت واجباً دينيا .............

- $\varepsilon r r 1$ ب - يسعدني أن أنفق من مالي على ما فيه خدمة للإسلام $0 \leqslant r<$ ^ 1 الدين يساعد على حفظ الحياة متزنة ومستقرة . وץ- أرى أن أي بلد يعتق ديناً ما يجب أن يجعل هذا الدين مصدر 0 \& r r

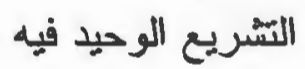

• r- إن لم تمنعني ظروف قاهرة، فإنني حتماً ساذهب إلى المسجد لكل

- \& r 1 صلاة

0 $\varepsilon r r 1$ ا آr- لا شُك عندي في أن الإسلام هو وحده الدين الحن - \& r r rr- أشعر أن ايماني بالله يضفي كثيراً من المعنى على حياتي ............ rr- مع ما يجب لعلماء الدين من مكانة واعتبار، فإنه يجب أن تكون 0 $\varepsilon r r 1$

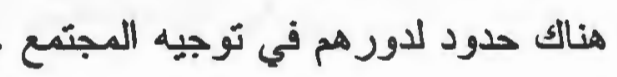
عَ- أعتقد أنه يجب على المسلم أن يتبع تعاليم الإسلام حتى في أدق

- \& r r التفاصبل في شُون حياته

0 $\varepsilon r r$ هr- أحب المجالس التي يكون موضوع الحديث فيها عن الدين

- $\varepsilon r r$ وr- لا غنى للإنسان أبداً عن معتقد ديني يضبط مسيرة حياته .. $0 \& r$ r r r - معظم أصدقاتي من المتدينين هץ- يجب أن يكون الاسلام مصدر التشريع الوحيد في جميع السئون 0 $\varepsilon r r 1$ في البلاد الإسلامية

الاستباتة رتم " ا" .... صعدة (§) 


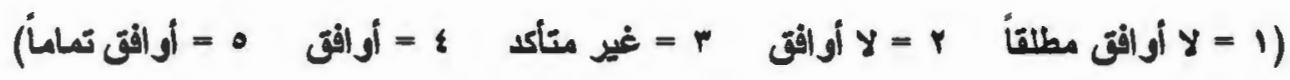

9"- أومن بانه سيكون هناك يوم حساب، حيث يحاسب كل إنسان على

$0 \leqslant r \quad r$

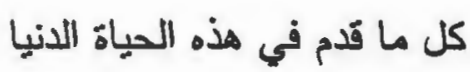

• ع أداء الصلوات المفروضة جزء ثابت من سلوكي اليومي ................

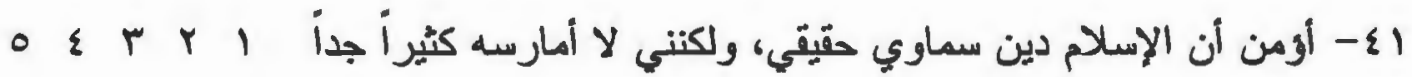

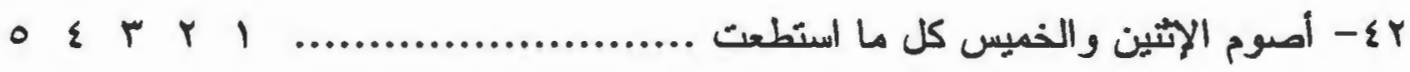

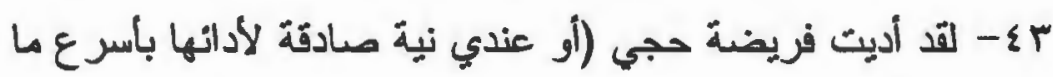

$0 \leqslant r$ r

يمكن)

ع - أعتمد أن توزيع الإسلام للحقوق والواجبات بين الرجل والمرأة

$0 \&$ r $r$ توزيع مناسب

$0 \varepsilon r$ r 1

هـ- أومن أن محمداً رسول الله حقاً .

ح - في المجتمع الإسلامي يجب أن تكون الكلمة الأولى والأخيرة

$0 \varepsilon r r 1$

لعلماء الدين الزين

P أحاول جاهذاً إذخال ديني في كل معاملاتي الأخرى في الحياة .....

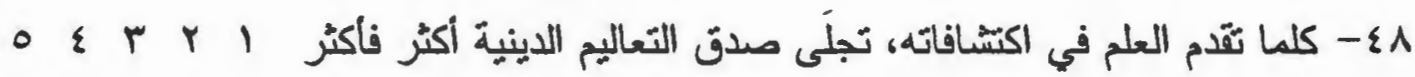

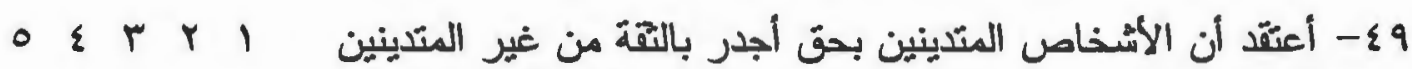

$$
\begin{aligned}
& \text { •- أتعاطى المخدرات: } \\
& \text { 1- كثيراً جداً } \\
& \text { r- كثيراً } \\
& \text { ك- كا لأستطيع الإجابة } \\
& \text { ع- قليلاً } \\
& \text { ه- لا أتعاطاها مطلقاً }
\end{aligned}
$$

|الاستباتة رقم "1" .... صلعة (0) 


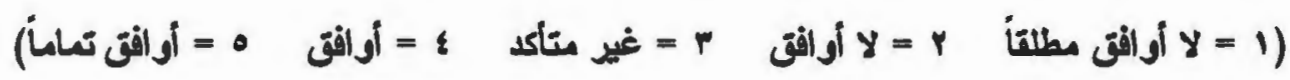

o $\varepsilon r r 1$ 10 الاين مهم جداً بالنسبة لي

ror أعثقد أن نقص الوازع الديني هو أهم سبب في مشكلات المسلمين

- $\varepsilon r r 1$ اليوم

ror- لكي يحقق العلم خدمة للبُّرية لا بد له من ضوابط دينية تحكم - $\varepsilon r r 1$ خطواته

عه- أرى أن المتدينين -في أي مجتمع أو أي دين- أفضل من غير - $\varepsilon r r 1$ المتدينين - \& r 1 هـ- محبتي لله تفوق محبتي لأي إنسان أو أي شيء آخر $0 \leqslant r r 1$ 4ه- أومن أن مصير كل إنسان بيد الله VV إنتي أستسعر وأفكر في مراقبة الله لي في تصر فاتي: 1 - 1 دائما r- أحياناً r- r أستطيع التحديد i 0- لا أفكر في ذلك مطلقاً

^ه- الواجب الأساسي على كل إنسان هو طاعة الله وعبادته ............. 9ه- لا يمكن لبشر أن يعيش سوياً دون الإيمان بالله ......................

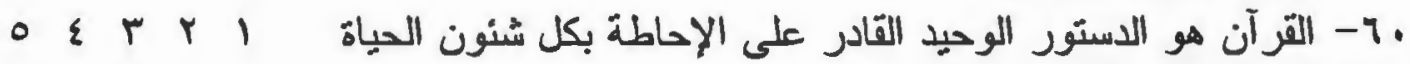

|لامتباتة رقم "ا" .... صلحة (1) 


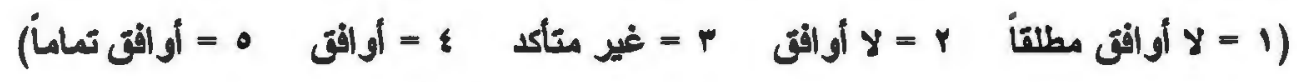

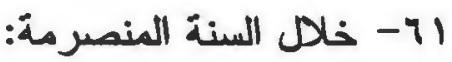

ا- ختمت القرآن أكثر من مرة

r- بتمت القر آن مرة واحدة

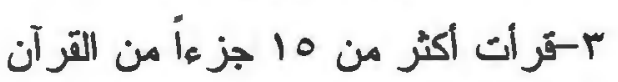

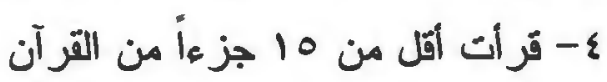

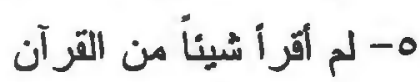

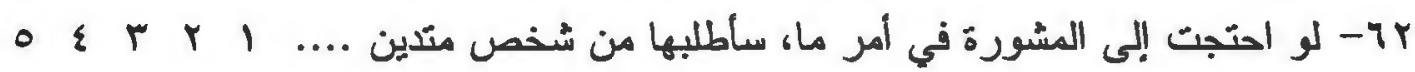

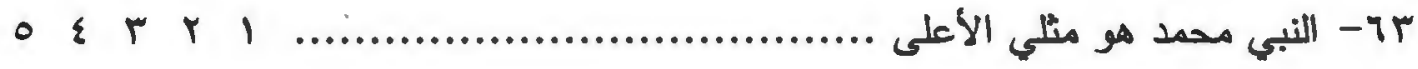

ع ع- أومن بأن رسالة محمد جاءت للناس كافة ..........................

ه - أؤمن بجميع الرسل السابقين لمحد ....................................

r

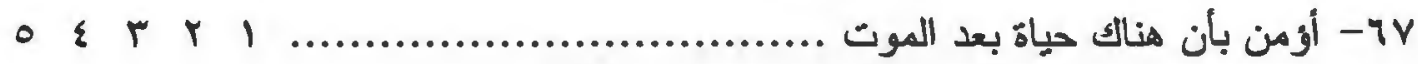

14- أؤمن بجميع الكتب المنزلة السابقة للقر آن .............................

ه

•

ا أو - أومن بقدرة الشيطان على إغواء الإنسان ...........................

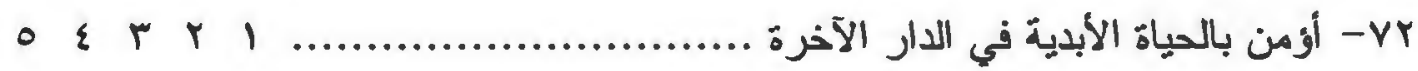

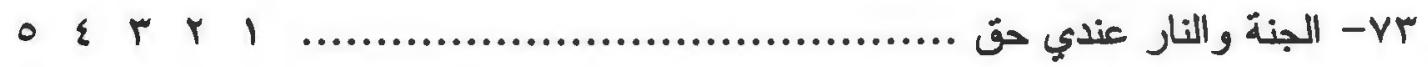

الاستباتة رقّ " ا" .... صلحة (v) 
(1 = لا أوافتى مطلتاً

$$
\begin{aligned}
& \text { ع - أودي صلاة الوتز : } \\
& \text { ا- كل ليلة }
\end{aligned}
$$$$
\text { r- أكثر من ثلاث مرات في الأسبوع }
$$

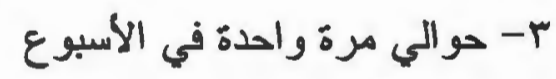

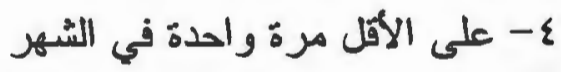$$
\text { - أو أوديها أبدا }
$$

$$
\begin{aligned}
& \text { هV- أصلي النوافل: } \\
& \text { ا- } \\
& \text { r- أحياناً } \\
& \text { r- لا أستطيع التحديد } \\
& \text { ع- نادراً } \\
& \text { 0- لا أصليها أبداi }
\end{aligned}
$$

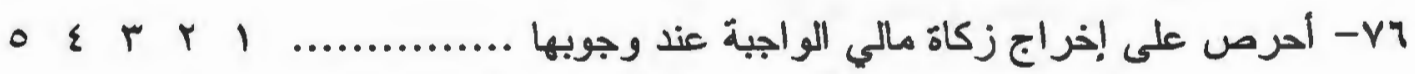
منذ بدأتُ أصوم رمضان لم أفطر عمدأ في حياتي مطلقاً دون - $\varepsilon r r 1$ عذر شرعي - $\varepsilon r r$

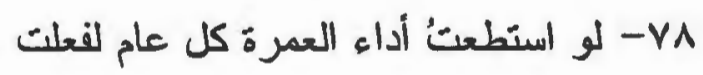
- V9 - إن دافعي الأول إلى الحرص على زيارة أترباتي وأصدقاتي هو - $\varepsilon r r 1$ غالباً طلب مرضاة الله سبحانه

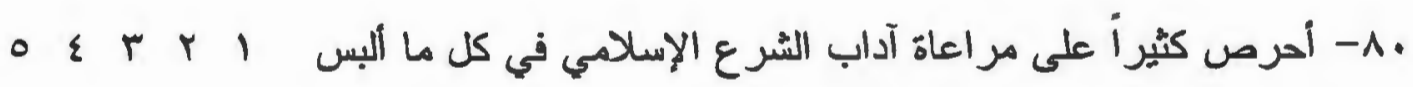
ا 1- لا بد من إعادة النظر في وضع المر أة المسلمة تمشيّاً مع الحياة - $\varepsilon r r 1$ العصرية

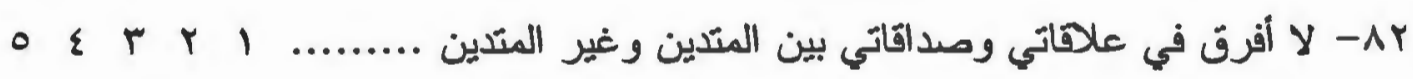
الاستبّاتة رقم " " ..... صفحة (1) 


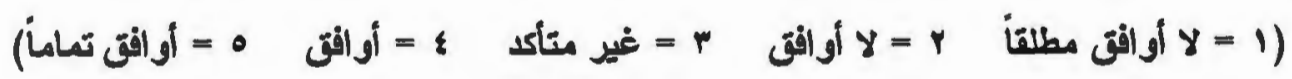

ب ب يزعجني تدخل علماء الدين في ما صغر وكبر من قضايا الأهة .... ع 1- لا أرى حاجة لوجود ما يسمى هينات الأمر بالمعروف والنهي عن

- $\varepsilon r r 1$ المنكر

هـ- بجب المساواة بين الرجل والمرأة في كل شيء حتى في الميرات - E r 1 والشهادة .

جی- أرى أهمية مشاركة المرأة في كل مجالات الحياة بما في ذلك تولي - $\& r$ r 1 المناصب القيادية السياسية . - E r $r$ -AV الصلي ركعتي الاستخارة عندما أهم باتخاذ قرار مهم . 11 خلال الشهر المنصرم حضرت صلاة الفجر في المسجد: ا- أكثر من عشرين مرة Y- بين عشر مرات وعشرين مرة من مرة r- بين خمس وعشر مرات ع- أقل من خمس مرات 0- لم أحضر ها ولا مرة من مرات

الاستبانة رتم "1" .... صفحة (9) 


\section{Appendix I}

Questionnaire \# "2" (Arabic Version)

\section{الاستباتة رقم "r"}

ينكون هذا المقياس من عدة عبارات حول موضوعات مختلفة، وقد أعطي لكل عبارة

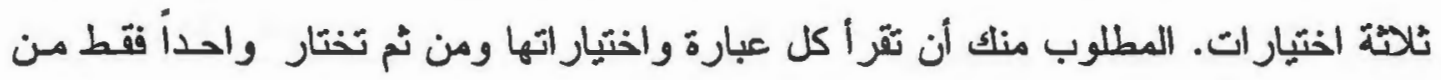
الاختيار ات الثُاثة وتضع دائرة على رقم ذلك الاختيار (أ، ب، ج).

الاستباتة رتم "צ" .... صفحة (1) 


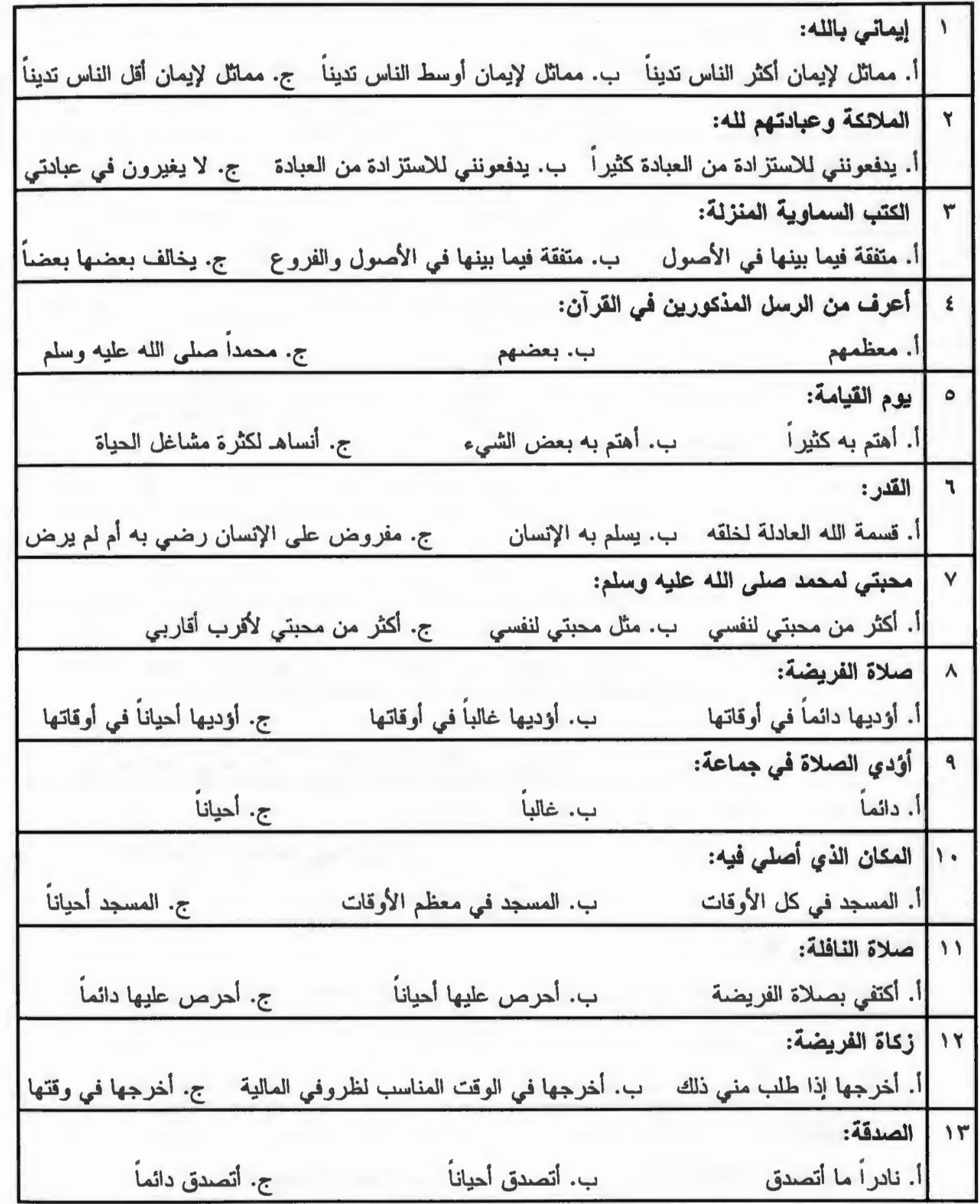

الامتباتة رتم "r" .... صفحة (Y) 


\begin{tabular}{|c|c|}
\hline أ. في رمضان: أسلوب حياتي كما هو عليه في غيرهـ & $1 \varepsilon$ \\
\hline أ صيام التطوع: & 10 \\
\hline أ الـ أنج: أنكر فيه الآن & 17 \\
\hline أ أ. لا أنكرة فيها الآن & iv \\
\hline 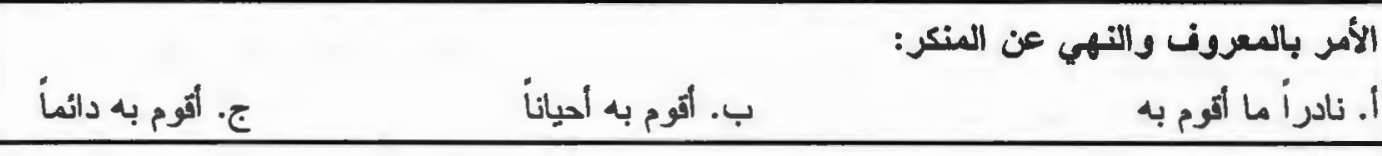 & 11 \\
\hline أ. ناعة الو الدين: & 19 \\
\hline 1. أتكاسل الأرحام: & $r$. \\
\hline 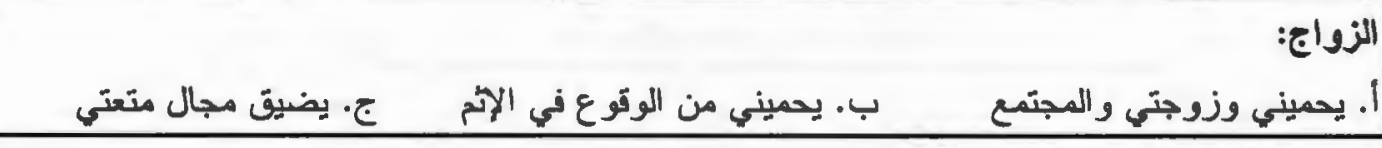 & Y \\
\hline أ. ألتوم بهلاط بالمرأة الأجنبية: & rr \\
\hline أ. أخذ الربح على المال من البنوك: أجد فيه بعض الفائدة & $r r$ \\
\hline ج. أشربها غالباً لأسعر بالنشوة & $r \leqslant$ \\
\hline أو أوداء الشهادة: & rop \\
\hline
\end{tabular}

الامتياتة رقم "Y" .... صفحة (r) 


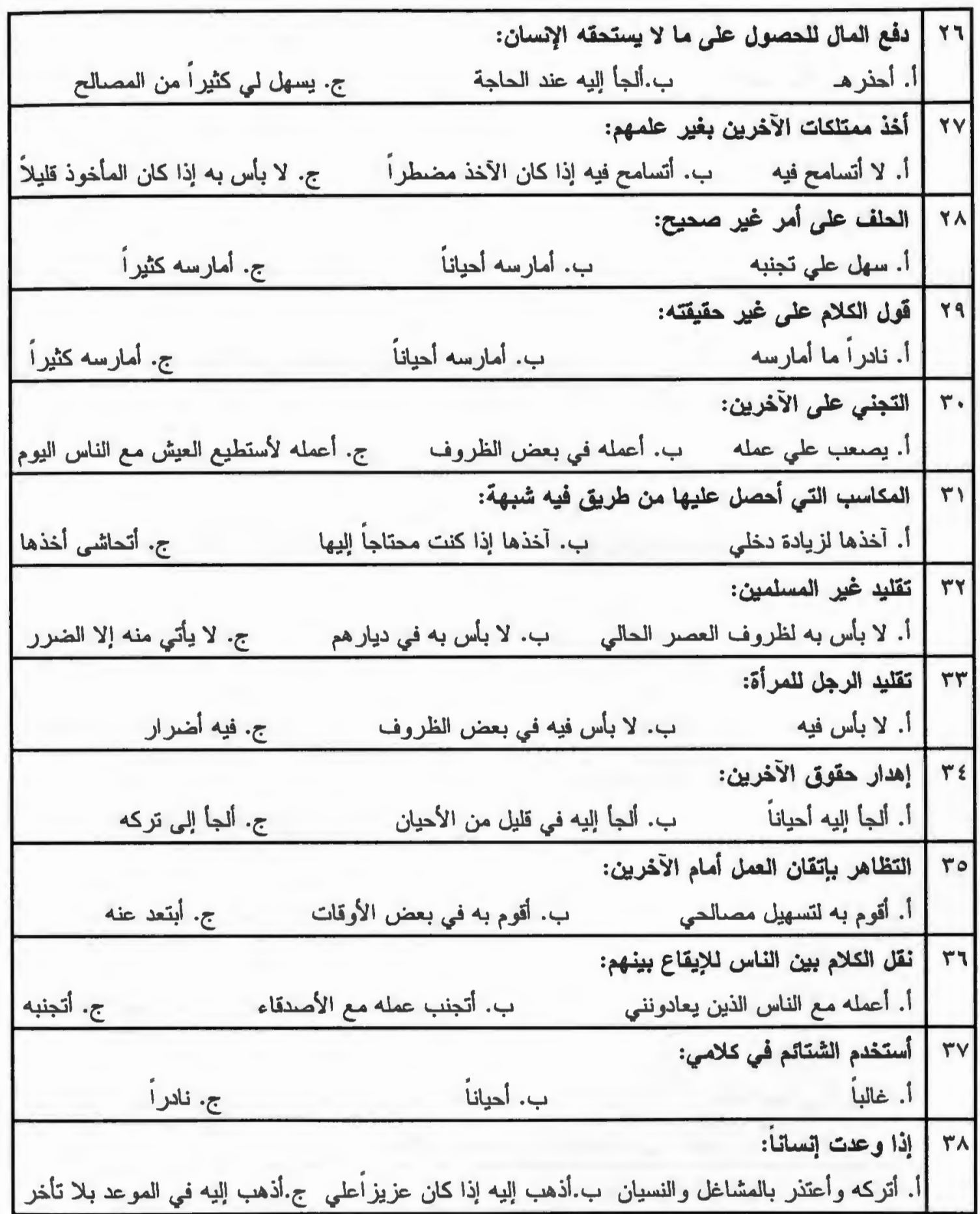

الاستباتة رتم "r" .... صعة (i) 


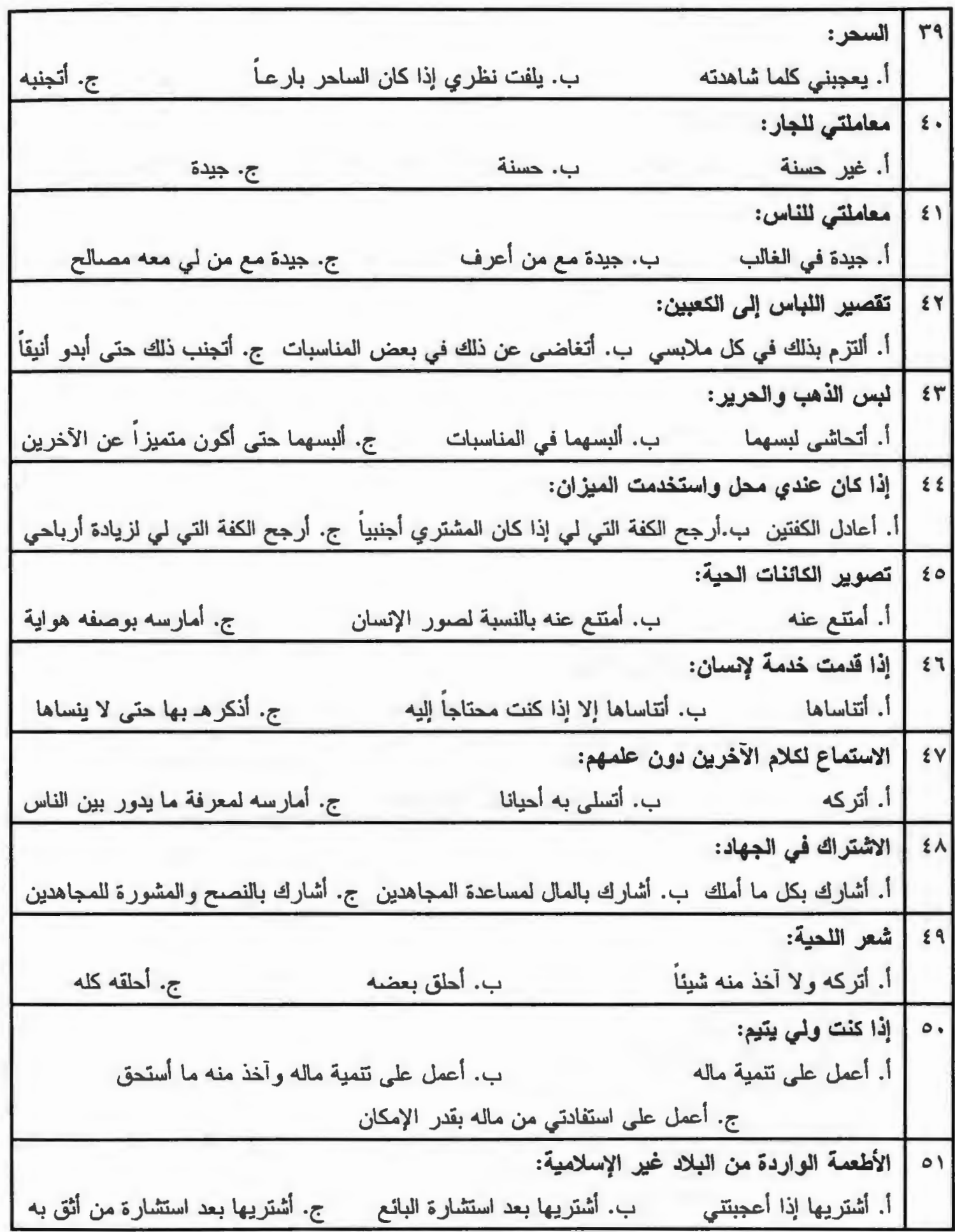

الامتباتة رقم "צ" .... صفحة (0) 


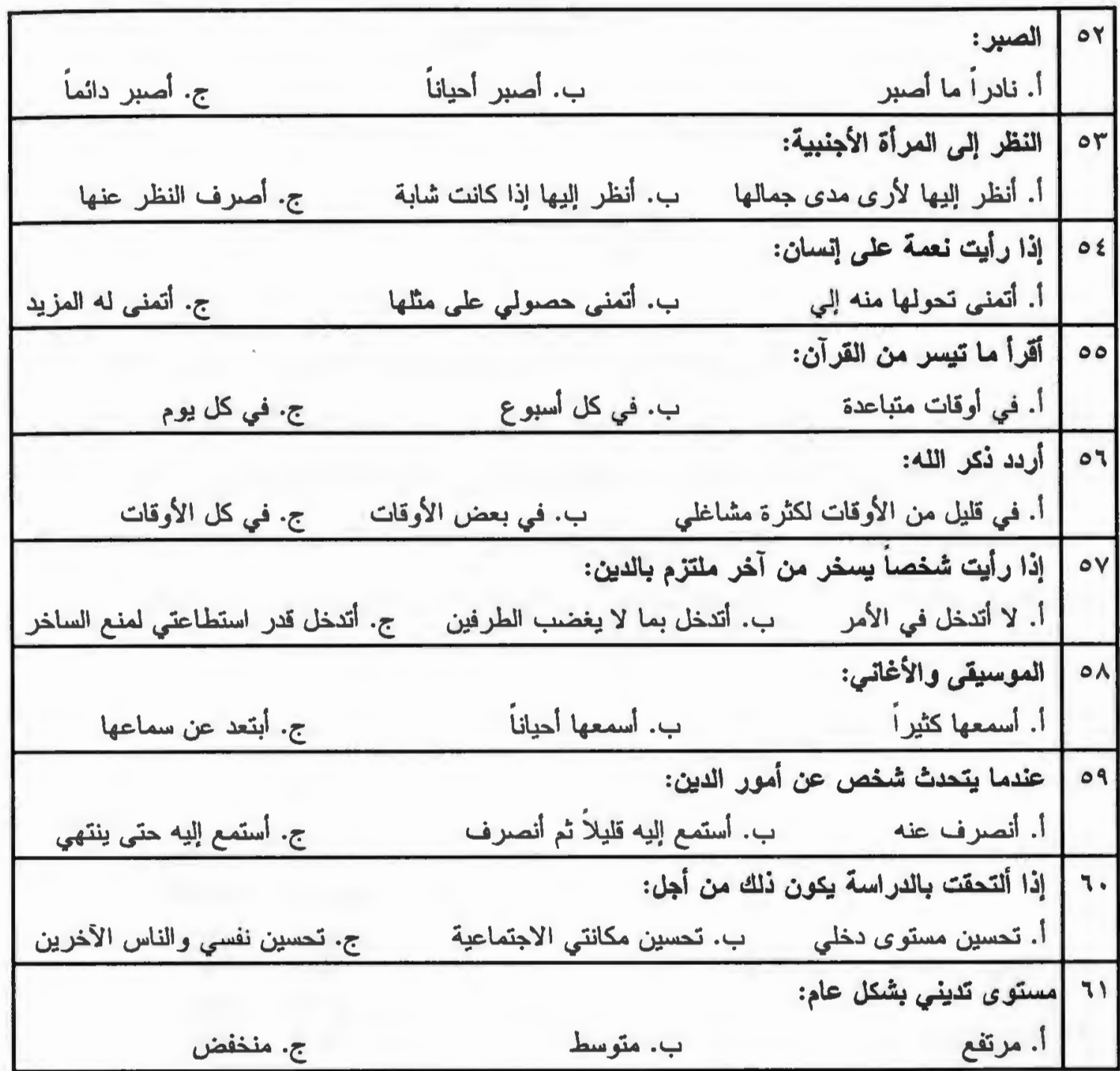

الاستهاتة رقم "ץ" .... صفحة (1) 


\section{Appendix J}

Questionnaire \# "3” (Arabic Version)

\section{الاستباتة رقم "r" - م"}

يهدن هذا المقياس إلى معرفة سلوك الأفر اد نحو بعض القضايا الاجتماعيـة المتعلقة

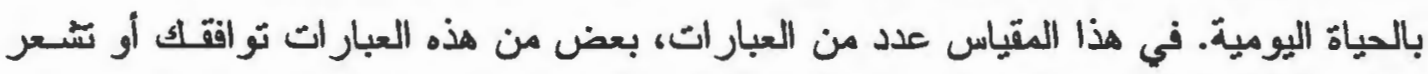

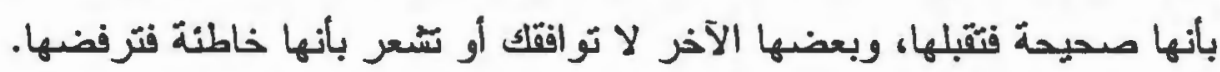

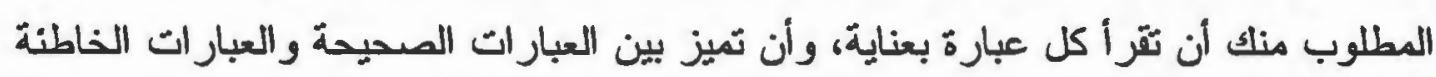
وأن تضع علامة (x) تصت الاجابة المناسبة في المكان المخصص على بسار العبارة.

$$
\text { الاجابة }
$$

مثال:

صحيحة خاطئة

$\square \quad \mathrm{X}$

ا- الإيمان بالله يمنح الطمانينة

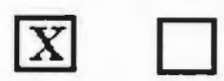

العبارة:

يرجى الإجابة على جميع العبارات دون ان ترك إحداها وفي حالة عدم القدرة على القى إعطاء استجابة محددة، خمن الإجابة لاحد البديلين (صحيحة أو (خاطنة).

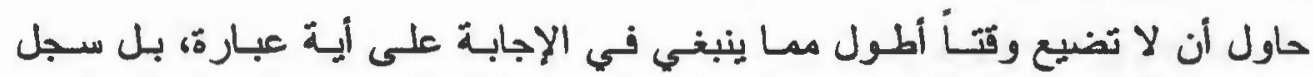

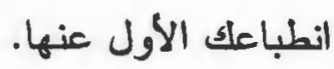

الاستبانة رقم "r" .... صفحة (1) 


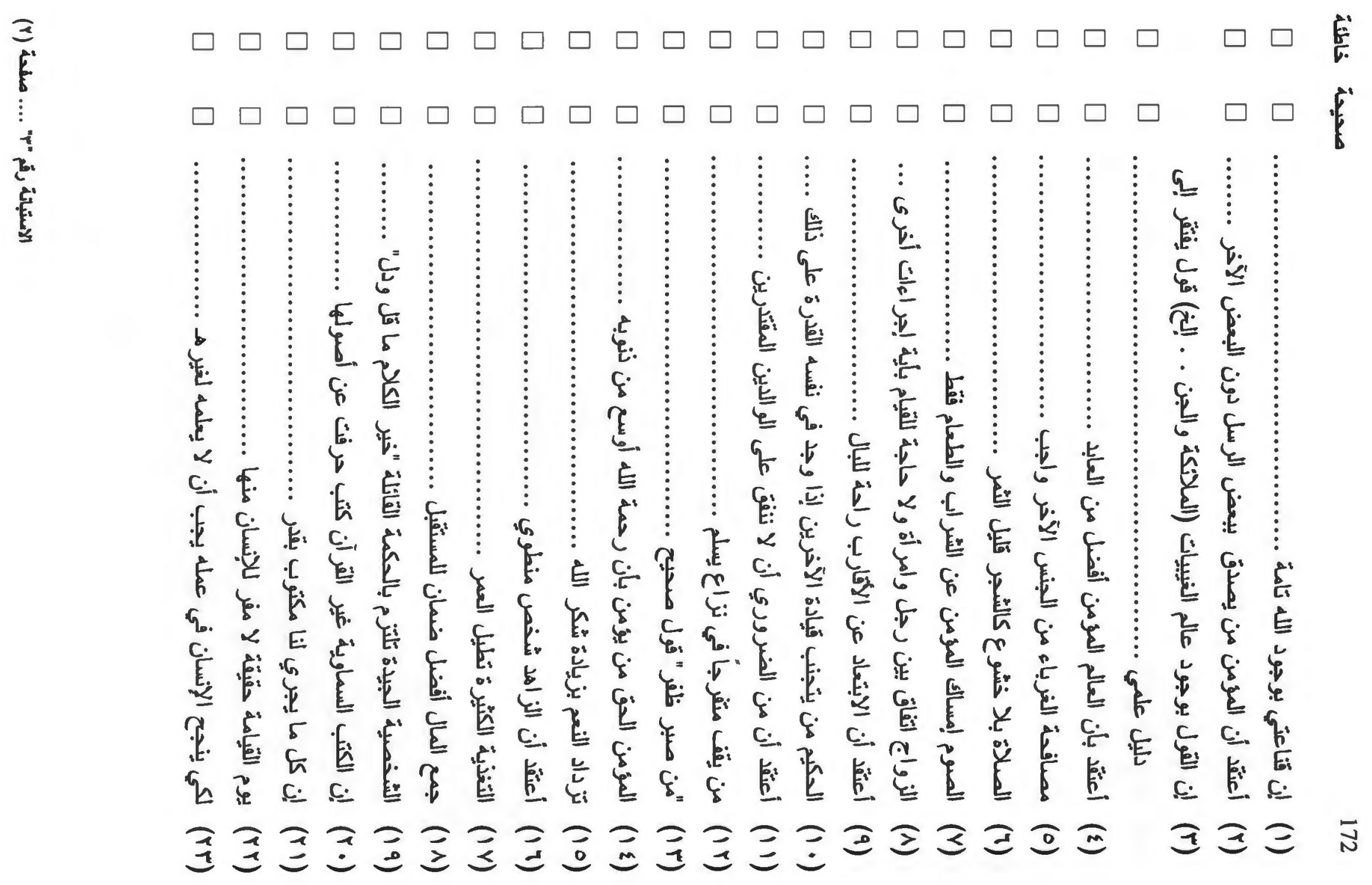


$\begin{array}{ll}\square & \square \\ \square & \square \\ \square & \square \\ \square & \square \\ \square & \square \\ \square & \square \\ \square & \square \\ \square & \square \\ \square & \square \\ \square & \square \\ \square & \square \\ \square & \square \\ \square & \square \\ \square & \square\end{array}$ لا تتعارض تربية الكلاب مع الإيمان .إن

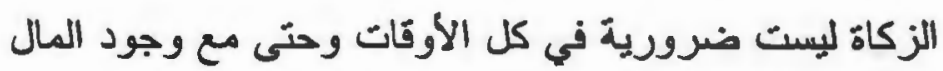
الحج هجرة إلى الله من الواجب أداوهـ

(YV)

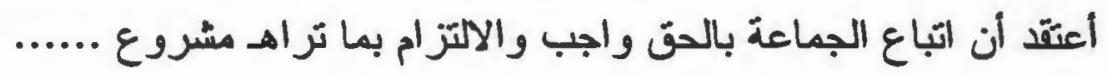
أساس التعاون بين الناس بعتمد على الأعمال الخيرة

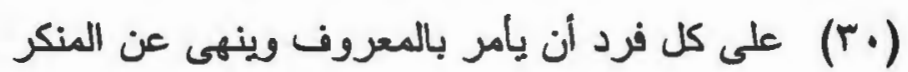

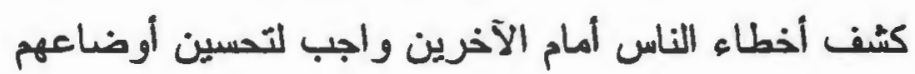
الرجاء سراج العبادة .

"الخوف من الأشياء يبعدك عنها إلا الخوف من الله فيقربك إليه" .......

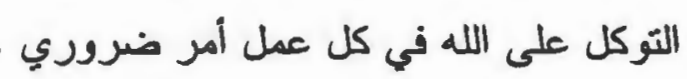

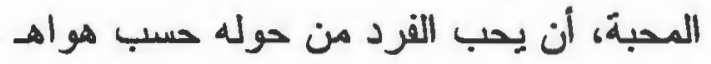

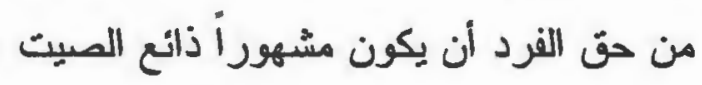
الانيا حلوة فلا بد من الحرص بل عليها الممسكون لأنفهم لحظة الغضب أقدر الناس على مواجهة المواقف

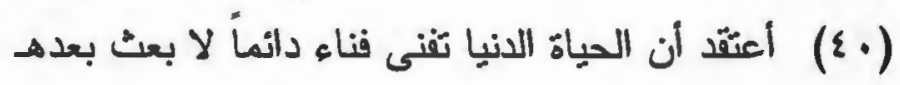

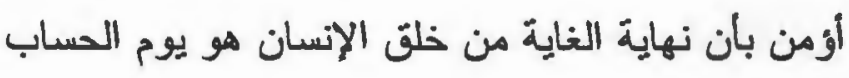

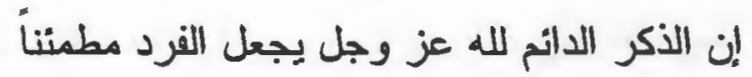
الأفضل أن نصلي على الجنازة دون متابعتها والقيام بامر الافن . من الخير أن نعطف على صغارنا ونحترم كبارنا ... 


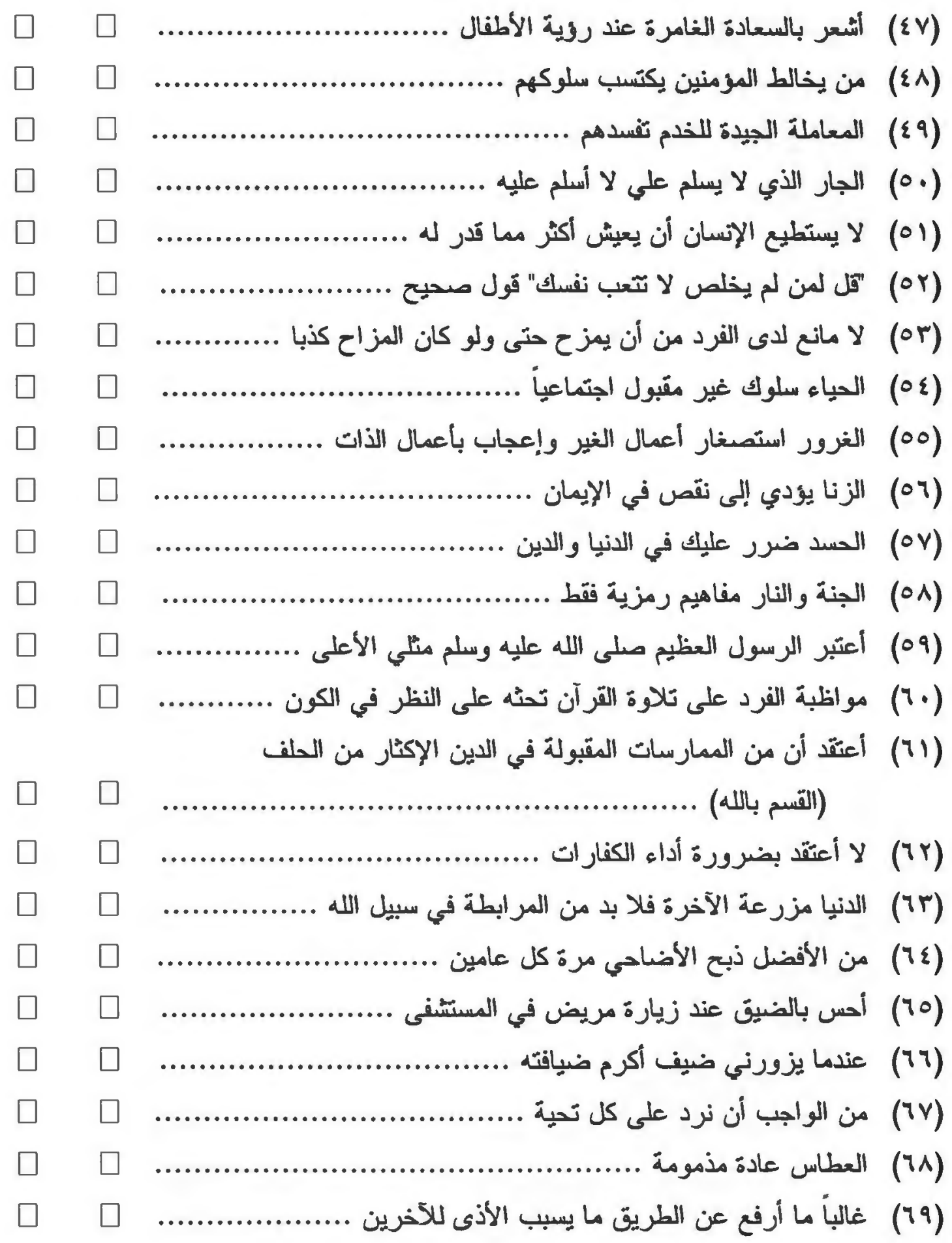

الاستباتة رقم "ه" .... صلحة (8) 


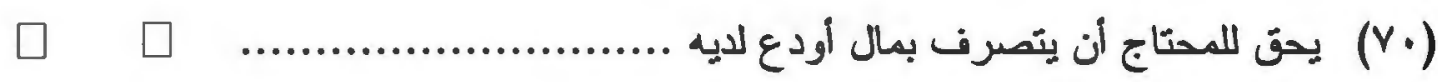

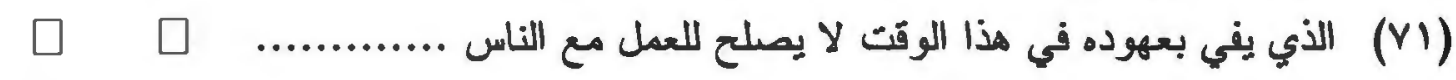

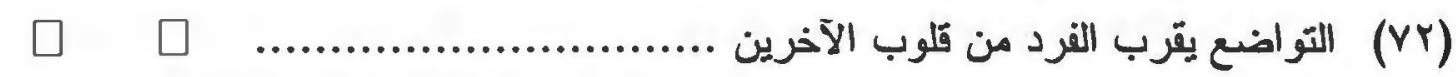

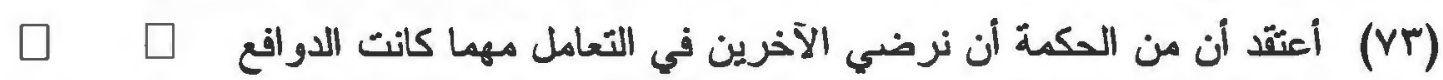

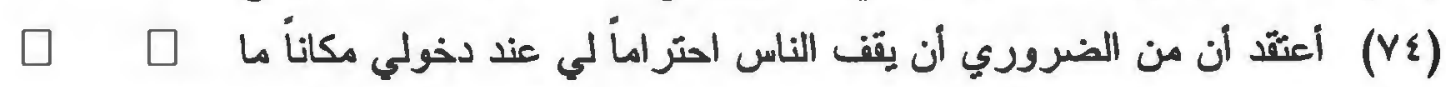

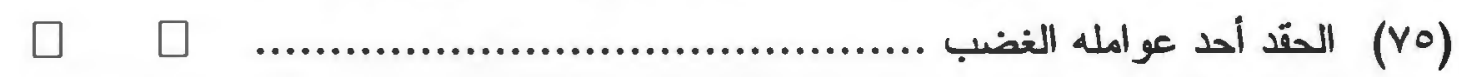

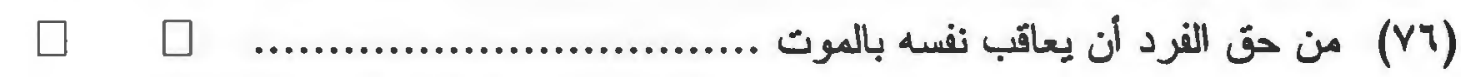

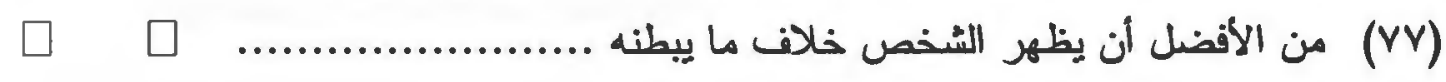




\section{Bibliography}

Aguinis, H., \& Aguinis, M. (1995). Integrating psychological science and religion. American Psychologist, 50, 541-542.

Albehairi, A. A., \& Demerdash, A. (1988). Meqyas alwaai addeeni [Religious orientation scale]. Cairo, Egypt: Egyptian Renascence Bookstore.

Albelaikhi, A. A. (1988). Religious orientation and fear of death among Muslim and Christian individuals. Unpublished manuscript, University of Rhode Island, Psychology Department, Kingston.

Ali, A. (1988). Scaling an Islamic work ethic. The Journal of Social Psychology, 128, 575-583.

Allport, G. W. (1950). The individual and his religion: A psychological interpretation. New York: Macmillan.

Allport, G. W. (1959). Religion and prejudice. Crane Review, 2, 1-10.

Allport, G. W., \& Ross, J. M. (1976). Personal religious orientation and prejudice. Journal of Personality and Social Psychology, 5, 432-443.

Alsanie, S. I. (1989). Alalaqato bayna mustawa attadayyon wa assolook alejrami [Relationship between level of religiosity and criminal behavior]. Unpublished doctoral dissertation, Imam Mohammad Ibn Saud Islamic University, Saudi Arabia.

Alston, J. P. (1975). Review of the polls: Three measures of the current levels of religiosity. Journal for the Scientific Study of Religion, 14, 165-168.

Arbuckle, D. S. (1975). Counseling and psychotherapy: An existential-humanistic view (3rd ed.). Boston: Allyn and Bacon.

Arnold, J. D. (1985). Psychology of religion: Placing paradigm in a historical and metatheoretical perspective. American Psychologist, 40, 1060-1062.

Balk, D. E. (1988, August). Resolution of sibling death during adolescence: Interaction with religion. Paper presented at the annual convention of the American Psychological Association, Atlanta, GA.

Basinger, D. (1990). The measurement of religiousness: Some "philosophical" concerns. Journal of Psychology and Christianity, 9, 5-13. (from Psychological Abstracts, 1990, 77, Abstract No. 30756). 
Beg, M. A., \& Zilli, A. S. (1982). A study of the relationship of death anxiety and religious faith to age differentials. Psychologia, 25, 121-125.

Bergin, A. E. (1991). Values and religious issues in psychotherapy and mental health. American Psychologist, 46, 394-403.

Boivin, M. J., Donkin, A. J., \& Darling, H. W. (1990). Religiosity and prejudice: A case study in evaluating the construct validity of Christian measures. Journal of Psychology and Christianity, 9 41-55. (From Psychological Abstracts, 1990, 77, Abstract No. 29824).

Booth, H. J. (1981). Edwin Diller Starbuck: Pioneer in the psychology of religion. Washington, D. C., University Press of America.

Brown, D. G., \& Lowe, W. L. (1951). Religious beliefs and personality characteristics of college students. The Journal of Social Psychology, 33, 103-129.

Brown, L. B. (1987). The psychology of religious belief. London: Academic Press.

Butman, R. E. (1990). The assessment of religious development: Some possible options. Journal of Psychology and Christianity, 9, 14-26. (From Psychological Abstracts, 1990, 77, Abstract No. 30758).

Carroll, J. W., \& Roozen, D. A. (1973). National sample questions on religion: An inventory of material available from the Roper Public Opinion Research Center. Journal for the Scientific Study of Religion, 12, 325-338.

Chaplin, J. P. (1982). Dictionary of psychology. New York: Dell Publishing.

Cline, B. C., \& Richards, J. M. (1965). A factor-analytic study of religious belief and behavior. Journal of Personality and Social Psychology, 1, 569-578.

Comrey, A. L. (1973). A first course in factor analysis. New York: Academic Press.

Comrey, A. L. (1988). Factor analytic methods of scale development in personality and clinical psychology. Journal of Consulting and Clinical Psychology, 56, 754761.

Cox, B. L. (1995). Belief versus faith. American Psychologist. $50,541$.

Cureton, E. E., \& D'Agostino, R. B. (1983). Factor analysis: An applied approach. Hillsdale, New Jersey: Lawrence Erlbaum.

Degelman, D., \& Lynn, D. (1995). The development and preliminary validation of the belief in divine intervention scale [CD-RAM]. Journal of Psychology and Theology 23, (1), 37-44. Abstract from: SilverPlatter File: PsycLIT Item: 8239315 
DeVellis, R. F. (1991). Scale development: Theory and applications. (Sage University Paper Series on Applied Social Research Methods, series no. 26). Newbury Park, CA: Sage

Dittes, J. E. (1971). Two issues in measuring religion. In M. P. Strommen (Ed.), Research on religious development: A comprehensive handbook (pp. 78-106). New York: Hawthorn Books.

Donahue, M. J. (1985). Intrinsic and extrinsic religiousness: Review and meta-analysis. Journal of Personality and Social Psychology, 48, 400-419.

Dynes, R. R. (1955). Church-sect typology and socio-economic status. American Sociological Review, 20, 555-560.

Feagin, J. R. (1964). Prejudice and religious types: A focused study of Southern Fundamentalists. Journal for the Scientific Study of Religion, 4, 3-13.

Florian, V., \& Kravetz, S. (1983). Fear of personal death: Attribution, structure, and relation to religious belief. Journal of Personality and Social Psychology, 44, 600-607.

Francis, L., Pearson, P. R., Carter, M., \& Kay, K. (1981). The relationship between neuroticism and religiosity among English 15- and 16-year-olds. The Journal of Social Psychology, 114, 99-104.

Freud, S. (1961). The future of an illusion (J. Strachey, Trans.). New York: W. W. Norton \& Company. (Original work published 1928)

Fuller, A. R. (1977). Psychology and religion: Eight points of view. New York: University Press of America.

Fullerton, J. T., \& Hunsberger, B. (1982). A unidimensional measure of Christian orthodoxy. Journal for the Scientific Study of Religion, 21, 317-326.

Gorsuch, R. L. (1974). Factor analysis. Philadelphia: W. B. Saunders.

Gorsuch, R. L. (1984). Measurement: The boon and bane of investigating religion. American Psychologist, 39, 228-236.

Hafsi, M. (1987). The effect of religious involvement on work centrality. Psychologia, 30, 258-266.

Havens, J. (1968). Psychology and religion: A contemporary dialogue. Princeton, New Jersey: D. Van Nostrand.

Hoelter, J. W., \& Epley, R. J. (1979). Religious correlates of fear of death. Journal for the Scientific Study of Religion, 18, 404-411. 
Hood, R. W. (1971). A comparison of the Allport and Feagin scoring procedures for intrinsic/extrinsic religious orientation. Journal for the Scientific Study of Religion, 10, 370-374.

Hoshmand, L. T. (1995). Psychology's ethics of belief. American Psychologist, 50, 540-541.

Hunsberger, B. (1987). More on the dimensionality of Christian orthodoxy. Journal for the Scientific Study of Religion, 26, 256-259.

Hunt, R. A., \& King, M. (1971). The intrinsic-extrinsic concept: A review and evaluation. Journal for the Scientific Study of Religion, 10, 339-356.

Jackson, D. N. (1970). A sequential system for personality scale development. In C. D. Spielberger (Ed.), Current Topics in Clinical and Community Psychology (Vol. 2, pp. 61-96). New York: Academic Press.

Jackson, L. E., \& Coursey, R. D. (1988). The relationship of God control and internal locus of control to intrinsic religious motivation, coping and purpose in life. Journal for the Scientific Study of Religion, 27, 399-410.

James, W. (1961). The varieties of religious experience. New York: Macmillan.

Johnson, P. E. (1945). Psychology of religion. New York: Whitemore and Stone.

Jolliffe, I. T. (1986). Principal component analysis. New York: Springer-Verlag.

Jones, S. L. (1994). A constructive relationship for religion with the science and profession of psychology: Perhaps the boldest model yet. American Psychologist, 49, 184-199.

Jones, S. L. (1995). Psychology and religion. American Psychologist, 50, 545.

Kahoe, R. D., \& Dunn, R. F. (1975). The fear of death and religious attitudes and behavior. Journal for the Scientific Study of Religion, 14, 379-382.

Karna, N. L., \& Panjiar, H. N. (1987). Religiosity as a function of caste, sex, age and habitation: A study of the people of Mithila. Indian Psychological Review, 32 (2), 1-4 (From Psychological Abstracts, 1989, 트, Abstract No. 1185)

Kennedy, J., Barnes, S., \& Greenwell, M. (1988, August). Eating disorders and religiosity in college women. Poster presented at the annual convention of the American Psychological Association, Atlanta, GA.

Kershaw, R. M. (1973). Attitudes toward religion of Saudi Arabian students in the United States. Dissertation Abstracts International, 34, 4405A-4406A. (University Microfilms No. 74-927) 
Kim, J. O., \& Mueller, C. W. (1978a). Introduction to factor analysis: What it is and how to do it. (Sage University Paper Series on Quantitative Applications in the Social Sciences, series no. 07-013). Newbury Park, CA: Sage.

Kim, J. O., \& Mueller, C. W. (1978b). Factor analysis: Statistical methods and practical issues. (Sage University Paper Series on Quantitative Applications in the Social Sciences, series no. 07-014). Newbury Park, CA: Sage.

King, M. B., \& Hunt, R. A. (1975). Measuring the religious variable: National replication. Journal for the Scientific Study of Religion, 14, 13-22.

Kline, P. (1979). Psychometrics and psychology. London: Academic Press.

Kung, H. (1979). Freud and the problem of God (E. Quinn, Trans.). New Haven: Yale University Press.

Lester, D. (1970). Religious behavior and the fear of death. Omega, 1, 181-188.

Lewis, E. L., \& Gladding, S. T. (1983). Test-retest reliability of the Gladding, Lewis, Adkine scale of religiosity: A longitudinal study. Psychological Reports, 52 (34), 34.

Lindsey, D. B., Sirotnik, B. W., \& Heeren, J. (1986). Measuring Christian orthodoxy: Reassessing the issue of unidimensionality. Journal for the Scientific Study of Religion, 25, 328-338.

Link, H. C. (1936). The return to religion. New York: The Macmillan Company.

Long, D. D., \& Elghanemi, S. (1987). Religious correlates of fear of death among Saudi Arabians. Death Studies, 11 (2), 89-97.

Malony, H. N. (1985). Assessing religious maturity: Psychotherapy and the religiously committed patient [Special Issue]. Psychotherapy Patient, 1, 25-33. (From Psychological Abstracts, 1985, $\underline{72}$, Abstract No. 27027).

Maslow, A. H. (1970). Religions, values, and peak-experiences. New York: Penguin Books.

McFarland, S. (1984). Psychology of religion: A call for a broader paradigm. American Psychologist. 39, 321-324.

Mercer, G. W., Bunting, B., \& Snook, S. (1979). The effects of location, experience with the civil disturbances and religion on death anxiety and manifest anxiety in a sample of Northern Ireland university students. British Journal of Social and Clinical Psychology, 18, 151-158. 
Minton, B., \& Spilka, B. (1976). Perspectives on death in relation to powerlessness and form of personal religion. Omega, 7, 261-267.

Neeleman, J. \& Persaud, R. (1995). Why do psychiatrists neglect religion? [CD-RAM]. British Journal of Medical Psychology, 68 (2),169-178. Abstract from: SilverPlatter File: PsycLIT Item: 83-05433

Pareek, M. (1987). A study of attitudes of the students of secondary classes towards some factors responsible for becoming good citizens. Indian Psychological Review, 32, 22-24 (From Psychological Abstracts, 1989, 76, Abstract No. 11515)

Patrick, J. W. (1979). Personal faith and the fear of death among divergent religious populations. Journal for the Scientific Study of Religion, 18, 298-305.

Ponton, M. O., Hickel, D. B., \& Gorsuch, R. L. (1988, August). Religiosity and prejudice: Attitudes towards Arabs. Poster presented at the annual convention of the American Psychological Association, Atlanta, GA.

Richardson, J. T. (1995). Two steps forward, one back: Psychiatry, psychology, and the new religions [CD-RAM]. International Journal for the Psychology of Religion, 5 (3), 181-185. Abstract from: SilverPlatter File: PsycLIT Item: 8243519

Robinson, J. P., \& Shaver, P. R. (1973). Measures of social psychological attitudes. Ann Arbor, Michigan: University of Michigan.

Schwartz, S. H., \& Huismans, S. (1995). Value priorities and religiosity in four Western religions. Social Psychology Quarterly, 58 (2), 88-107.

Sleek, S. (1994). Spiritual problems included in DSM-IV. The Monitor, 25 (6), p. 8. American Psychological Association.Spilka, B., Stout, L., Minton, B., \& Sizemore, D. (1977). Death and personal faith: A psychometric investigation. Journal for the Scientific Study of Religion, 16, 169-178.

Strayhorn, J. M., Weidman, C. S., \& Larson, D. (1990). A measure of religiousness, and its relation to parent and child mental health variables. Journal of Community Psychology, 18, 34-43. (From Psychological Abstracts, 1990, 77, Abstract No. 16979).

Strommen, M. P., Brekke, M. L., Uderwager, R. C., \& Johnson, A. L. (1972). A study of generations: Report of a two-year study of 5,000 Lutherans between the ages of 15-65: Their beliefs, values, attitudes, behavior. Minneapolis, Minnesota: Augsubrge Publishing House.

Sturgeon, R. S., \& Hamley, R. W. (1979). Religiosity and anxiety. The Journal of Social Psychology, 108, 137-138. 
Taai, N. M. (1985). Meqyas Assolook Addeeni [Religious behavior scale]. Kuwait: Arrobyaan Publishing.

Van, W., \& John, F. (1990). Conceiving and measuring ways of being religious. Journal of Psychology and Christianity, 9, 27-40. (From Psychological Abstracts, 1990, 77, Abstract No. 30779).

Velicer, W. F., DiClemente, C. C., \& Corriveau, D. P. (1984). Item format and the structure of the Personal Orientation Inventory. Applied Psychological Measurement, $8,409-419$.

Velicer, W. F., Fava, J. L., Zwick, W. R., \& Harrop, J. W. (1988). Component analysis Extended [Computer software]. University of Rhode Island.

Velicer, W. F., Govia, J. M., Cherico, N. P., \& Corriveau, D. P. (1985). Item format and the structure of the Buss-Durkee Hostility Inventory. Aggressive Behavior. $11,65-82$.

Velicer, W. F., \& Jackson, D. N. (1990). Component analysis versus common factor analysis: Some issues in selecting an appropriate procedure. Multivariate Behavioral Research, 25, 1-28.

Velicer, W. F., \& Stevenson, J. F. (1978). The relation between item format and the structure of the Eysenck Personality Inventory. Applied Psychological Measurement, 2, 293-304.

Ward, L. C. (1995). Religion and science are mutually exclusive. American Psychologist, 50, 542-543.

Weiss, A. S. (1995). Can religion be used as a science in psychotherapy? American Psychologist, 50, 543-544.

Wilson, W. C. (1960). Extrinsic religious values and prejudice. Journal of Abnormal and Social Psychology, 60, 286-288.

Wilson, W., \& Miller, H. L. (1968). Fear, anxiety, and religiousness. Journal for the Scientific Study of Religion, 7, 111.

Wrenn, C. G. (1958). Psychology, religion, and values for the counselor. In F. T. Severin (Ed.), Discovering man in psychology: A humanistic approach (pp. 235-240). New York: McGraw-Hill Inc. [1973]

Wrobel, T. A., \& Stogner, B. L. (1988, August). Beliefs and religious behaviors in Fundamentalist Christian and college students. Paper presented at the annual convention of the American Psychological Association, Atlanta, GA. 
Wulf, D. M. (1988, August). Rethinking the rise and fall of the psychology of religion. Paper presented at the annual convention of the American Psychological Association, Atlanta, GA.

Zwick, W. R., \& Velicer, W. F. (1982). Factors influencing four rules for determining the number of components to retain. Multivariate Behavioral Research, 17, 253-269.

Zwick, W. R., \& Velicer, W. F. (1986). Comparison of five rules for determining the number of components to retain. Psychological Bulletin, 99, 432-442. 